\title{
Evaluation of Arsenic and Selenium Quantitation in Marcellus Shales and Flowback Saline Waters using Thiol Cotton Fibre- Graphite Furnace Atomic Absorption Spectroscopy and Diffusive Gradient in Thin Film Techniques
}

Ronald S. Balaba

West Virginia University

Follow this and additional works at: https://researchrepository.wvu.edu/etd

\section{Recommended Citation}

Balaba, Ronald S., "Evaluation of Arsenic and Selenium Quantitation in Marcellus Shales and Flowback Saline Waters using Thiol Cotton Fibre-Graphite Furnace Atomic Absorption Spectroscopy and Diffusive Gradient in Thin Film Techniques" (2013). Graduate Theses, Dissertations, and Problem Reports. 286. https://researchrepository.wvu.edu/etd/286

This Dissertation is protected by copyright and/or related rights. It has been brought to you by the The Research Repository @ WVU with permission from the rights-holder(s). You are free to use this Dissertation in any way that is permitted by the copyright and related rights legislation that applies to your use. For other uses you must obtain permission from the rights-holder(s) directly, unless additional rights are indicated by a Creative Commons license in the record and/ or on the work itself. This Dissertation has been accepted for inclusion in WVU Graduate Theses, Dissertations, and Problem Reports collection by an authorized administrator of The Research Repository @ WVU. For more information, please contact researchrepository@mail.wvu.edu. 
Evaluation of Arsenic and Selenium Quantitation in Marcellus Shales and Flowback Saline Waters using Thiol Cotton Fibre-Graphite Furnace Atomic Absorption Spectroscopy and Diffusive Gradient in Thin Film Techniques

\author{
Ronald S. Balaba
}

Dissertation Submitted to Eberly College of Arts and Sciences at West Virginia University in Partial Fulfillment of the Requirements for the Degree of Doctor of Philosophy in Chemistry

\author{
Dr. Ronald B. Smart, Chair \\ Dr. Fred L. King \\ Dr. Bjørn Söderberg \\ Dr. Glen Jackson \\ Dr. John J. Renton
}

West Virginia University

C. Eugene Bennett Department of Chemistry

Morgantown, WV 26505

2013

Keywords: Marcellus shale, flowback wastewater, diffusive gradients in thin films, thiol cotton fiber, selenium, arsenic 


\section{Abstract \\ Evaluation of Arsenic and Selenium Quantitation in Marcellus Shales and Flowback Saline Waters using Thiol Cotton Fibre-Graphite Furnace Atomic Absorption Spectroscopy and Diffusive Gradient in Thin Film Techniques}

\section{Ronald S. Balaba}

Trace levels of arsenic and selenium can be toxic to living organisms yet their quantitation in high ionic strength or high salinity aqueous media is difficult due to the matrix interferences which can either suppress or enhance the analyte signal. The objective of this proposed study has been to apply and/or modify inexpensive, simple, and interference-free analytical methods for the sub-ppb to ppb quantification of both inorganic and bioavailable arsenic and selenium fractions in highly saline/salty waters such as flowback wastewater produced from natural gas well drilling sites in the Marcellus shale and/or simulated or artificial high-salinity prepared from deionized water and spikes of different ions, selenium and arsenic concentrations.

A modified thiol cotton fiber (TCF) method employing lower flow rates and centrifugation has been developed and used to remove the analyte from complex aqueous media and minimize the matrix interferences. This method has been tested using a USGS (SGR-1b) certified reference shale. It has been used to analyze Marcellus shale samples following microwave digestion as well as spiked samples of high salinity water (HSW) and flowback wastewater (WRF6) obtained from an actual gas well drilling operation. Quantitation of arsenic and selenium was carried out by graphite furnace atomic spectroscopy (GFAAS). Extraction of arsenic and selenium from Marcellus shale exposed to HSW and WRF6 for varying lengths of time is also reported.

In addition, the role of hydrofluoric acid in microwave-assisted digestion and in the elimination of spectral interferences from the aluminum matrix at $189 \mathrm{~nm}$ for arsenic quantitation by GFAAS with deuterium lamp back-ground correction has been investigated. When sufficient amounts of hydrofluoric acid are added to the sample for microwave-assisted digestion, the excess or residual hydrofluoric acid serves an additional role of matrix modification to inhibit the formation of aluminum oxide that has been reported to cause the spectral interference. The presence of sufficient fluoride in the sample enables formation of aluminum fluoride which volatilizes at $1291^{\circ} \mathrm{C}$, and this significantly reduces the spectral interference. The use of $0.5 \mathrm{~mL}$ of concentrated hydrofluoric acid and $4 \mathrm{~mL}$ of concentrated trace metal grade nitric acid and $0.25 \mathrm{~g}$ of sample enabled accurate and precise determination of arsenic in saline matrices containing aluminum up to $0.053 \mathrm{M} \mathrm{Al}^{3+}$ with LOD and LOQ varying with amount of hydrofluoric acid used.

Furthermore, since mobility and toxicity of arsenic and selenium in natural waters are related to the aqueous species distribution, a Diffusive Gradients in Thin Film technique (DGT) employing a polyacrylamide diffusive gel or 3-mecarptopropyl-functionalized silica and highcapacity nanocrystalline titanium (IV) oxide adsorbent (Metsorb) has been modified and used to isolate the bioavailable analytes species and thereby minimize the matrix effects observed in quantitation by graphite furnace atomic absorption spectroscopy (GFAAS). The DGT-GFAAS procedure has been used to determine the bioavailable arsenic and selenium isolated from 
flowback water from an actual gas well drilling operation (WRF6), as well as spiked samples of WRF6 and flowback wastewater (FS1). In addition, Marcellus shale samples were exposed to WRF6 for varying lengths of time and DGT-GFAAS was used to determine the bioavailable arsenic and selenium in these solutions. Speciation analysis was also carried out. The elution efficiencies using $1 \mathrm{M}$ sodium hydroxide for arsenic and selenium were between 80 - 93\% and the detection limit for arsenic and selenium for 3 day deployments based on the standard deviation of the blank were 0.064 and $0.10 \mu \mathrm{g} / \mathrm{L}$, respectively. 


\section{Dedication}

I dedicate this work to my Mother, Ms Frista Nakinobe, my Fiancee, Tosha Ware and my Brothers, Dan and Moses for their relentless moral support to diligently work harder.

\section{Acknowledgements}

I gratefully acknowledge Dr. R. B. Smart for his tremendous input and always prompt academic advice in carrying out this work, and his fatherly advice to overcome social problems by learning to disregard trivialities. His patience with me, readiness to help and attend to my problems at all times was a big inspiration and a fantastic experience in the execution of this study. Without his priceless contribution little progress would have been achieved. I am also grateful to Dr. Bjorn Soderberg and Dr. Fred King for writing me recommendations for my job pursuits.

I also specially thank Dr. Innocent Pumure and Dr. Brent Reschke for their help in the initial use of the analytical instruments and software. Their willingness and techniques to start from simple to complicated manipulations of the machines and software made life easier for me.

I recognize the valuable help of Mr. Allen Burns for making the plastic spacers and cutting the glass plates to the right dimensions with military precision, and periodically promptly providing me with and/or directing me where to find the necessary materials to fix some electrical faults on the instruments used in this study. His contribution, too, simplified my work 
and made my working environment less stressful. I am grateful to Lee Avery of the West Virginia Economic and Geological Survey for providing the Marcellus shale samples and the WVU Water Resources Institute for providing the wastewater (WRF6 and FS) samples.

I specially thank my fiancée, Toshua Ware for the relentless encouragement to work harder and understanding the time limitations and sacrifices of this academic pursuit. Her charming and pleasant personality always relaxed and refreshed me after a hectic day. May the Almighty God abundantly bless everyone whose contribution made my work materialize. 


\section{Table of Contents}

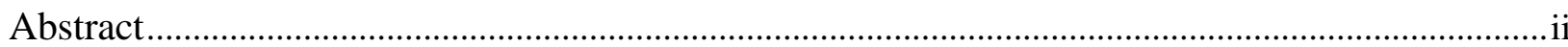

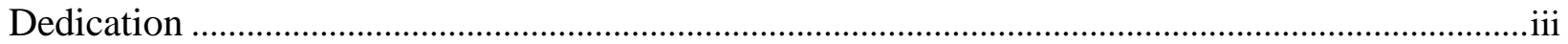

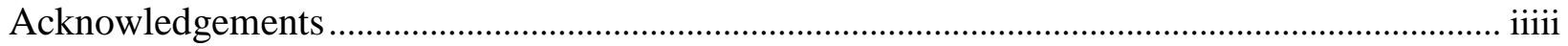

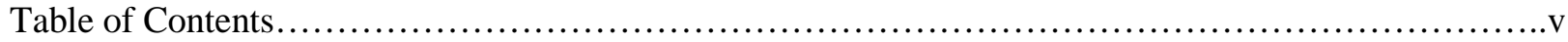

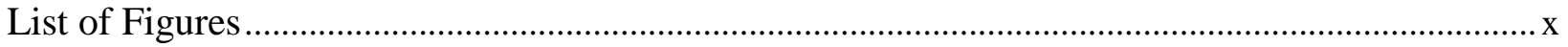

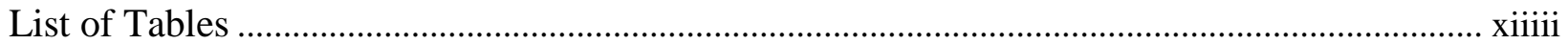

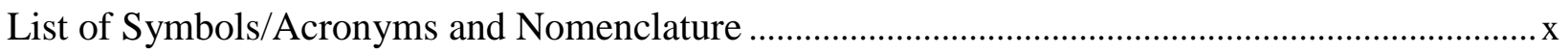

Chapter One: Natural Gas Exploration of the Marcellus Shale, Potential Ecotoxicological

Effects of Arsenic and Selenium and their Quantitation in Saline Waters ............................ 1

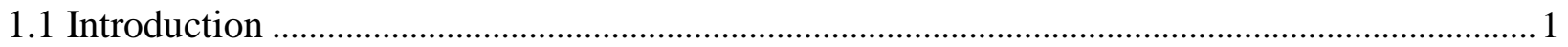

1.2 Natural gas drilling technologies and hydrological concerns .................................................. 2

1.3 USEPA Arsenic and selenium regulatory limits in waters....................................................... 5

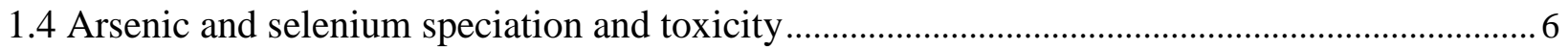

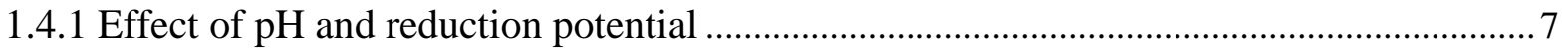

1.5 Quantitation of arsenic and selenium in high-salinity matrices............................................. 11

1.6 Diffusive Gradient in Thin Films Technique (DGT) principles ............................................... 15

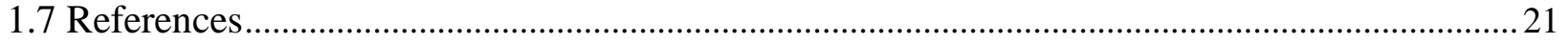

Chapter Two: Total Arsenic and Selenium Analysis in Marcellus Shale, High-Salinity 


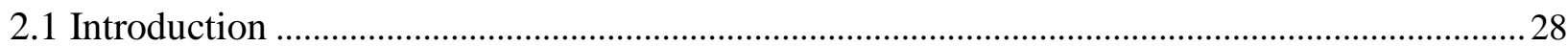

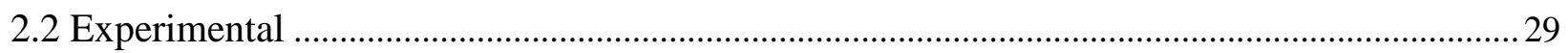

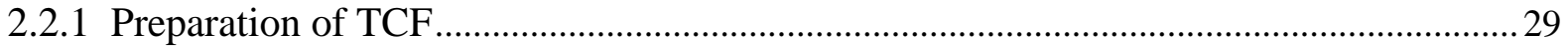

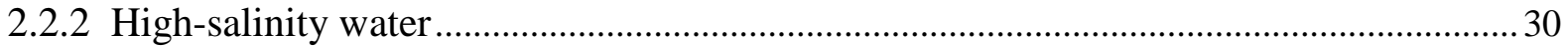

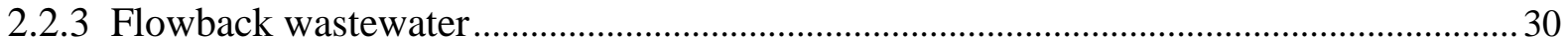

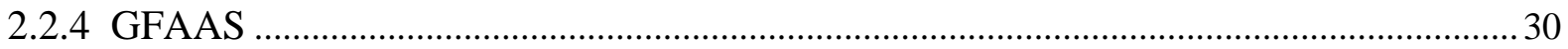

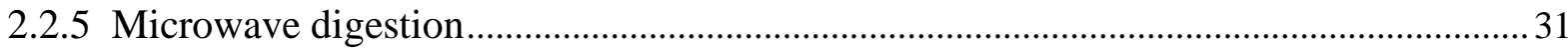

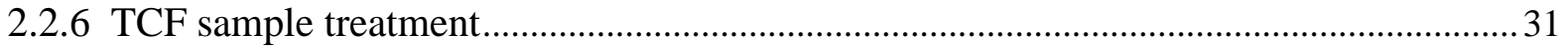

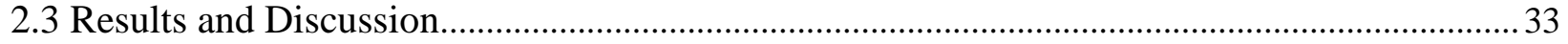

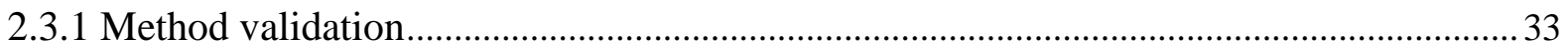

2.3.2 Microwave digestion of Marcellus shale samples........................................................... 33

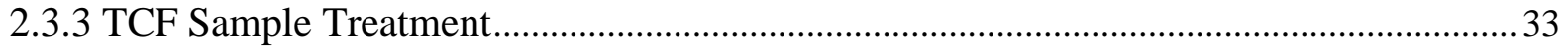

2.4 Matrix interferences from high salt concentrations and atomization profiles ......................... 34

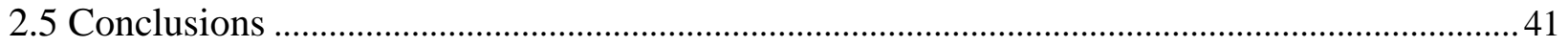

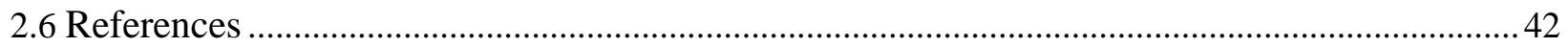

Chapter Three: Determination of Arsenic in Marcellus Shale by Microwave Digestion-

Graphite Furnace Atomic Absorption Spectroscopy: Dual Role of Hydrofluoric Acid........ 44

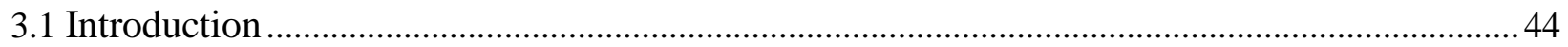

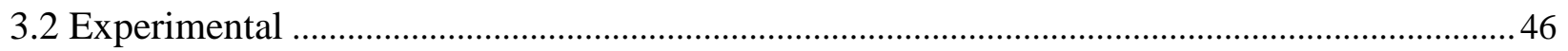


3.3.1 Recovery of arsenic versus aluminum concentration 47

3.3.2 Effect of ash temperature and HF concentration 49

3.3.3 Effect of ash time at various temperatures .51

3.4 Arsenic concentration in WV Marcellus shale

Chapter Four: Investigation of Diffusive Gradients in Thin Film Techniques in the Quantitation of Arsenic and Selenium Bioavailable Fractions in Hydrofracture Wastewater 56

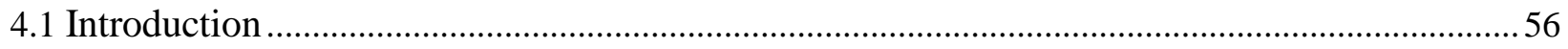

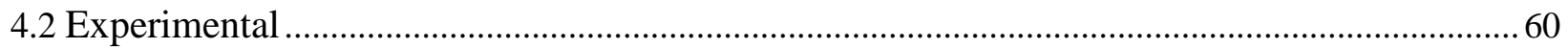

4.2.1 General procedures (Reagents, materials, solutions and GFAAS) ................................. 60

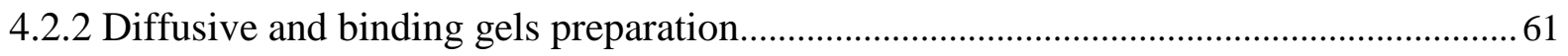

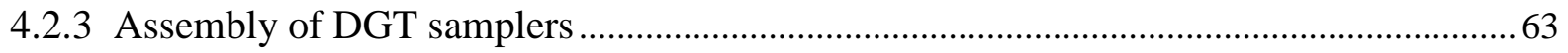

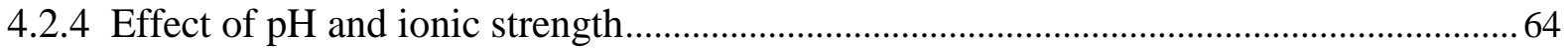

4.2.5 Preliminary analysis of DGT samplers, uptake and elution for arsenic(V) in 
WRF6

4.2.5.1 Long-term mass accumulation versus deployment time evaluation . 65

4.2.6 Arsenic (III), arsenic(V) and selenium (IV) mass accumulation over deployment time using Metsorb and Fe-Zr binary oxide adsorbents in WRF6. 66

4.2.7 Fe- $\mathrm{Zr}$-Bioavailable arsenic and selenium quantitation in undiluted unspiked and 5x diluted WRF6 66

4.2.8 Arsenic (III), arsenic(V) and selenium (IV) mass accumulation over deployment time using Metsorb and Fe-Zr binary oxide adsorbents in FS. 66

4.2.9 Fe-Zr - Bioavailable arsenic and selenium quantitation in undiluted unspiked and $5 x$ diluted FS 66

4.2.10 Evaluation of arsenic (III) mass accumulation over time using DGT-Fe-Zr

binary oxide adsorbent in $0.01 \mathrm{M} \mathrm{NaNO}$ 66

4.2.11 Speciation analysis 67

4.2.12 Determination of total arsenic and selenium in WRF6 and FS solids. 67

4.2.12.1 Method 67

4.2.12.2 Microwave digestion. 68

4.3 Extraction of total arsenic and selenium from Marcellus shales .68

4.3.1 Leaching of arsenic and selenium from Marcellus shale 68

4.4 Results and Discussion 69

4.4.1 Effect of solution composition on arsenic accumulation 69 viii 
4.4.2 Fe-Zr -Arsenic and Selenium-Undiluted unspiked and 5x diluted unspiked WRF6..... 76

4.4.3 Comparison of Fe-Zr and Metsorb for determination of bioavailable arsenic and selenium in FS.

4.4.3.1 Why different diffusion coefficients and analyte mass accumulation with

Fe- Zr binary oxide and Metsorb?

4.4.4 Fe-Zr -Arsenic and selenium-undiluted unspiked and 5x diluted unspiked FS 82

4.5 Speciation Analysis. 84

4.5.1 Why different diffusion coefficients in 0.01 M sodium nitrate in DI water, diluted FBW and FBW? 88

4.6 Total arsenic and selenium quantitation in the FS solid by TCF-GFAAS 92

4.7 Extraction of Arsenic and Selenium from Marcellus shale 92

4.7.1 Bioavailable arsenic and selenium $\left(\mathrm{C}_{\mathrm{DGT}}\right)$ and total arsenic and selenium $\left(\mathrm{C}_{\mathrm{TCF}}\right)$ extraction from the Marcellus shale into WRF6 vs exposure time .95

4.8 Conclusions 97

4.9 References 98

Chapter Five: Future Directions . .101 


\section{List of Figures}

Figure 1.1: West to East section A-A'of middle and upper Devonian rocks in the Appalachian Basin..........................................................

Figure 1.2: Combination of directional drilling and hydraulic fracturing technology used for gas production from the Marcellus Shale in the Appalachian Basin.......................2

Figure 1.3: (a) Arsenite (b) Arsenate speciation as a function of $\mathrm{pH}$ at ionic strength of

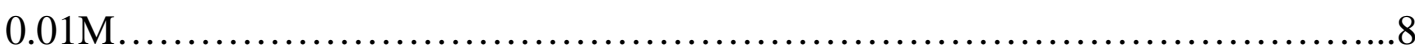

Figure 1.4: Species distribution diagrams for selenic acid (selenate), selenous acid

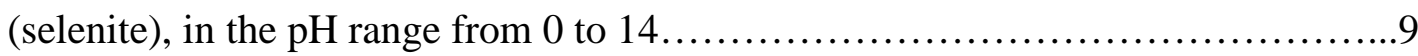

Figure 1.5: Eh-pH diagram for aqueous arsenic species in the system $\mathrm{As}-\mathrm{O}_{2}-\mathrm{H}_{2} \mathrm{O}$ at $25^{\circ} \mathrm{C}$ and 1 bar pressure.............................................................. 10

Figure 1.6: Predominance areas for selenium species in a $\mathrm{pH}$-pe diagram......................10

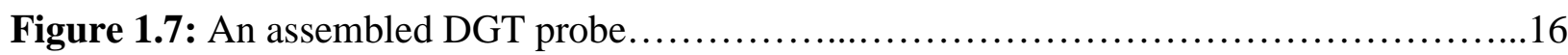

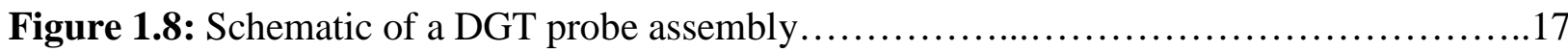

Figure 1.9: Concentration profile of ionic species in a DGT device in contact with aqueous solution at steady state.............................................

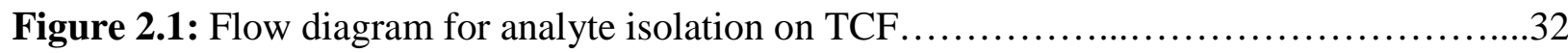

Figure 2.2: Atomization profiles and matrix interference manifestations for arsenic.............36

Figure 2.3: Atomization profiles and matrix interference manifestations for selenium..............37

Figure 2.4: Analyte recovery from WRF6 versus flow rate...............................39

Figure 3.1: Effect of aluminum on arsenic quantitation by GFAAS. Ash temperature $1450{ }^{\circ} \mathrm{C}$ and ash time $8 \mathrm{~s}$. 
Figure 3.2: Arsenic concentration determined at various ash temperatures and HF concentrations for SGR-1b. Ash time 8 s (Target value $=67 \pm 3 \mu \mathrm{g} / \mathrm{g}) \ldots \ldots \ldots \ldots . . .50$

Figure 3.3: Concentration at various ash temperatures for the Marcellus shale (Gilmer 1978) at different HF concentrations. Ash time of 8 s. (Target value $=153 \pm 4 \mu \mathrm{g} / \mathrm{g}) \ldots \ldots \ldots . . .51$

Figure 3.4: Arsenic concentrations determined at various ash temperatures and times for SGR-1b using 0.14 M HF .52

Figure 4.1: Schematic representation of the concentration gradients of Me and MeL in the diffusive layer showing, A: completely labile complex, B: completely inert complex, and C: partially labile complex 59

Figure 4.2: Assembly for making diffusive and binding gels

Figure 4.3: Long-term arsenic mass (ng) accumulation versus deployment time (h) in 5x diluted WRF6. $40 \mathrm{ppb} \mathrm{As}(\mathrm{V})$ in $20 \mathrm{~mL}$ .72

Figure 4.4: Arsenic(III) and arsenic(V) mass (ng) accumulation in diluted (5x) and undiluted WRF6 spiked with 40 ppb versus deployment time (h) .73

Figure 4.5: Selenium(IV) mass (ng) accumulation in diluted (5x) WRF6 spiked with 40 ppb versus deployment time (h)

Figure 4.6: Arsenic(III) mass (ng) accumulation versus deployment time (h) in undiluted WRF6 using 40ppb spike. .76

Figure 4.7: Total bioavailable arsenic and selenium mass (ng) accumulation versus deployment time in unspiked diluted (5x) and undiluted WRF6 ( $\mathrm{n}=3)$. .78

Figure 4.8: Arsenic (III) mass (ng) accumulation versus deployment time (h) in undiluted FS. .79

Figure 4.9: Arsenic (V) mass (ng) accumulation versus deployment time (h) in 20 ppb spiked 
undiluted FS

Figure 4.10: Selenium (IV) mass (ng) accumulation versus deployment time (h) in 20ppb spiked undiluted FS 80

Figure 4.11: Mechanism of arsenic (V) and arsenic (III) adsorption on Fe-Zr binary oxide adsorbent

Figure 4.12: Total bioavailable arsenic and selenium mass (ng) accumulation versus deployment time (h) in diluted (5x) and undiluted FS

Figure 4.13: Arsenic(III) mass (ng) accumulation versus deployment time (h) 20 ppb spiked $0.01 \mathrm{M} \mathrm{NaNO}$ .85

Figure 4.14: Selenium(IV) mass (ng) accumulation versus deployment time (h) in $0.01 \mathrm{M}$ $\mathrm{NaNO}^{-}$

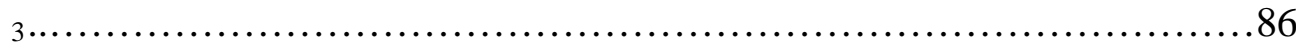

Figure 4.15: Total arsenic versus arsenic(III) and Arsenic(V) mixture in the same sample of 10 ppb of each in $0.01 \mathrm{M} \mathrm{NaNO}$

Figure 4.16: Arsenic(III) mass (ng) accumulation versus deployment time (h) in 40 ppb spiked undiluted FS using mercaptosilica

Figure 4.17: Total arsenic versus arsenic(III) and Arsenic(V) mixture in the same sample of 10 ppb of each in undiluted FS .89

Figure 4.18: Arsenic extracted from Marcellus shale (Gilmer 1978) by WRF6 and HSW at various exposure times .95

Figure 4.19: Selenium extracted from Marcellus shale (Gilmer 1978) by WRF6 and HSW at various exposure times. .96

Figure 4.20: Labile arsenic and selenium $\left(\mathrm{C}_{\mathrm{DGT}}\right)$ and total arsenic and selenium $\left(\mathrm{C}_{\mathrm{TCF}}\right)$ extracted xii 
from the Marcellus shale into WRF6 vs exposure time.

\section{List of Tables}

Table 1.1: Common Composition of Fracking Fluid......................................

Table 1.2: Comparison of Chemical Composition of Seawater and Flowback Water............4

Table 2.1: Arsenic and selenium concentrations obtained from $0.25 \mathrm{~g}$ of Marcellus shale with TCF treatment.............................................................

Table 2.2: Arsenic and selenium recoveries in WRF6 after TCF treatment....................40

Table 2.3: Arsenic and selenium recoveries in HSW after TCF treatment......................41

Table 3.1: Arsenic concentration and spiked sample recoveries for three WV Marcellus

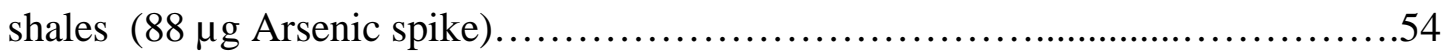

Table 4.1: Arsenic spike concentrations obtained at various pHs and ionic strengths using DGTMetsorb and $100 \mathrm{ppb}$ arsenic solutions and various ionic strengths $\left(\mathrm{NaNO}_{3}\right) \ldots \ldots \ldots .71$

Table 4.2: Diffusion coefficients $\left(\mathrm{cm}^{2} / \mathrm{s}\right)$ for various arsenic species and selenium in spiked undiluted WRF6........................................................ 76

Table 4.3: Arsenic and selenium concentrations in unspiked WRF6........................77

Table 4.4: Diffusion coefficients $\left(\mathrm{cm}^{2} / \mathrm{s}\right)$ for various arsenic species and selenium in spiked

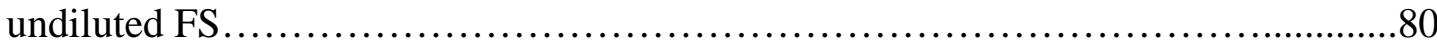

Table 4.5: Arsenic and selenium concentrations in unspiked FS.........................85

Table 4.6: Diffusion coefficients $\left(\mathrm{cm}^{2} / \mathrm{s}\right)$ for various arsenic species and selenium in $0.01 \mathrm{M}$

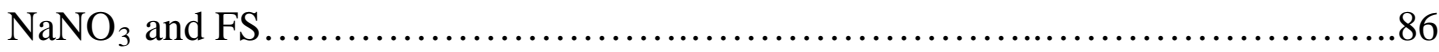

Table 4.7: Arsenic and selenium concentrations in flowback waste water solids by TCF-GFAAS 


\section{List of Symbols/Acronyms and Nomenclature}

CCC - Criterion Contaminant Concentration

CTAB - Cetyl trimethylammonium Bromide

DBNPA - 2,2-dibromo-3-nitrilopropionamide

DGT - Diffusive Gradient in Thin Films Technique

Fe-Zr - Iron-Zirconium binary oxide

$\mathrm{ft}$ - feet

GFAAS - Graphite Furnace Atomic Absorption Spectroscopy

GTA - Graphite Thermal Atomizer

HSW - High Salinity Wastewater

LOD - Limit of Detection

LOQ - Limit of Quantitation

MCL - Maximum Contaminant Level

SGR-1b - Certified Green River Shale

TCF - Thiol Cotton Fiber

TDS - Total Dissolved Solids

TEMED - Tetramethylethylenediamine

USEPA - United States Environmental Protection Agency

WRF6 and FS Flowback wastewater

xiv 


\section{Chapter One}

Natural Gas Exploration of the Marcellus Shale, Potential Ecotoxicological Effects

of Arsenic and Selenium and their Quantitation in Saline Waters

\section{Introduction}

\subsection{Marcellus Shale}

There is enormous interest in commercial exploitation of the Marcellus shale for natural gas production using new drilling technologies such as hydraulic fracturing. It is an organic-rich shale containing high quantities of natural gas in the pore spaces between its grains and fractures. In addition, the natural gas is also chemically adsorbed onto organic matter within the shale. It is found at depths ranging from 1000 feet from the top of the Devonian shale in Ohio to 7000 feet in the Appalachian basin as shown in Figure 1.1[1].

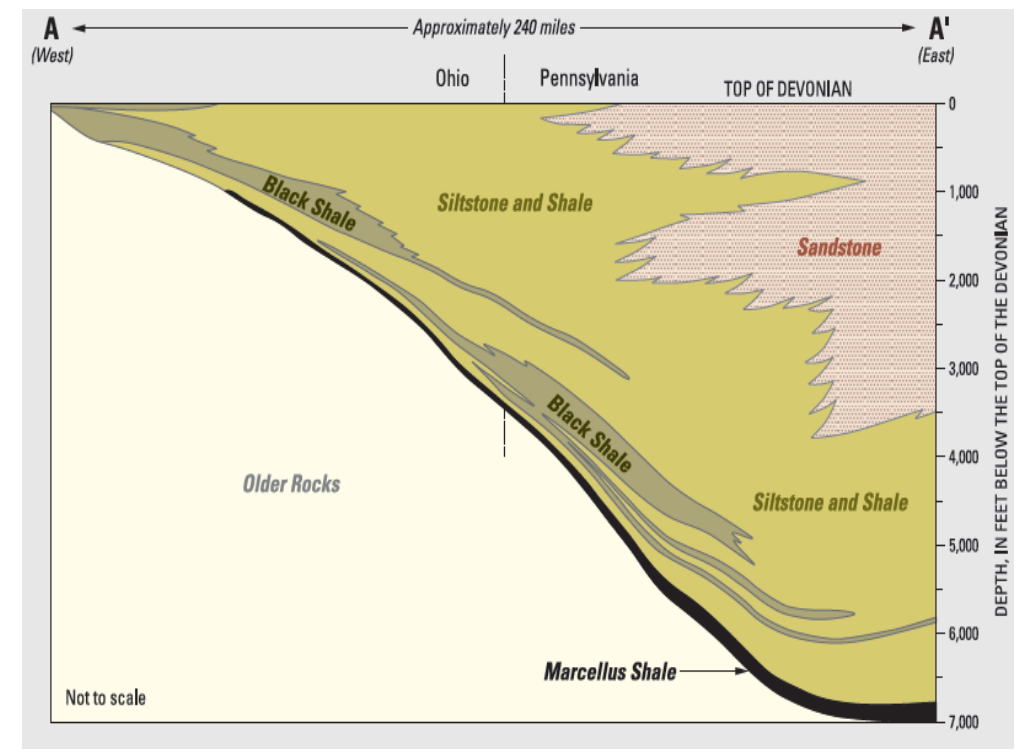

Figure 1.1 West to East section A-A’of middle and upper Devonian rocks in the Appalachian Basin [1]. 


\subsection{Natural gas drilling technologies and hydrological concerns}

The drilling technology generally employed in the Marcellus shale utilizes hydraulic fracturing combined with directional drilling. This involves steering an initially vertical drill hole at 90 degrees to penetrate long horizontal distances through the shale as shown in Figure 1.2 [1]. A large number of hydraulic fractures or high-permeability pathways are created in the shale at intervals along the horizontal section of the borehole [1-2]. This process requires millions of gallons of water under high pressure to provide path ways for the gas to move to the well. However, Warner et al. 2012 [3] have recently compiled geochemical data which suggests that natural migration of Marcellus formation brines to shallow aquifers in Pennsylavania is possible.

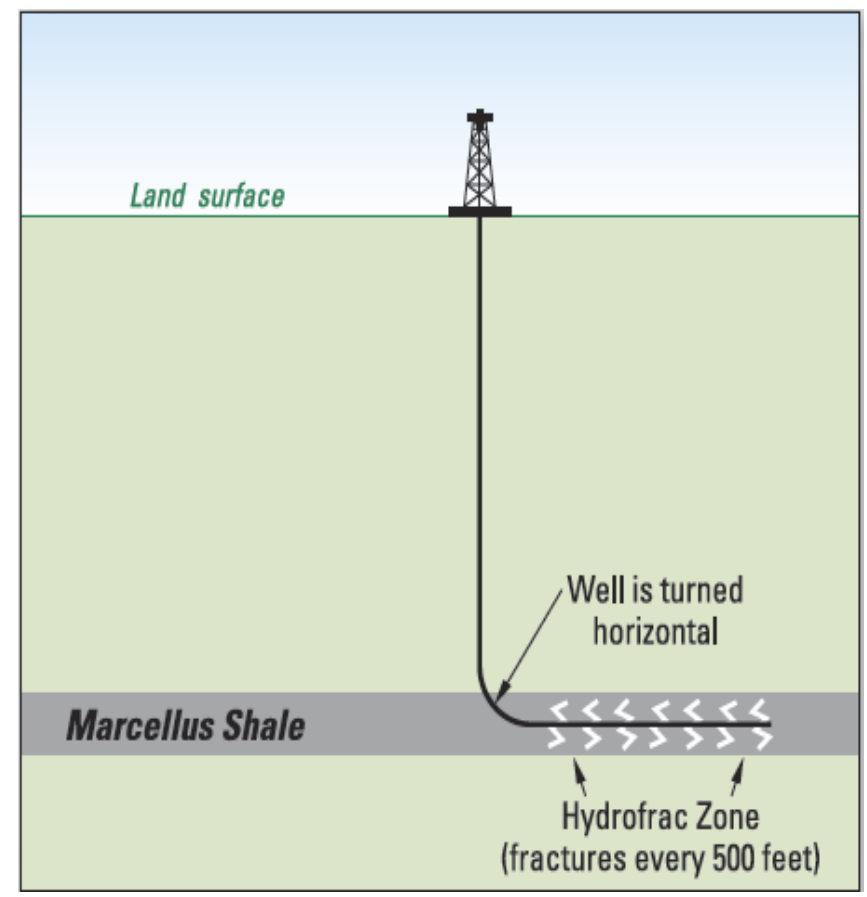

Figure 1.2. Combination of directional drilling and hydraulic fracturing technology used for gas production from the Marcellus Shale in the Appalachian Basin [1]. 
Concerns about this type of drilling in the Marcellus shale have arisen because of the chemicals shown in Table 1.1 which are added to the hydraulic fracturing fluid [2] as well as constituents found in flowback wastewater as a result of its contact with the Marcellus shale during stimulation treatment.

Table 1.1. Common Composition of Fracking Fluid [2].

\begin{tabular}{|c|c|c|}
\hline Chemical additive type & Examples of compounds & Purpose \\
\hline Acid & Hydrochloric acid & $\begin{array}{l}\text { Clean out the wellbore, } \\
\text { dissolve minerals and initiate } \\
\text { cracks in shale/rock }\end{array}$ \\
\hline Friction reducer & $\begin{array}{l}\text { Polyacrylamide, petroleum } \\
\text { distillate }\end{array}$ & $\begin{array}{l}\text { Minimize friction between the } \\
\text { fluid and the pipe }\end{array}$ \\
\hline Corrosion inhibitor & Isopropanol, acetaldehyde & $\begin{array}{l}\text { Prevent corrosion of pipe by } \\
\text { dilute acid }\end{array}$ \\
\hline Iron control & Citric acid, thioglycolic acid & $\begin{array}{l}\text { Prevent precipitation of metal } \\
\text { oxides }\end{array}$ \\
\hline Biocide & $\begin{array}{l}\text { Glutaraldehyde, 2,2-dibromo- } \\
\text { 3-nitrilopropionamide } \\
\text { (DBNPA) }\end{array}$ & Bacterial control \\
\hline Gelling agent & $\begin{array}{l}\text { Hydroxethylcellulose or } \\
\text { guar/xantham gum }\end{array}$ & $\begin{array}{l}\text { Thicken water to suspend the } \\
\text { sand }\end{array}$ \\
\hline Crosslinker & Borate salts & $\begin{array}{l}\text { Maximize fluid viscosity at } \\
\text { high temperatures }\end{array}$ \\
\hline Breaker & $\begin{array}{l}\text { Ammonium persulfate, } \\
\text { magnesium peroxide }\end{array}$ & $\begin{array}{l}\text { Promote breakdown of gel } \\
\text { polymers }\end{array}$ \\
\hline Oxygen scavenger & Ammonium bisulfite & $\begin{array}{l}\text { Remove oxygen from fluid to } \\
\text { reduce pipe corrosion }\end{array}$ \\
\hline pH adjustment & $\begin{array}{l}\text { Potassium or sodium } \\
\text { hydroxide or carbonate }\end{array}$ & $\begin{array}{l}\text { Maintain effectiveness of } \\
\text { other additives such as } \\
\text { crosslinker }\end{array}$ \\
\hline Proppant & Silica quartz sand & Keep fractures open \\
\hline Scale inhibitor & Ethylene glycol & Reduce deposition on pipes \\
\hline Surfactant & $\begin{array}{l}\text { Ethanol, Isopropyl alcohol, 2- } \\
\text { butoxyethanol }\end{array}$ & $\begin{array}{l}\text { Decrease surface tension to } \\
\text { allow water recovery }\end{array}$ \\
\hline
\end{tabular}

In order to obtain the gas, most of the water injected into the well during the fracturing process must first be recovered. This water is called flowback wastewater and is returned early 
in the life of a well. Because this flowback water has been in contact with the shale, it is contaminated with brines composed of varying high concentrations of sodium (50-40000 ppm), chloride (5000-80000 ppm), barium (50-9000 ppm), strontium (50-6000 ppm), magnesium (502000 ppm), calcium (500-12000 ppm), iron (50-160 ppm), manganese (5-7 ppm), sulphate (10$400 \mathrm{ppm}$ ), silica (50-300 ppm). In addition to total dissolved solids (1000-150000 ppm), toxic inorganic constituents such as arsenic and selenium, radionuclides, organics and other noxious inorganic constituents have been reported[2, 3-9]. Flow back water is many times more saline than seawater. Seawater salinity averages to $35 \mathrm{~g} / \mathrm{L}$ in most marine areas and it is the total dissolved salts in water with sodium and chloride constituting the highest proportion (85.6 \%) as shown in Table 1.2 [10-11].

Table 1.2. Chemical Composition of Seawater and Flowback Water Compared [10-11].

\begin{tabular}{|c|c|c|c|}
\hline $\begin{array}{l}\text { Chemical ion } \\
\text { contributing to } \\
\text { seawater } \\
\text { salinity }\end{array}$ & $\begin{array}{l}\text { Average } \\
\text { concentration } \\
\text { in seawater } \\
(\mathrm{ppm})\end{array}$ & $\begin{array}{l}\text { Proportion of } \\
\text { total salinity } \\
(\%)\end{array}$ & $\begin{array}{l}\text { Chemical species } \\
\text { in Flowback } \\
\text { water (ppm) }\end{array}$ \\
\hline Chloride & 19345 & 55.03 & $50000-80000$ \\
\hline Sodium & 10752 & 35.59 & $50-40000$ \\
\hline Sulfate & 2701 & 7.68 & $10-400$ \\
\hline Magnesium & 1295 & 3.68 & $50-2000$ \\
\hline Calcium & 416 & 1.18 & $500-12000$ \\
\hline Potassium & 390 & 1.11 & - \\
\hline Bicarbonate & 145 & 0.41 & - \\
\hline Bromide & 66 & 0.19 & - \\
\hline Borate & 27 & 0.08 & - \\
\hline Strontium & 13 & 0.04 & - \\
\hline Fluoride & 1 & 0.003 & \\
\hline Other & $<1$ & $<0.001$ & \\
\hline
\end{tabular}


Arsenic and selenium are two toxic elements that can be leached from the Marcellus shale by the highly saline wastewaters produced during the process, yet their accurate quantitation in such complex saline media at the ppb level has not been explored. Dilution to minimize matrix effects on the analysis would not be a good option in the quantitation of low levels of arsenic and selenium in this highly salty solutions because it would require methods with exceptionally low detection limits to yield accurate results. Thus, inexpensive, simple and interference-free methods for the sub-ppb to ppb quantification of both inorganic and bioavailable arsenic and selenium in the highly saline/flowback wastewaters are needed to meet the EPA regulatory requirements for aquatic ecosystems.

Although current the disposal practice for flowback wastewater utilizes waste treatment plants, the effectiveness for removal of arsenic and selenium is not clear. Successful removal of salts and other dissolved solids is not usually achieved and numerous reports of high salinity in some Appalachian rivers have been attributed to disposal of Marcellus shale brines [1].

\subsection{USEPA Arsenic and selenium regulatory limits in waters}

The United States Environment Protection Agency (USEPA) has set the Maximum Contaminant Level (MCL) for arsenic at $10 \mathrm{ppb}$. The MCL is the highest level of a contaminant that is allowed in drinking water. The Criterion Continuous Concentration (CCC) is an estimate of the highest concentration of a material in surface water to which an aquatic community can be exposed indefinitely without resulting in an unacceptable effect, and the CCC for arsenic is 150

ppb [12-13]. Long-term exposure to arsenic above ppb can cause adverse health effects such as cancer of the bladder, prostate, lungs, skin, kidney, liver, and nasal passages, and other noncancer effects such as thickening and discoloration of the skin, stomach pain, nausea, vomiting, diarrhea, numbness in hands and feet, partial paralysis and blindness [12-14]. 
The USEPA's MCL and CCC for selenium have been set to $50 \mathrm{ppb}$ and $5 \mathrm{ppb}$, respectively [12-14]. Although selenium is an essential trace nutrient for proper functioning of selenoproteins in antioxidant enzymes and mercury removal from the body, long-term intake of too much selenium causes health effects symptomized by arthritis, brittle nails, bad breath, hair loss, irritability, tooth loss, jaundice, liver and kidney problems [15]. Selenium has also been reported to cause birth defects in aquatic nesting birds [16] and decimating lake fish species at concentrations as low as $10 \mathrm{ppb}$ [17-18].

\subsection{Arsenic and selenium speciation and toxicity}

The toxic forms of arsenic and selenium are of paramount importance when considering water quality monitoring for ecosystem protection. Their toxicological effects are largely dependent on their bioavailability and abundance. Bioavailability is defined as the ability of a chemical species (free-metal ions or labile complexes) to bind to or traverse the cell surface of an organism [19]. It depends on the exact arsenic and selenium chemical form, or speciation in the ecosystem. On the other hand, speciation is influenced by reactions such as oxidation, reduction, methylation, chemical adsorption, decomposition and/or desorption, which affect bioavailability, transport, solubility, reactivity and toxicity of arsenic and selenium. In general, speciation can refer to either different oxidation states or "free” versus complexed species. Total dissolved arsenic and selenium concentration is directly or indirectly indicative of toxicity as only the bioavailable fraction contributes to toxicity. Inert complexes and other constituents of the dissolved fractions such as colloidal matter and are not bioavailable and do not have toxicological effects [19].

Arsenic occurs in various oxidation states (-III, 0, III and V) in natural waters, but the most common oxidation states are III and V [20]. Selenium also occurs in various oxidation 
states (-II, 0, IV and VI), with the most common being IV and VI [21]. The most important and abundant species of arsenic are arsenite $\left(\mathrm{AsO}_{3}{ }^{3-}\right)$ and arsenate $\left(\mathrm{AsO}_{4}{ }^{3-}\right)$, whereas for selenium they are selenite $\left(\mathrm{SeO}_{3}{ }^{2-}\right)$ and selenate $\left(\mathrm{AsO}_{4}{ }^{2-}\right)$. Methylated arsenic compounds such as monomethylarsonic acid and dimethylarsinic acid are referred to as organic arsenic, and methylated selenium compounds such as selenocystine and trimethylselenonium are known as organic selenium [22]. Both organic arsenic and organic selenium compound scan be produced by biological reactions and their concentrations in natural waters are always lower compared to the inorganic arsenic and selenium species [20].

\subsubsection{Effect of $\mathrm{pH}$ and reduction potential}

Arsenic and selenium speciation depend on their physical and chemical properties such as oxidation state and size as well as a multitude of physico-chemical variables, which include $\mathrm{pH}$, ionic strength and dissolved oxygen [23]. These properties define their interactions with the physical environment while the physico-chemical variables control complex equilibrium reactions that influence speciation in natural waters.

Variations in $\mathrm{pH}$ in natural waters can affect the speciation of arsenic and selenium species by influencing the stability of their complexes. When the anion of a typically stable complex is the conjugate base of a weak acid, a decrease in $\mathrm{pH}$ can cause the dissociation of the complex into the anion base and free metal ion, hence increasing the concentration of free metal ions or labile complex species in solution [23-24]. Figures 1.3 and 1.4 show the different predominant species of arsenic and selenium in water at various pHs. Reduction potential in conjunction with $\mathrm{pH}$ are two key factors that control arsenic and selenium speciation. Simplified arsenic-water and selenium-water system Pourbaix diagrams showing the major 
thermodynamically stable species as a function of $\mathrm{pH}$ and reduction potential are shown in Figures 1.5 and 1.6, respectively. However, it should be pointed out that not all these conversions readily occur in the environment due to the lack of thermodynamic equilibrium in ambient systems and speciation may not be accurately predicted by only $\mathrm{pH}$ and reduction potential.
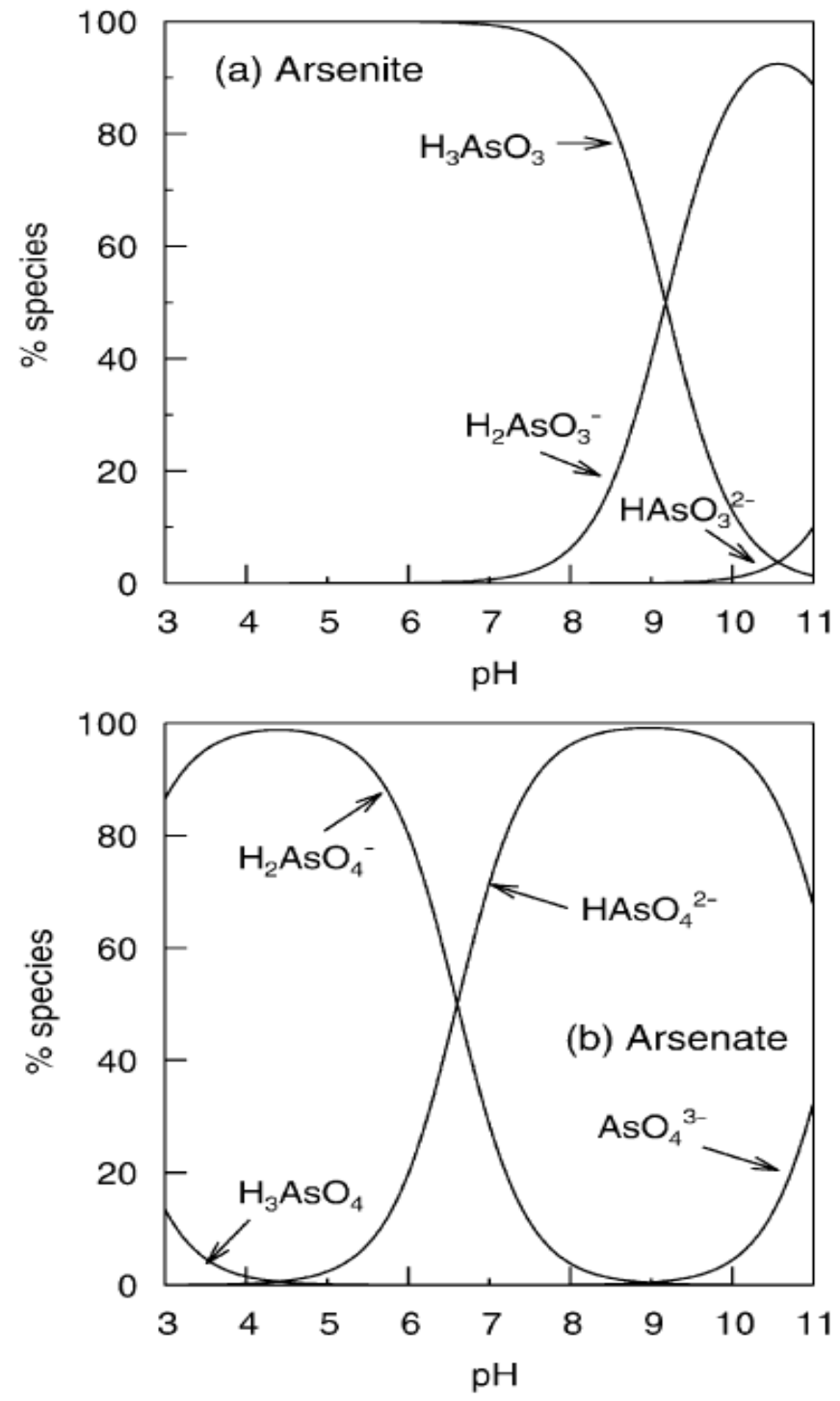

Figure 1.3. (a) Arsenite (b) Arsenate speciation as a function of pH at ionic strength of $0.01 \mathrm{M}$. Reduction potentials chosen to allow one oxidation state predominate the speciation [20]. 

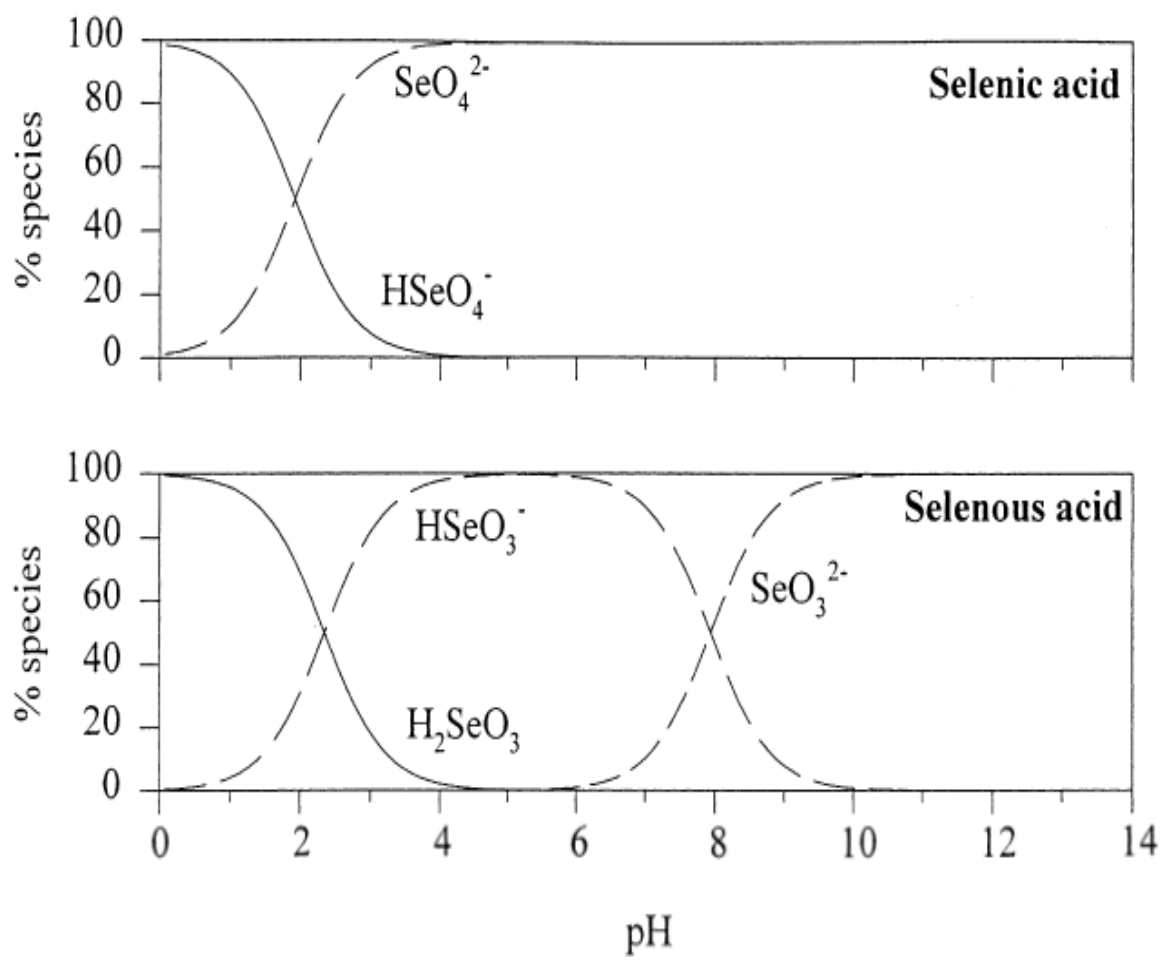

Figure 1.4. Species distribution diagrams for selenic acid (selenate), selenous acid (selenite), in the $\mathrm{pH}$ range from 0 to 14 [25-26]. 


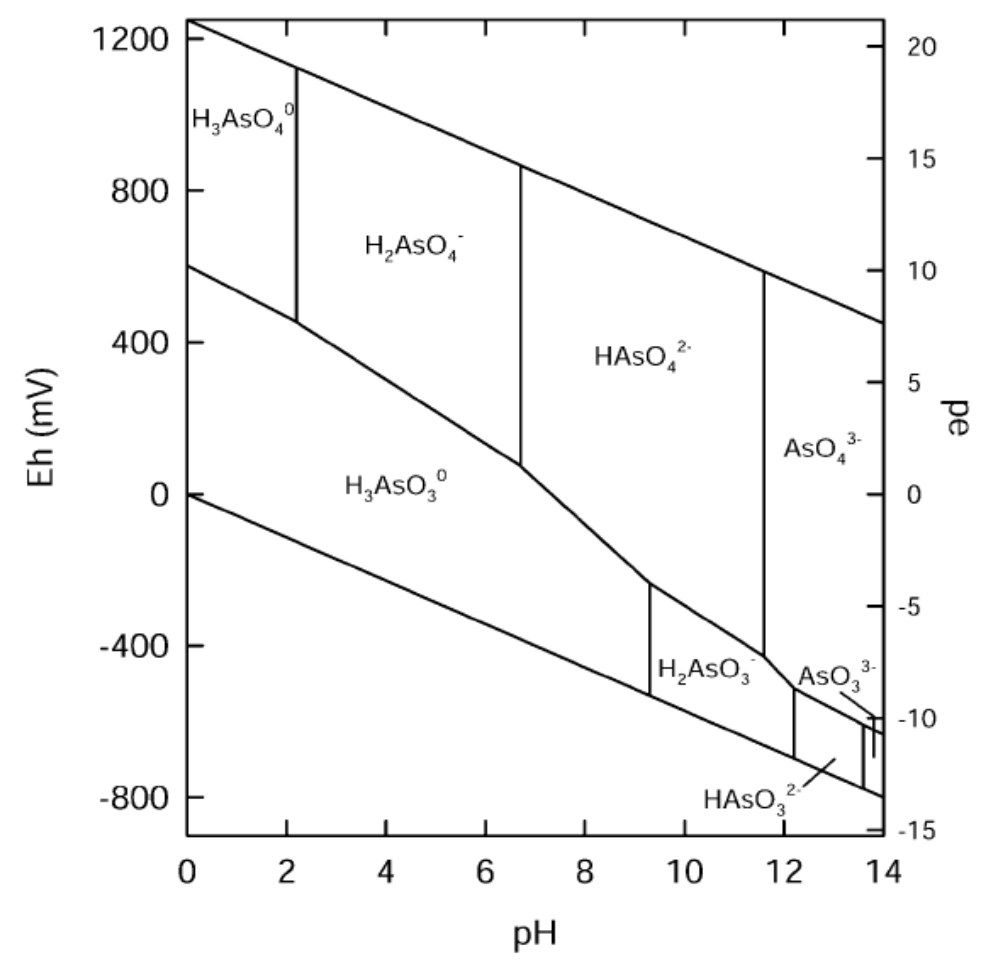

Figure 1.5. Eh-pH diagram for aqueous arsenic species in the system $\mathrm{As}-\mathrm{O}_{2}-\mathrm{H}_{2} \mathrm{O}$ at $25{ }^{\circ} \mathrm{C}$ and 1 bar pressure [20].

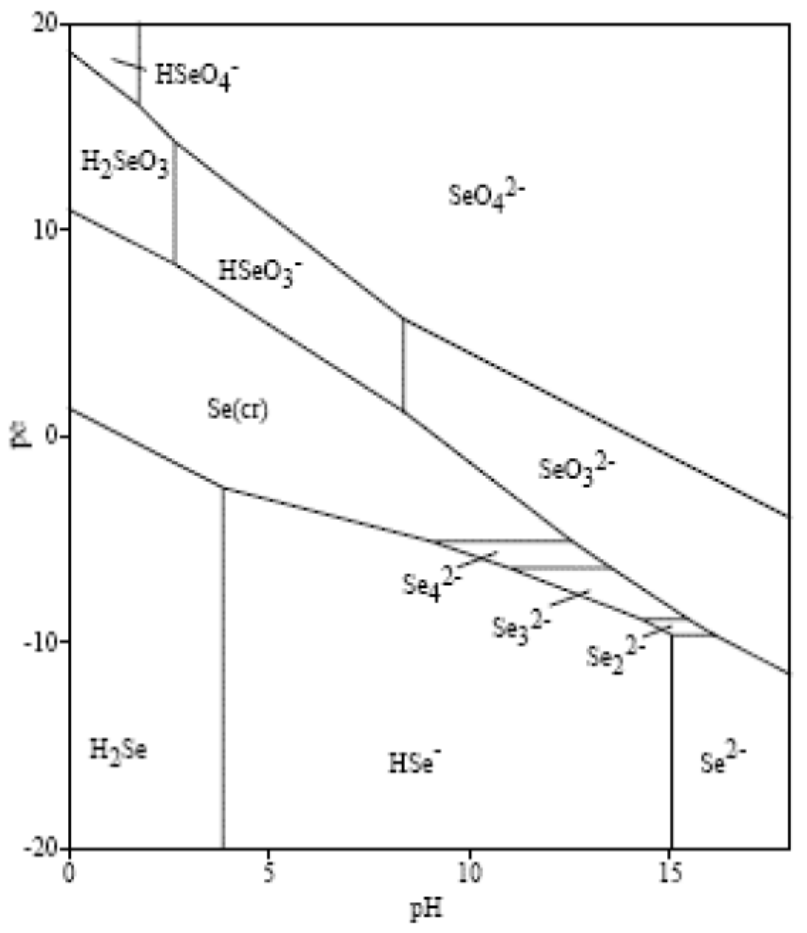

Figure 1.6. Predominance areas for selenium species in a pH-pe diagram [21, 26]. 


\subsection{Quantitation of arsenic and selenium in high-salinity matrices}

Methods for quantifying arsenic and selenium in high-salinity waters have been reported. For arsenic determination, electrothermal vaporization inductively coupled plasma mass spectrometry (ETV-ICP-MS) [27], inductively coupled plasma optical emission spectrometry (ICP-OES) [28], atomic fluorescence spectrometry (AFS) [29-30], adsorptive and anodic stripping voltammetry [31-33], hydride generation ICPMS (HG-ICP-MS) [34], neutron activation analysis (NAA) [35-37] have been reported. Whereas for selenium, HPLC-ICP-MS [38-39], anodic stripping voltammetry (ASV)/ICP-AES/ICP-MS [40] and cathodic stripping voltammetry (CSV) [41-43] have all been used for selenium measurement. However, these methods have drawbacks as some are quite expensive, slow or have interferences.

HGAAS and HG-AFS utilize the reaction of sodium borohydride with reduced arsenic and selenium species (arsenite and selenite) to produce volatile hydrides which are argon-purged from solution and detected spectrophotometrically [44]. While these methods can produce very low detection limits, they are prone to severe matrix interferences stemming from highly saline media [34]. The complexity of the sample matrix alters the efficiency of the reduction mechanism or the hydride generation reaction. In addition, the interferences from transition metals, dissolved organic carbon, and salinity have been reported, and cause significant biases in accuracy and precision especially at trace levels [45-46]. For instance, thiourea, L-cysteine and potassium iodide-ascorbic acid have been reported to act as masking agents to suppress the interference due to very high iron concentrations (up to $2500 \mathrm{mgFe} / \mathrm{L}$ ) in samples [46]. However, use of potassium iodide also causes a number of side reactions and there is general lack of control over it's secondary reducing abilities [47]. In addition, dissolved organic matter is known to affect the determination of Se(IV) by HG-AAS, by suspected direct interactions with 
the selenite ion[45], and optimization is not easily achievable because various parameters affect the efficiency of formation of gaseous hydrides such as concentration of sodium borohydride, concentration of acid media, mixing rate of the reagents and sample, composition of sparging gas, rate of sparging gas, interfering metals and chemical correction, and the valence state of the analyte [As (III) versus As(V) and Se (IV) versus Se(VI)].

Trace determination of arsenic and selenium in saline samples by ICP-MS is rendered inaccurate by the low analyte concentrations found. Matrix effects that lead to formation of polyatomic species in the argon plasma that interfere or match with the Se or As signals, such as ${ }^{40} \mathrm{Ar}^{35} \mathrm{Cl}^{+},{ }^{40} \mathrm{Ar}^{19} \mathrm{~F}^{16} \mathrm{O}^{+},{ }^{40} \mathrm{Ca}^{35} \mathrm{Cl}^{+}$for arsenic $\left({ }^{75} \mathrm{As}\right), \quad{ }^{40} \mathrm{Ar}^{38} \mathrm{Ar}^{+},{ }^{38} \mathrm{Ar}^{40} \mathrm{Ca}^{+}$for selenium $\left({ }^{78} \mathrm{Se}\right),{ }^{40} \mathrm{Ar}^{40} \mathrm{Ar}^{+},{ }^{32} \mathrm{~S}^{16} \mathrm{O}_{3}{ }^{+},{ }^{40} \mathrm{Ar}^{40} \mathrm{Ca}^{+}$for selenium $\left({ }^{80} \mathrm{Se}\right)$ and ${ }^{81} \mathrm{Br}^{1} \mathrm{H}^{+},{ }^{34} \mathrm{~S}^{16} \mathrm{O}_{3}{ }^{+}$for selenium $\left({ }^{82} \mathrm{Se}\right)$ and many others [40, 44, 47-48]. An ICP-DRC-MS, employing an ICP-MS equipped with dynamic reaction cell (DRC) technology, can be used to remove polyatomic (isobaric) interferences. A DRC involves a quadrupole enclosed within a reaction chamber that is between the ion lens system and the analyzing quadrupole. When a reactive gas such as $\mathrm{NH}_{3}$ or methane is introduced into the cell reaction with the ion beam ensues through a multitude of ion-molecule reaction mechanisms, converting the interfering ions into species that do not interfere with the analyte [45, 48-49]. The analyte of interest remains stable under the same conditions and proceeds to the detector. This method provides interference elimination, ruggedness and robustness for accurate total arsenic and selenium analysis in complex saline matrices and lowers the detection limits by eliminating false positives. However, the technology is expensive, requires a high level of technical sophistication and is not readily available in many analytical labs. 
Both anodic and cathodic stripping methods using different working electrodes such as mercury drop electrode, mercury film electrode, gold film electrode or solid gold electrode, have been used to quantify arsenic [33, 43, 50-53] and, to a less extent, selenium in mildy saline samples, but the saline matrices do impact heavily the quality of results [54-60]. Square wave anodic stripping voltammetry, in which during the stripping step the potential is applied in small incremental pulses generating a stair case wave form, will be employed because it enables effective resolution of the faradaic current from the charging or nonfaradaic (background) current.

Chronopotentiometry is another electroanalytical method that has been applied to minimize matrix interferences in both arsenic and selenium quantitation. It involves the measurement of the electrode potential (E) during an electrode process occurring at constant current. E sharply changes as the analyte concentration at the electrode surface drops to zero and the duration over which that occurs, called the transition time, is used to obtain information about the analyte concentration [61-66]. In stripping chronopotentiometry (SCP), the preconcentration step is electrochemical reduction similar to the one used in voltammetry procedures, but stripping is performed by the application of a constant current instead of potential sweeping [64-67]. When the E change in the working electrode is measured as a function of time, the analyte determination is not based on current measurement, and this eliminates measurement errors caused by liquid resistance between the electrode and the potential drop over the electrical double layer around the electrode, thus eliminating matrix interferences due to adsorbed organic matter that significantly compromise current measurements in the case of ASV or CSV measurements [67-72]. It has also been reported that chronopotentiometry enables working with non-deoxygenated samples provided the current 
generated by chemical oxidation is negligible compared to the imposed stripping current, and it is more rugged to chemical equilibrium and $\mathrm{pH}$ changes induced in the media [70-71].

Cyclic reciprocal derivative chronopotentiometry, also called galvanostatic stripping chronopotentiometry was developed recently, and involves the measurement of the dependence of $\mathrm{dt} / \mathrm{dE}$ versus $E$ to generate analytical signals or peaks similar to voltammetric peaks for stripping processes [63-64, 72-74].

Chronopotentiometric stripping analysis has been applied in flow-through systems [7576], but not on high salinity waters as intended in this study. In addition, ultra-trace accurate determination of inorganic Se(IV) concentrations in aqueous samples at sub-ppb levels without signal calibration was reported using stripping methods employing a gold working electrode together with a high-efficiency flow-through cell [60], however, this method is also susceptible to matrix interferences in saline waters.

A method that achieves separation and reduction of arsenic in a single process called 'reductillation' was also reported [61]. In this method, arsenic trichloride (boiling point, $130.2^{\circ} \mathrm{C}$ ) was distilled from a copper (I) chloride solution in concentrated hydrochloric acid using a special glass apparatus and the volatilized arsenic trichloride and $\mathrm{HCl}$ were collected in deionized water and analyzed for arsenic by anodic stripping voltammetry employing a gold working electrode [61]. This method was previously applied to quantitation of arsenic to eliminate matrix interferences and had a detection limit of $10 \mu \mathrm{g} / \mathrm{L}$, but not to the same type of highly saline water samples such as flowback water, and sample throughput was low [61].

Ultra-trace determination of total selenium concentrations in highly saline aqueous samples has also been reported involving reduction of selenium (VI) to selenium (IV) and subsequent application of stripping methods a gold wire working electrode in conjunction with a 
high-efficiency flow-through cell. This method has been previously applied without signal calibration in the quantitation of Se(IV) with minimal interferences at gold wire electrode with minimum quantitation limit of $16 \mu \mathrm{g} / \mathrm{L}$ [60], but not on highly saline waters like flowback water.

Various other techniques using arsenic and selenium separation and preconcentration methods have been developed and reported to eliminate matrix interferences and improve sensitivity and accuracy for trace determinations. Some of these include ultrasonic extractionHGAAS [77-78], thiol cotton fiber (TCF)-GFAAS [79-80], TCF-HGAAS [81], TCF-NAA [82], active carbon-GFAAS [83] and solvent extraction-GFAAS [84]. The TCF was originally developed for preconcentration of mercury, but has since been used to separate and preconcentrate many different elements [82]. The TCF preconcentrates Se(IV) and other elements in low oxidation state from $\mathrm{HCl}$ and the preconcentrated elements are analyzed by various methods, after digestion of the TCF with concentrated nitric and hydrofluoric acids [7982].

\subsection{Diffusive Gradient in Thin Films Technique (DGT) principles}

DGT was developed by Davison and Zhang at Lancaster University in 1993 and employs simple probes that accumulate dissolved ions over a period of time while deployed in solution [85-86]. Figure 1.7 is a photograph and a schematic of an assembled DGT probe. In situ concentration at the time of deployment is determined by conventional analytical methods such as GFAAS or ICP-MS. DGT has been used to quantify trace metal, phosphate, sulfide and radionuclides in fresh water and seawater [86].

Different binding agents with different selectivity for different analytes can be used such as chelex resin for trace metals [85-86], iron oxide for arsenic and phosphate [87], metsorb for 
arsenic and selenium [88], ammonium molybdophosphate(AMP) for radioactive cesium, silver iodide sulfide [85] and 3-mercaptopropyl silica gel for arsenic (III) [88]. The DGT probe accumulates the analyte in a binding gel after passage through a diffusive gel, which acts as a well-defined diffusion layer as shown in Figure 1.8. The binding agent that is selective for analyte ions embedded in the binding gel which is separated from solution by an ion-permeable diffusive gel of thickness, $\Delta \mathrm{g}$ and filter paper as shown in Figures 1.8 and 1.9.
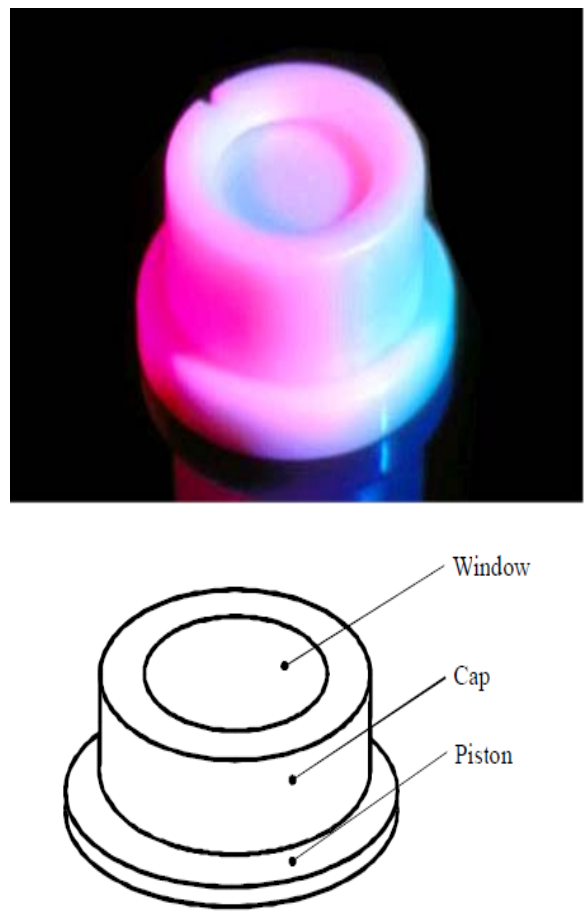

Figure 1.7. An assembled DGT probe [85]. 


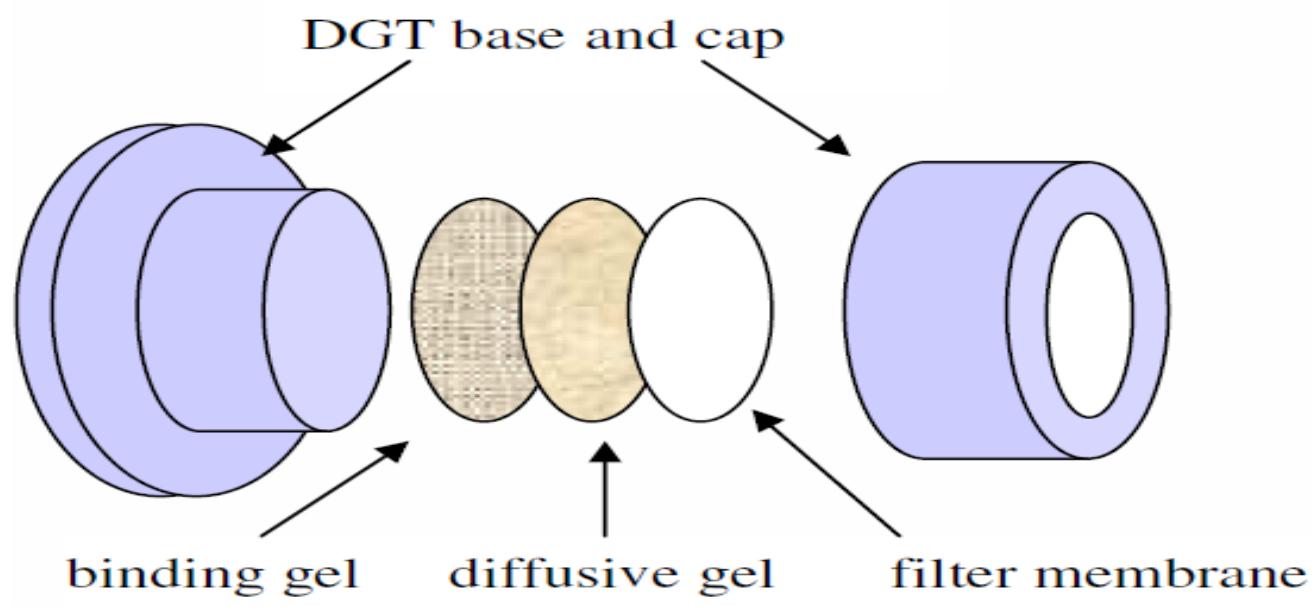

Figure 1.8 Schematic of a DGT probe assembly [89].

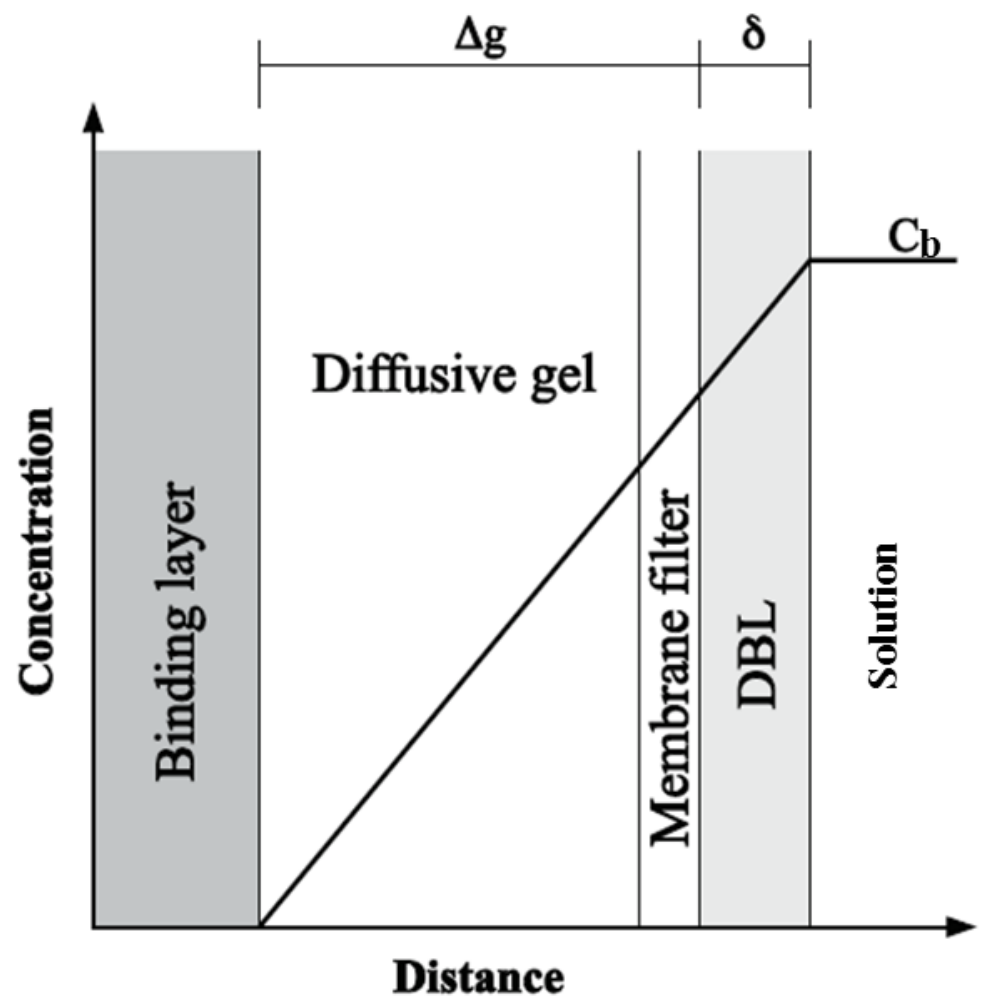

Figure 1.9. Concentration profile of ionic species in a DGT device in contact with aqueous solution at steady state [86]. 
Transport of ions to the diffusive gel by molecular diffusion gives rise to a diffusive boundary layer (DBL) of thickness $\delta$, which is dependent on bulk solution or water movement and/or agitation. After a few minutes submerging the DGT probe in the bulk solution, a steady state linear concentration gradient is established, which the DGT technique exploits to measure

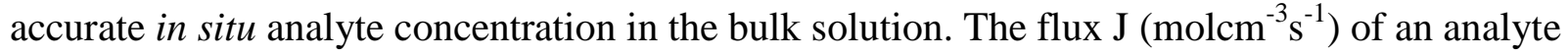
ion through the gel is given by Fick's first law of diffusion:

$$
\text { Flux, } \mathrm{J}=-\mathrm{D} \frac{\partial \mathrm{C}}{\partial \mathrm{x}}=\frac{\mathrm{D}\left(\mathrm{C}_{\mathrm{b}}-\mathrm{C}^{\prime}\right)}{(\Delta \mathrm{g}+\delta)} \approx \frac{\mathrm{DC}_{\mathrm{b}}}{\Delta \mathrm{g}}
$$

Where $D$ is the diffusion coefficient $\left(\mathrm{cm}^{2} \mathrm{~s}^{-1}\right), \partial C / \partial \boldsymbol{x}(\mathrm{mol} / \mathrm{cm})$ is the concentration gradient. Zhang and Davison (1995) [86] determined that the diffusion coefficient of analyte ions in the diffusive gel is the same as in water, within limits of experimental error. This simplifies the equation, where $C_{b}\left(\right.$ molcm $\left.^{-3}\right)$ is the bulk analyte ion concentration and $C^{\prime}$ is its concentration at the boundary between the binding gel and the diffusive gel. When the free analyte ions establish rapid equilibrium with the binding agent with a high binding constant, C' is effectively zero provided the binding gel is not saturated. In well-stirred or agitated solutions, the boundary layer thickness $\delta(\mathrm{cm})$ is negligible in comparison to the thickness of the diffusive layer $\mathrm{g}(\mathrm{cm})$. Thus, the flux equation then becomes as shown in Eq. 1.1.

DGT probes are deployed for a fixed time, $t$ (s) after which, the binding layer is removed and the mass of the accumulated analyte ion is quantified by immersion in an eluting medium of known volume, $\mathrm{V}_{\mathrm{e}}$, (mL) of 1 or $2 \mathrm{M}$ nitric acid or sodium hydroxide. The analyte ions are quantitatively eluted from the binding gel. The concentration of the analyte ions in the eluent, $C_{e}$ is then determined by a variety of analytical techniques after appropriate dilution. However, in batch mode elution, only a fraction of bound analyte ions are eluted from the gel. The ratio of the eluted to bound analyte ion concentration is referred to as the elution factor, $f_{e}$, which varies 
from analyte to analyte depending on the affinity of the biding gel for the analyte or competing ionic interferences.

Considering the elution factor, the accumulated mass (M) of the analyte ions in the binding gel is calculated from the Eq. 1.2:

$$
\mathrm{M}=\frac{\mathrm{C}_{\mathrm{e}}\left(\mathrm{V}_{\mathrm{g}}+\mathrm{V}_{\mathrm{e}}\right)}{\mathrm{f}_{\mathrm{e}}}
$$

Where, $\mathrm{V}_{\mathrm{g}}$ is the volume of the gel in the binding layer.

M can also be used to calculate the flux through the known area of the exposed diffusive layer, A $\left(\mathrm{cm}^{2}\right)$ using Eq. 1.3:

$$
J=\frac{M}{A t}
$$

Combining Eqs. 1.1 and 1.3 yields equation 1.4, from which the concentration of the analyte ions in the bulk solution is calculated from known values of $\mathrm{D}, \Delta \mathrm{g}, \mathrm{A}, \mathrm{t}$ and $\mathrm{M}$.

$$
\mathrm{C}_{\mathrm{DGT}}=\frac{\mathrm{M} \Delta \mathrm{g}}{\mathrm{DtA}}
$$

The bulk solution concentration is proportional to measured mass and depends on the values of $\Delta \mathrm{g}$ and A which are constant geometric parameters, and the diffusion coefficient in the diffusive gel.

Diffusion coefficients are temperature-dependent due to fluctuations in water viscosity and density with temperature, and can be corrected for temperatures other than $25{ }^{\circ} \mathrm{C}$, in field deployments where temperatures cannot easily be controlled as in the lab, using Eq. 1.5 [86]:

$$
\log \mathrm{D}_{\mathrm{T}}=\frac{1.37023(\mathrm{~T}-25)+8.36 \times 10^{-4}(\mathrm{~T}-25)^{2}}{109+\mathrm{T}}+\log \frac{\mathrm{D}_{25}(273+\mathrm{T})}{298}
$$

The concentration of other components in mildly salty solutions does not affect the analyte ion concentration determined by DGT and therefore periodic or individual calibrations in different mildly salty media is unnecessary. 
When a filter is employed to separate the diffusive gel from bulk solution, it provides some protection and allows free diffusion of analyte ions with diffusion coefficients close to those of the analyte in water. With effective stirring or solution mixing, the DBL in solution adjacent to the filter is negligible and Eq. 4 can be applied. However, when DBL is not negligible and the diffusion coefficients in the diffusive gel $\left(D_{g}\right)$, filter $\left(D_{f}\right)$ and water $\left(D_{w}\right)$ are all different, Eq. 1.6 applies:

$$
\frac{1}{\mathrm{M}}=\frac{1}{\mathrm{C}_{\mathrm{DGT}} \mathrm{At}}\left(\frac{\Delta \mathrm{g}}{\mathrm{D}_{\mathrm{g}}}+\frac{\Delta \mathrm{f}}{\mathrm{D}_{\mathrm{f}}}+\frac{\delta}{\mathrm{D}_{\mathrm{w}}}\right)
$$

Where $\Delta \mathrm{g}$ and $\Delta \mathrm{f}$ are the thicknesses of the diffusive gel and filter, respectively. The DBL is significant in stirred solutions at low speeds and can be determined by deploying DGT devices with different diffusive gel thicknesses $(\Delta \mathrm{g})$ [89-91]. The DBL thickness, $\delta$, can then be derived from the intercept $(b)$ divided by the slope $(m)$ of a plot of $1 / \mathrm{M}$ versus $\Delta \mathrm{g}$ according to Eq. 1.7:

$$
\frac{1}{\mathrm{M}}=\frac{\Delta \mathrm{g}}{\mathrm{C}_{\mathrm{DGT}} \mathrm{At}}+\frac{\delta}{\mathrm{C}_{\mathrm{DGT}} \mathrm{At}}=\frac{1}{\mathrm{C}_{\mathrm{DGT}} \mathrm{At}}\left(\frac{\Delta \mathrm{g}}{\mathrm{D}_{\mathrm{g}}}+\frac{\Delta \mathrm{f}}{\mathrm{D}_{\mathrm{f}}}+\frac{\delta}{\mathrm{D}_{\mathrm{w}}}\right)
$$

From which equation 1.7,

$$
\delta=\frac{\mathrm{b}}{\mathrm{m}}, \mathrm{D}_{\mathrm{DGT}}=\left(\frac{1}{\mathrm{mDAt}}\right)
$$

However, with sufficient stirring of the solutions in which DGT probes are deployed, the DBL is greatly minimized. In that case the diffusion coefficient is calculated from the Eq. 1.9:

$$
D=\frac{\alpha \Delta g}{C_{D G T} A}
$$

Where $\alpha$ is the slope of the linear regression of the mass of analyte, M (ng), accumulated in the binding gel over time, $\mathrm{t}(\mathrm{s})$, and $\Delta \mathrm{g}, \mathrm{D}$ and $\mathrm{A}$ are the thickness of the diffusive gel $(0.08 \mathrm{~cm})$, diffusion coefficient in gel in $\mathrm{cm}^{2} \mathrm{~s}^{-1}$ and area in $\mathrm{cm}^{2}\left(3.14 \mathrm{~cm}^{2}\right)$, respectively [90-92]. 


\subsection{References}

[1] Soeder D. J., Water resource and natural gas production from the marcellus shale (http://pubs.usgs.gov/fs/2009/3032/, website browsed on Feb. 20 2011).

[2] Vidic, R. D., Brantley, S. L., Vandenbossche, J. M., Yoxtheimer D. and Abad, J. D., Science, 2013, 340, 826-835.

[3] Warner, N. R., Jackson, R. B., Darrah, T. H., Osborn, S. G., Down, A., Zhao, K., White, A. and Vengosh, A., Geochemical eveidence for possible natural migration of Marcellus formation brines to shallow aquifers in Pennyslavania, 2012, 109(30), 11961-11966.

[4] Kargbo, D. M., Wilhelm, R. G. and Campbell, D. J., Env. Sc. and Technology, 2010, 44(15), 5679-5684.

[5] Howarth, R. W. and Ingraffea, A., Nature, 2011, 477, 271-275.

[6] Schmidt, C.W., Environmental Healthy Perspectives, 2011, 119(8), A348-A353.

[7] Gregory, K. B., Radisav, D. V., and Dzombak, D. A., Elements, 2011, 7, 181-186.

[8] Bomgardner, M. M., Chemical and Engineering News, October 15 ${ }^{\text {th }}$, 2012, 13-16.

[9] Shramko A., Palmgren T., Gallo D. and Dixit R., $16^{\text {th }}$ Annual Petroleum \& Biofuels

Environmental Conference (IPEC), 2009, Houston, Nov. 3-5.

[10] http://www.marinebio.net/marinescience/02ocean/swcomposition.htm , website browsed on June 11, 2010 at 18.15 hours.

[11] http://www.seafriends.org.nz/oceano/seawater.htm\#salinity , website browsed on June 11, 2010 at 18.00 hours.

[12] http://www.epa.gov/safewater/arsenic/index.html, website browsed on June 16, 2010 at 15.30 hours. 
[13] http://www.epa.gov/safewater/consumer/pdf/mcl.pdf, website browsed on June 16, 2010 at 16.00 hours.

[14] http://www.epa.gov/waterscience/criteria/wqctable/nrwqc-2009.pdf, website browsed on June 17,2010 at 16.00 hours.

[15] http://ods.od.nih.gov/factsheets/Selenium_pf.asp, website browsed on June 17, 2010 at 17.00 hours.

[16] Lemly, A. D., Ecotoxicological Environmental Safety, 1985, 10, 314-338.

[17] Ohlendorf, H. M.; Hoffman, D. J.; Saiki, M. K.; Aldrich, T. W., The Science of Total Environment, 1986, 52, 49-63.

[18] Hamilton, S. J., Buhl, K. J., Faerber, N. L., Bullard, F. A., Wiedmeyer, R. H., Environmental Toxicology and Chemistry, 1990, 9 (3): 347-358.

[19] Sunda, W.G. and Huntsman, S.A., The Science of the Total Environment, 1998, 219, 165181.

[20] Smedley, P. L.; Kinniburgh, D. G., Applied Geochemistry, 2002, 17, (5), 517-568.

[21] Sandy T. and DiSante C., Review of available technologies for the removal of selenium from water, Final Report, North America Metals Council, June 2010, 37-41.

[22] Hasegawa, T., Mihara, M., Nakamuro, K., Sayato,Y., Archives of Toxicology,1996,71(1-2), 31-38.

[23] Cao, J., Lam, K.C., Dawson, R.W., Liu, W.X. and Tao, S., Chemosphere, 2004, 54, 507514.

[24] Hunter, A.K., Jonathan, P.K. and Malcom R.R., Marine and Freshwater Research,1999,50, 367-372.

[25] Stadlober, M., Sager, M. and Irgolic, K. J., Food Chemistry, 2001, 73, 357-366. 
[26] Benedicto, A., Missana, T. and Degueldre, C., The Science of the Total Environment., 2013, 449, 214-222.

[27] Gregoire D. C. and Ballinas M. D., Spectrochimica Acta Part B, 1997, 52, 75-82.

[28] Bradford G. R. and Bakhtar D., Environmental Science and Technology, 1991, 25, 17041708.

[29] Li X., Su Y., Xu K., Hou X. and Lv Y., Talanta, 2007,72, 1728-1732.

[30] Pacheyran, C., Amouroux D. and Donard O. F. X, Journal of Analytical Atomic Spectrometry, 1998, 13, 615-621.

[31] De Carvalho L. M., do Nascimento P. C., Bohrer D., Pilau E. J., Stefanello R., Lauer M., Electroanalysis, 2006, 18(11), 1081-1089.

[32] Profumo A., Fagnoni M., Merli D., Quartarone E., Protti S., Dondi D., Albini A., Analytical Chemistry, 2006, 78, 4194-4199.

[33] Li, H. and Smart, R. B., Analytica Chimica Acta, 1996, 325, 25-32.

[34] Creed J. T., Magnuson M. L., Brockhoff C. A., Chamberlain I. and Sivaganesan, M., J., Journal of Analytical Atomic Spectrometry, 1996,11,505-509.

[35] Bem E. M., Environmental Health Perspectives, 1981, 37, 183-200.

[36] Drabaek I., Carlsen V. and Just L., Journal of Radioanalytical and Nuclear Chemistry, 1986, 103(4), 249-260.

[37] Acharya R., Nair, A. G. C. and Reddy, A. V. R., Journal of Radioanalytical and Nuclear Chemistry, 2009, 281, 279-282.

[38] Chatterjee, A., Shibata, Y., Tao, H., Tanaka, A. and Morita, M., Journal of Chromatography A, 2004, 1042, 99-106.

[39] Juresa, D., Kuehnelt, D. and Francesconi, K. A, Analytical Chemistry, 2006, 78, 8569-8574. 
[40] Pretty, J. R., Blubaugh, E. A. and Caruso, J. A, Analytical Chemistry, 1993, 65, 33963403

[41] Korolczuk, M. and Grabarczyk, M., Electroanalysis, 2003, 15(9), 821-826.

[42] Winkel, L., Feldmann, J. and Meharg, A. A, Environmental Science and Technology, 2010, 44, 382-387.

[43] Tongesayi, T. and Smart, R. B., Electroanalysis, 2008, 20(4), 434-437.

[44] Tanner, S.D. and Baranov, V. I., Atomic Spectroscopy, 1999, 20(2), 45-52.

[45] Roden D. R. and Tallman, D. E., Analytical Chemistry, 1982, 54, 307-309.

[46] Naykki T., Peramaki P., Kujala J. and Mikkonen A., Analytica Chimica Acta, 2001, 439, 229-238.

[47] Niedzielski P., Siepak M., Siepak J. and Przybylek J., Polish Journal of Environmental Studies, 2002, 11(3), 219-224.

[48] McShane, W. J., Pappas, R. S. and Paschal, D., Journal of Analytical Atomic Spectrometry, 2007, 22, 630-635.

[49] Kawabata, K., Kishi Y. and Thomas R., Analytical Chemistry, 2003, 75(9), 422A.

[50] Kopanica, M., and Novotny L., Analytica Chimica Acta, 1998, 368, 211-218.

[51] Zima J, van den Berg C. M. G., Analytica Chimica Acta, 289, 291-298

[52] Bodewig F., Valenta P., Nurnberg H., Analytical Bioanalytical Chemistry, 1982, 311, 187191

[53] Sadana R. S., Analytical Chemistry, 1983, 55,304-307

[54] Adeloju S. B., Jagner D., Renman L., Analytica Chimica Acta, 1997, 338, 199-207.

[55] Adeloju S. B. and Bond M. A., Analytical Chemistry, 1984, 56, 2397-2401.

[56] Jiajie L. and Nagaosa Y., Analytica Chimica Acta, 2007, 593, 1-6. 
[57] Ishiyama T. and Tanaka T., Analytical Chemistry, 1996, 68, 3789-3792.

[58] Yang H. and Sun I., Analytical Chemistry, 2000, 72, 3476-3479.

[59] Fernando B., de Souza S. S. and Krug F. J., Journal of Analytical Atomic Spectrometry, 2002,17,382-388.

[60] Hazelton S.G. and Plerce D.T., Analytical Chemistry, 2007, 79, 4558-4563.

[61] Davis P. H., Dulude G. R., Griffin R. M., Matson W. R. and Zink E. W., Analytical Chemistry, 1978, 50(1),137-143.

[62] Vandenhecke, J., Waeles, M., Riso, R. D. and Le Corre, P., Analytical Bioanalytical Chemistry, 2007, 388, 929-937.

[63] Town R. M., van Leeuwen H. P., Journal of Electroanalytical Chemistry, 2001, 509,58-65.

[64] Basa A., Magnuszewska J., Krogulec T., and Baranski A. S., Analytical Chemistry, 2006, 78,6747-6755.

[65] Dugo G., La Pera L, Lo Turco V., Di Bella G., Chemosphere, 2005, 61, 1093-1101.

[66] Bergveld R., Eijkel, J. C. T., Olthuis, W., Biosensors and Bioelectronics, 1997, 12, 905-916.

[67] Adeloju S. B., Young T. M., Jagner D., Batley G. E., Analytica Chimica Acta, 1999, 381, 207-213.

[68] Estela J. M., Tomas C., Cladera A., Cerda V., Critical Reviews in Analytical Chemistry, 1995, 25, 91-141.

[69] Soares H. M., Vasconcelos M. T., Analytica Chimica Acta, 1995, 314, 241-249.

[70] Jagner, D., Analytical Chemistry, 1979, 51, 342-345.

[71] Riso R. D, Le Corre P., Chaumery C. J., Analytica Chimica Acta, 1997, 351, 83-89.

[72] Bi, S. and Yu J. J., Journal of Electroanalytical Chemistry, 1996, 405, 51-58.

[73] Molina, A., Gonza'lez, J., Saavedra, F., Abrantes, L. M., Electrochimica Acta, 1999, 45, 
761-773.

[74] Wang J., Tian B., Analytical Chemistry, 2000, 72, 3241-3244

[75] Beinrohr, E., Dzurov, J., Annus, J., Broekaert, J. A. C., Fresenius Z. Journal of Analytical Chemistry, 1998, 362, 201-204.

[76] Schulze, G., Han, E., Frenzel W., Fresenius Z. Journal of Analytical Chemistry, 1989, 332, 844.

[77] Pumure I., Renton J. J. and Smart R. B., Environmental Geology, 2009, 56, 985-991. 59

[78] Pumure I., Renton J. J. and Smart R. B., Chemosphere, 2010, 78, 1295-1300.

[79] Xiao-Quan S. and Kai-Jing H., Talanta, 1985, 32, 23-26.

[80] Marin L., Lhomme J. and Carignan J., Journal of Geostandards and Geoanalysis, 2001, 25(2-3), 317-324.

[81] Yu M., Liu G. and Jin Q., Talanta, 1983, 30, 265-270.

[82] Savard D., B’edard L. P. and Barnes S. J., Talanta, 2006, 70, 566-571.

[83] Kubota T., Suzuki K. and Okutani T., Talanta, 1995, 42, 949-955.

[84] Torgov V.G., Vall G.A., Demidova M.G. and Yatsenko V.T., Chemical Geology, 1995, 124, 101-107.

[85] http://www.dgtresearch.com/dgtresearch/dgtresearch.pdf, Website browsed on January 17th, 2011.

[86] Zhang H. and Davison, W., Analytical Chemistry, 1995, 67, 3391-3400.

[87] Panther, J. G., Stillwell, K. P., Powell, K. J. and Downard, A. J., Analytica Chimica Acta, 2008, 622, 133-135.

[88] Zhang H., Santner J. and Davison W., Analytical Chemistry, 2010, 82 (21), 8903-8909. 
[89] Bennett, W.W., Teasdale P. R., Panther J. G., Welsh D. T. and Jolley D. F., Analytical Chemistry, 2011, 83, 8293-8299.

[90] Bennett, W.W., Teasdale, P. R., Panther, J. G., Welsh D. T., and Jolley D. F., Analytical Chemistry, 2010, 82,7401-7407.

[91] Zhang H. and Davison W., Gadi R. and Kobayashi T., Analytica Chimica Acta, 1998, 370, 29-39.

[92] Santner J., Prohaska T., Luo J., and Zhang H., Analytical Chemistry, 2010, 82, 7668-7674. 


\section{Chapter Two}

\section{Total Arsenic and Selenium Analysis in Marcellus Shale, High-Salinity Water and Hydrofracture Flowback Wastewater}

\section{Introduction}

As discussed in Chapter 1 section 1.2, the concentrations of different chemicals may vary in flowback water from different areas and shales, due to different chemical additives used in hydraulic fracturing, and fracturing water contact with the shale yielding flowback wastewaters of various high ionic strengths [1-9].

Most analytical techniques used for trace arsenic and selenium analysis have interferences, especially in highly saline water, which can often significantly bias results. Therefore, accurate and precise determination of arsenic and selenium in such high-salinity waters is important for regulatory environmental monitoring. It is also important to quantify arsenic and selenium concentration in the Marcellus shales being used for natural gas exploration to give insights about the possibility of leaching of these toxic elements from the shale into the flowback water.

Various methods have been reported for overcoming matrix interferences in arsenic and selenium analysis. These methods include anodic stripping voltammetry in conjunction with a flow-through cell [10] inductively-coupled plasma dynamic reaction cell mass spectrometry [1114] TCF-graphite furnace atomic absorption spectroscopy [15-19] as well as other atomic spectroscopic techniques involving use of preconcentrating agents such as activated carbon [20] cetyltrimethylammonium (CTAB) bromide modified alkylsilica sorbent $\mathrm{m}$ [21] and lanthum hydroxide coated on cellulose fiber [22] and electrochemical based methods such as anodic 
stripping chronopotentiometry [23-27]. In this study, a modified TCF-GFAAS technique was employed to quantify arsenic and selenium in Marcellus shale, HSW and WRF6 because it is less expensive and enables very good matrix interference removal from the analytes.

\subsection{Experimental}

All solutions were prepared from ACS reagent grade chemicals using ultrapure d.i. water (18.0 m $\Omega$ ). Trace metal grade nitric acid, Optima hydrochloric acid, and trace metal grade hydrofluoric acid (Fisher Scientific) were used for preparation of acid solutions. Arsenic and selenium solutions were prepared from 1000 ppm Spex Certiprep Assurance grade standard solutions. All glassware and polyethylene bottles were washed and left overnight in $5 \%$ nitric acid, and rinsed with ultrapure water before use. The Marcellus shale samples were obtained from the WV Economic and Geological Survey and ground to $\leq 60$ micron size. Field-collected flowback wastewater (WRF6) was provided by the WVU Water Research Institute, who also provided the analysis as follows: chloride (150,000 mg/L), TDS (187,000 mg/L), calcium (21,000 mg/L), barium (2,290 mg/L), magnesium (2,120 mg/L), iron (64 mg/L), potassium (1,180 mg/L), sodium (4,270 mg/L), and strontium (5,060 mg/L).

\subsubsection{Preparation of TCF}

The TCF was prepared by adding commercial cotton $(10 \mathrm{~g})$ to a mixture of $53 \mathrm{~mL}$ of thioglycollic (mercaptoacetic) acid, $35 \mathrm{~mL}$ of acetic anhydride, $16.5 \mathrm{~mL}$ of acetic acid and 0.15 $\mathrm{mL}$ of concentrated sulphuric acid followed by heating for five days in a water bath at $40{ }^{\circ} \mathrm{C}$ with daily stirring following the preparation method described by Xiao-Quan and Kai-Jing [25]. The 
solution containing the TCF was vacuum-filtered, rinsed with d.i. water, and dried at room temperature for two days and before being ground into a powder.

\subsubsection{High-salinity water}

High-salinity water (HSW) samples $\left(1.0 \times 10^{5} \mathrm{ppm} \mathrm{NaCl}\right)$ were prepared in triplicate using sodium chloride and a 3\% solution of trace metal grade nitric acid. Samples were spiked with either 1 or 100 ppm standard arsenic solutions to obtain 100-mL volume with arsenic concentrations of $0,5,10,20,50$ and $100 \mathrm{ppb}$. The pH of the HSW was 6.8 and all solutions were stored at $4 \circ \mathrm{C}$.

\subsubsection{Flowback wastewater}

Triplicate samples of field-collected flowback wastewater (WRF6) from an actual gas drilling operation were spiked with arsenic to obtain arsenic concentrations of $0,5,10,50$ and $100 \mathrm{ppb}$. The $\mathrm{pH}$ of this wastewater was 6.7 and all solutions were stored at $4{ }^{\circ} \mathrm{C}$.

\subsubsection{GFAAS}

The arsenic and selenium concentrations were measured using GFAAS (Varian SpectraA Model 55B, GTA 101 with autosampler) with deuterium lamp correction at 193.7 and $196.0 \mathrm{~nm}$, respectively. A 6000 ppm palladium nitrate modifier (Sigma Aldrich) was used for selenium, while $3 \mu \mathrm{L}$ of $50 \mathrm{ppm}$ nickel solution prepared from nickel nitrate hexahydrate (Fisher) was used as modifier for arsenic quantitation. 


\subsubsection{Microwave digestion}

Samples of Marcellus shale $(0.25 \mathrm{~g}, \mathrm{n}=3$ ) were weighed and transferred into acid-washed microwave digestion vessels. Trace metal grade concentrated nitric acid $(4.0 \mathrm{~mL})$ and $0.5 \mathrm{~mL}$ of concentrated hydrofluoric acid were added and the vessels were placed into a CEM Corporation

Mars 5 (Mathews, NC) microwave digester. The digestion was done at $400 \mathrm{~W}$ and 700 psi pressure, with ramping to a maximum temperature of $190^{\circ} \mathrm{C}$ over a period 40 minutes followed by holding at that temperature for 15 minutes. Samples were cooled to room temperature and transferred into a $100 \mathrm{~mL}$ volumetric flask and brought to volume with $3 \%$ solution of trace metal grade $\mathrm{HNO}_{3}$. No solid remained after digestion. These samples were then transferred into polyethylene bottles.

To assess the recovery of the digestion method, samples $(0.25 \mathrm{~g}, \mathrm{n}=3)$ were spiked with $22 \mu \mathrm{g}$ arsenic and $0.75 \mu \mathrm{g}$ selenium. The same reagents and amounts were added and the digestion procedure was done simultaneously with the unspiked replicates under the same microwave digestion conditions above. The resultant solution was diluted to $100 \mathrm{~mL}$ using a 3\% solution of trace metal grade $\mathrm{HNO}_{3}$. The samples were analyzed by GFAAS.

\subsubsection{TCF sample treatment}

A flow diagram for analyte isolation on TCF is shown in Figure 2.1. The powdered TCF (120 mg) was placed into a polypropylene column with a tapered end (inner diameter of $1.5 \mathrm{~cm}$ at one end and $1 \mathrm{~mm}$ at the tip, and height $12 \mathrm{~cm}$ ), rinsed twice with either $2.5 \mathrm{~mL}$ of 2.5 or 0.8 M HCl for arsenic and selenium quantitation, respectively. 


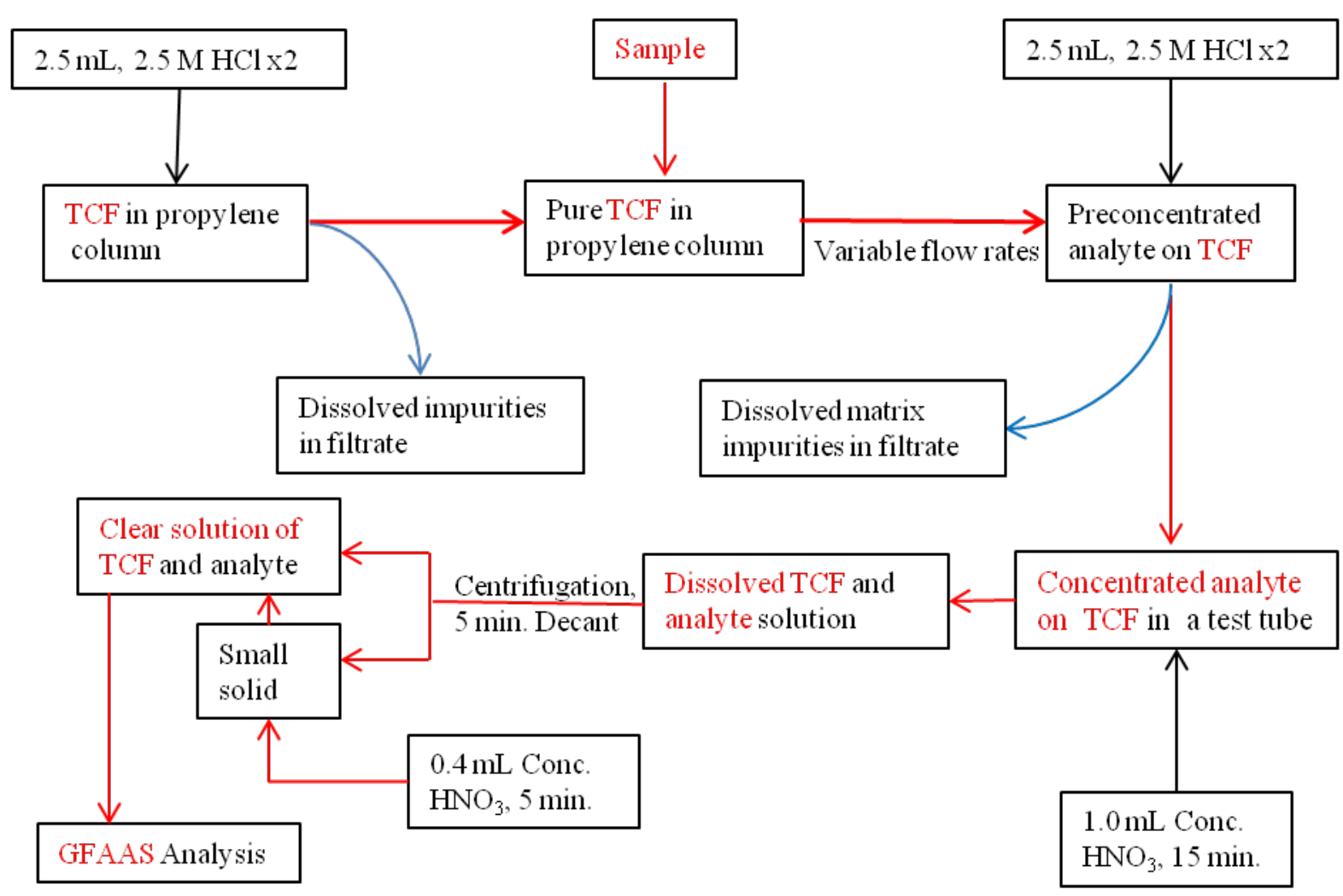

Figure 2.1. Flow diagram for analyte isolation on TCF.

A 20-mL aliquot of the microwave digested shale sample solution was then placed on the TCF column. For the spiked WRF6 and HSW samples, a similar treatment was done on TCF. For 5 and $10 \mathrm{ppb}$ spikes, all of the $25 \mathrm{~mL}$ aliquot was used, whereas for the 50 and $100 \mathrm{ppb}$ spikes, 10 and $5 \mathrm{~mL}$ were used, respectively.

The TCF containing the analyte from the microwave digests, HSW, or WRF6 was transferred into a small test tube and $1 \mathrm{~mL}$ of trace metal grade concentrated nitric acid added to destroy the TCF. After 15 minutes, the dissolved TCF and rinses were transferred into a $10 \mathrm{~mL}$ volumetric flask. The samples were centrifuged at 3400 rpm (Centrific Model 228, Fisher Scientific) for 5 minutes prior to the analysis. After centrifugation, a clear solution containing the analyte was the decanted. A small amount of solid that remained was dissolved by adding 0.4 
$\mathrm{mL}$ of trace metal grade concentrated nitric acid, and quantitatively transferred to the decanted clear solution of the analyte, and diluted to final volume.

\subsection{Results and Discussion}

\subsubsection{Method validation}

The values determined for total arsenic and selenium concentrations in SGR-1b were 69 $\pm 3 \mu \mathrm{g} / \mathrm{g}$ and $4.0 \pm 0.3 \mu \mathrm{g} / \mathrm{g}$, respectively. These values compare well with the certified values of $67 \mu \mathrm{g} / \mathrm{g}$ arsenic and $3.5 \mu \mathrm{g} / \mathrm{g}$ selenium in the SGR-1b reference shale. The percentage recoveries for arsenic and selenium spiked shale were $98 \pm 5$ and $97 \pm 6 \%$, respectively.

\subsubsection{Microwave digestion of Marcellus shale samples}

The determination of arsenic without TCF treatment gave low results with percent recoveries ranging from $89 \pm 8$ to $92 \pm 6$. No reliable selenium results were measured without TCF treatment because of the high \% RSD (40-100) obtained. This is attributed to the smaller selenium concentrations in these samples and the matrix interferences that suppress the GFAAS signal.

\subsubsection{TCF sample treatment}

The arsenic and selenium concentrations obtained from the microwave digested- TCF treated shales (Gilmer 1978, Boone 598 and Wet 465) as well as the recoveries from the spiked samples are shown in Table 2.1. The TCF treatment eliminates the matrix interferences giving better accuracy and higher recoveries. This TCF procedure coupled with centrifugation provided 
arsenic and selenium recoveries of over $90 \%$ in the Marcellus shale samples at flow rates of 2 and $5 \mathrm{~mL} / \mathrm{minute}$ for arsenic and selenium, respectively. These flow rates are similar to those suggested by Yu et. al [19]. Flow rate was determined by dividing the volume of the sample passed through the TCF column by the total time it took the entire sample to flow through the column (contact or exposure time). For small volumes, the sample was retained on the TCF for a reasonable amount of time before flow was initiated to reach a maximum of one hour contact time. Flow rate was controlled by adjusting the vacuum connected to the column.

Table 2.1. Arsenic and selenium concentrations obtained from $0.25 \mathrm{~g}$ of Marcellus shale with TCF treatment.

\begin{tabular}{|c|c|c|c|c|}
\hline \multirow[t]{2}{*}{ Sample } & \multicolumn{2}{|c|}{$\begin{array}{l}\text { [As] with TCF } \\
\text { (5 mL/min) }\end{array}$} & \multicolumn{2}{|c|}{$\begin{array}{c}\text { [Se] with TCF } \\
(2 \mathrm{~mL} / \mathrm{min})\end{array}$} \\
\hline & $\mu g / g$ & $\begin{array}{c}\text { Percent } \\
\text { Recovery }\end{array}$ & $\mu g / g$ & $\begin{array}{c}\text { Percent } \\
\text { Recovery }\end{array}$ \\
\hline Gilmer 1978 & $153 \pm 4$ & \multirow[b]{2}{*}{$99 \pm 6$} & $3.9 \pm 0.4$ & \multirow[b]{2}{*}{$97 \pm 6$} \\
\hline Gilmer 1978 spike & $238 \pm 3$ & & $6.7 \pm 0.5$ & \\
\hline Boone 598 & $139 \pm 4$ & \multirow[b]{2}{*}{$105 \pm 6$} & $4.2 \pm 0.2$ & \multirow[b]{2}{*}{$97 \pm 5$} \\
\hline Boone 598 Spike & $239 \pm 3$ & & $7.0 \pm 0.3$ & \\
\hline Wet 465 & $154 \pm 5$ & \multirow[b]{2}{*}{$97 \pm 7$} & N.D & \multirow[b]{2}{*}{$90 \pm 4$} \\
\hline Wet 645 spike & $235 \pm 3$ & & $2.8 \pm 0.4$ & \\
\hline
\end{tabular}

\subsection{Matrix interferences from high salt concentrations and atomization profiles}

There are several types of interferences associated with graphite furnace atomic absorption spectroscopy that are classified into three major categories: spectral, matrix and memory. An atomic absorption spectrometer has the capability to graphically display absorbance versus time and can be used to evaluate interferences.

Spectral interference arises due to absorption of light by an element or molecule that is not the analyte of interest or from black body radiation. However, in GF-AAS spectral 
interference caused by another element is rare due the narrow atomic line widths emitted by source lamps and the narrow absorption profiles of atoms. Molecular species, however, can produce broadband absorption profiles. The use of matrix modifiers, optimized furnace temperature programs and Zeeman effect and deuterium lamp background correction are common practices used to minimize the effect of this nonspecific absorption. In addition, black body emission from the hot graphite tube can also produce spectral interferences. Maintaining proper furnace alignment and not using atomization temperatures higher than what is necessary to volatilize the analyte can minimize this type of interference [28].

Matrix interferences are caused by a myriad of matrix components in the analytical portion that suppress the formation of free analyte atoms during the furnace program's atomization step. Other matrix components may also contribute to pre-atomization volatilization of analyte. The use of graphite tube platform atomization provides good analyte confinement and a more constant temperature environment for volatilization of analyte and atomization of free analyte atoms, which somewhat contributes to minimizing matrix interferences in mildly salty matrices [28].

However, matrix interference was still an analytical challenge to overcome in both undiluted and 5x diluted highly salty flowback water without using TCF even with these aids for reducing interferences for GFAAS for arsenic and selenium quantitation as shown in Figure 2.2 A,B,C and D, and Figure 2.3 A,B,C and D, respectively. Dilution and standard addition did not eliminate the matrix interferences totally and yielded analyte concentrations close to the instrument's detection limit. 

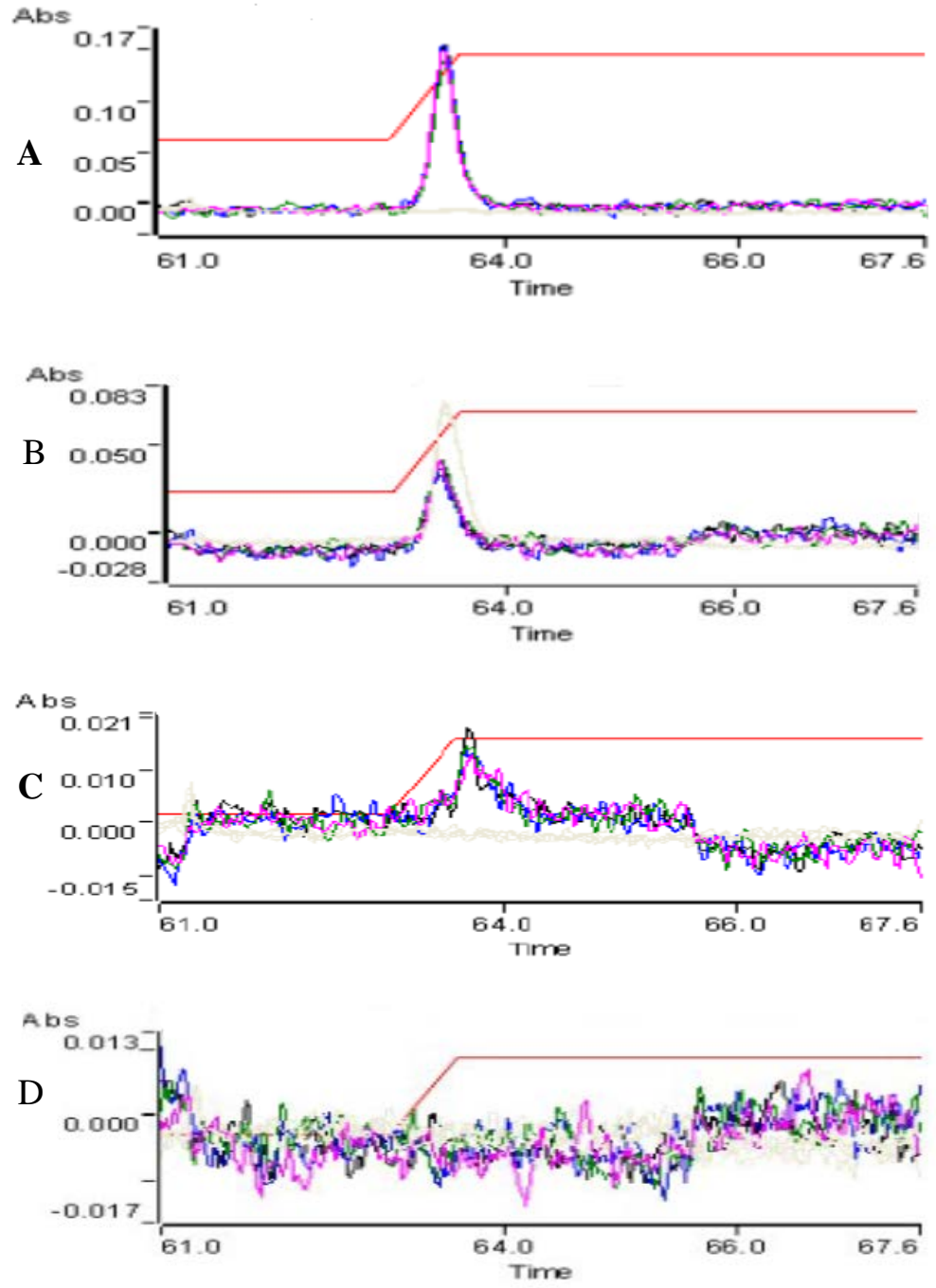

Figure 2.2. Atomization profiles and matrix interference manifestations for arsenic. A. Analyte signal graphics after isolation and preconcentration from matrix using TCF and centrifugation. B. After 5x dilution without TCF. C. Without dilution and TCF. D. Reagent blank. 

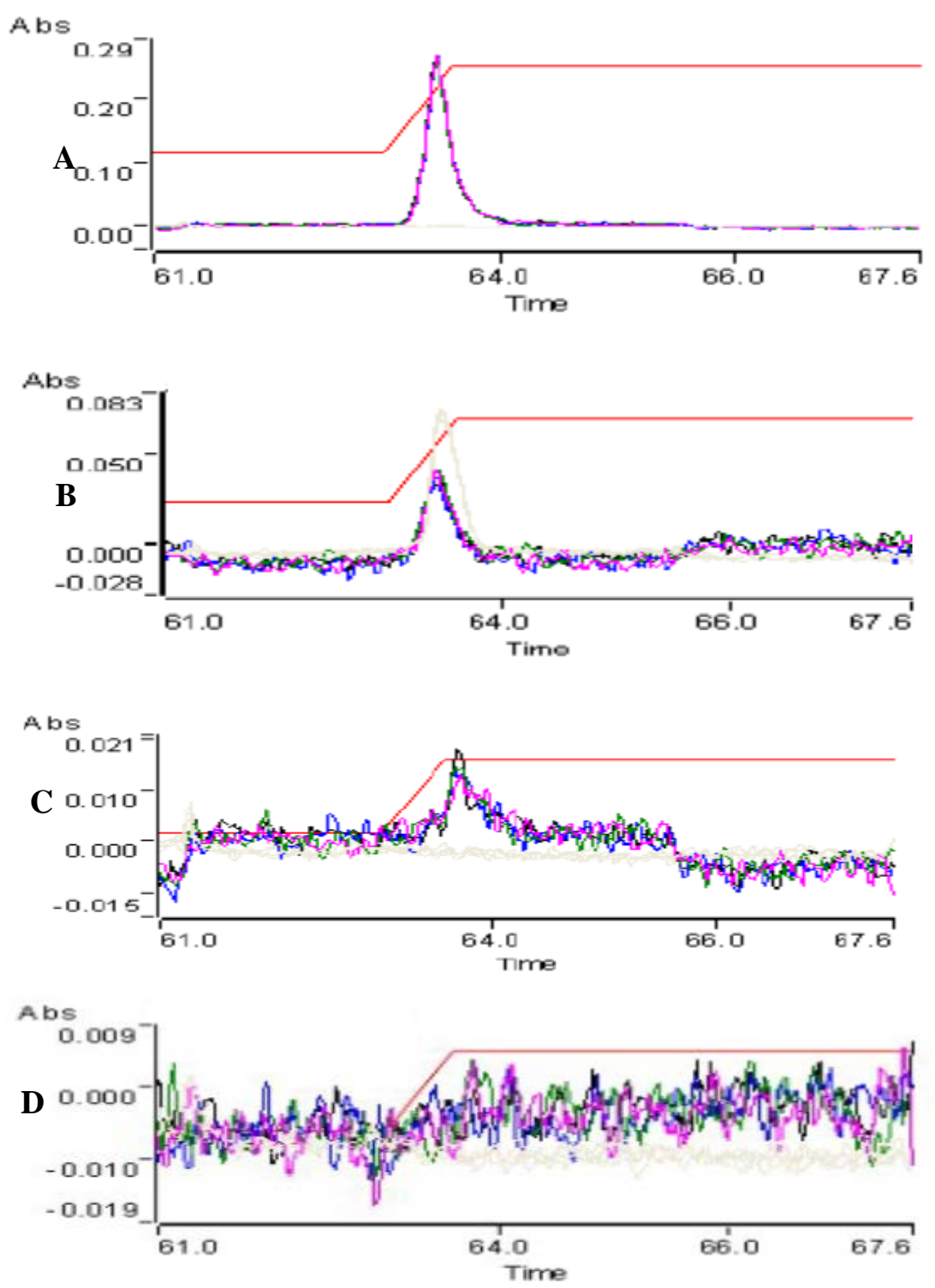

Figure 2.3. Atomization profiles and matrix interference manifestations for selenium. A. Analyte signal graphics after isolation and preconcentration from matrix using TCF and centrifugation. B. After 5x dilution without TCF. C. Without dilution and TCF. D. Reagent blank.

High matrix interefence yielded irregular peak profiles with broadened peaks (low peak height to peak area ratio) doubled or multiple analyte peaks or a peak's appearance time shifted from expected (Figures 2.2 and $2.3 \mathrm{~B}$ and C). Peak profile (shape of absorbance vs. time graph) is used to evaluate the quality of the analyte atomization. The profiles of the standard solutions 
or good peaks without any matrix interference should be very close to the manufacturer's example of an ideal peak for the particular instrument/graphite tube/furnace/element combination. The ratio of peak height to area $(\mathrm{H} / \mathrm{A})$ provides for an objective way to qualitatively evaluate peak profiles. Narrow peaks with a larger H/A were observed with use of use of TCF in conjunction with centrigugation as shown in Figures 2.2 and 2.3 A. Wider peaks with smaller H/A and indicating slow release of analyte were obtained with dilution and no dilution without TCF (Figures 2.2 and $2.3 \mathrm{~B}$ and C). Matrix suppression is suspected if the H/A ratio for an analytical solution is $<80 \%$ of the ratio for a standard solution or matrix interference free analyte. For sufficiently slow analyte release or atomization (low H/A), some analyte might still be present in the tube after the end of the read step resulting in the peak not returning to baseline. A low H/A can also indicate a doubled peak, which is another manifestation of matrix interference (Figures 2.2 and $2.3 \mathrm{~B}$ and $\mathrm{C}$ ).

In addition, in high-salt water samples pre-atomization analyte loss can occur during the ashing or char step. This phenomenon causes an analytical result that is negatively biased due to low absorbance. This loss also occurred even when using a matrix modifier and a default or recommended ashing temperature without using TCF. Pre-atomization loss was shown by an absorbance less than zero at the beginning of the read cycle and ending with the peak's tail dipping below the baseline.

Analytes in high concentrations in the sample may not be completely volatilized out of the graphite furnace tube. This residual analyte may have what is called a memory effect on the next measurements, resulting in positively biased results. In addition, highly salty water samples can have a matrix memory effect on the next measurement. Use of a clean-out step of a few 
seconds after atomization at maximum temperature $\left(2800^{\circ} \mathrm{C}\right)$ was applied to minimize memory effects.

The optimum flow rates for analyte isolation on TCF for the HSW and WRF6 solutions were achieved by varying the flow rates of spiked samples through the TCF and the data for arsenic and selenium recoveries are shown in Figure 2.4 for WRF6. Arsenic is initially removed by TCF at a slightly faster rate than selenium at the same flow rates.

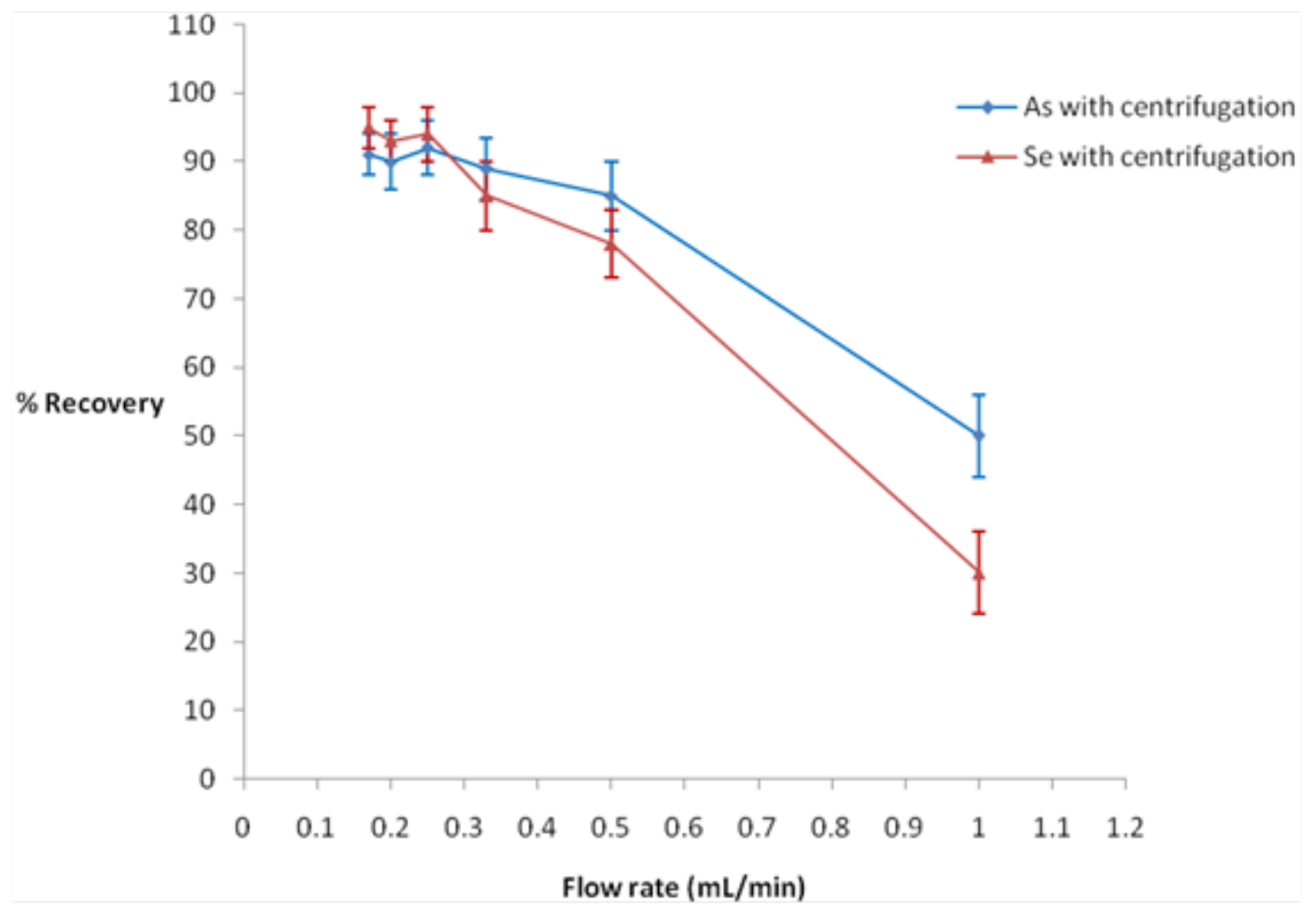

Figure 2.4. Analyte recovery from WRF6 versus flow rate (Error bars are 95\% C.I).

$$
[\mathrm{As}]=[\mathrm{Se}]=50 \mathrm{ppb}
$$

The optimum flow rate of the sample through TCF to achieve isolation of arsenic was $\leq$ $0.35 \mathrm{~mL} / \mathrm{min}$, while that for selenium was $\leq 0.25 \mathrm{~mL} / \mathrm{min}$. A flow rate of $0.35 \mathrm{~mL} / \mathrm{min}$ was used 
for arsenic yielded results which were statistically equivalent to that of $0.25 \mathrm{~mL} / \mathrm{min}$, yet provided somewhat shorter analysis times.

These samples required much lower flow rates than those reported by others [80-82]. By performing GFAAS analysis with and without centrifugation, we determined that centrifugation of dissolved TCF solutions containing arsenic or selenium and nitric acid dissolution of the small solid material remaining resulted in more accurate GFAAS analysis as well as higher recoveries. This is likely attributable to a more uniform sample flow rate in the autosampler of the GFAAS which is crucial for accurate and precise microliter injections.

The optimum sample flow rate through TCF for arsenic and selenium is dependent on the composition and the ionic strength of the sample. This is shown in Table 2.1, where flow rates of 2 and $5 \mathrm{~mL} / \mathrm{min}$ for selenium and arsenic were used for Marcellus shales compared to Figure 2.2, where flow rates of 0.25 and $0.35 \mathrm{~mL} / \mathrm{min}$ for selenium and arsenic were used for both WRF6 and HSW.

Table 2.2. Arsenic and selenium recoveries in WRF6 after TCF treatment.

\begin{tabular}{|c|c|c|c|c|}
\hline $\begin{array}{c}\text { Spiked } \\
\text { [As] }=\text { [Se] } \\
\text { (ppb) }\end{array}$ & $\begin{array}{l}\text { TCF-GFAAS } \\
\text { determined } \\
\text { [As] (ppb) }\end{array}$ & $\begin{array}{l}\text { Percent } \\
\text { recovery }\end{array}$ & $\begin{array}{l}\text { TCF-GFAAS } \\
\text { determined } \\
\text { [Se] (ppb) }\end{array}$ & $\begin{array}{l}\text { Percent } \\
\text { recovery if } \\
\text { original Se is } \\
\text { considered }\end{array}$ \\
\hline 100 & $94 \pm 2$ & $94 \pm 2$ & $109 \pm 2$ & $99 \pm 2$ \\
\hline 50 & $46 \pm 4$ & $92 \pm 8$ & $57 \pm 2$ & $94 \pm 4$ \\
\hline 10 & $9 \pm 0.5$ & $90 \pm 5$ & $19 \pm 1$ & $90 \pm 10$ \\
\hline 5 & $3 \pm 1$ & $60 \pm 20$ & $14.6 \pm 1.0$ & $92 \pm 20$ \\
\hline $\mathbf{0}$ & $<\mathbf{1}$ & - & $\mathbf{1 0 . 0} \pm \mathbf{2 . 0}$ & - \\
\hline
\end{tabular}


The recoveries obtained for WRF6 are given in Table 2.2 and 2.3. For the 5 and $10 \mathrm{ppb}$ spiked HSW samples, $50 \mathrm{~mL}$ of the sample solution was introduced into the column. A sample volume of $20 \mathrm{~mL}$ was used for the $50 \mathrm{ppb}$ and $100 \mathrm{ppb}$ spikes.

Table 2.3. Arsenic and selenium recoveries in HSW after TCF treatment.

\begin{tabular}{|c|c|c|c|c|}
\hline $\begin{array}{c}\text { Spiked } \\
\text { [As] }=[\text { [Se] } \\
\text { (ppb) }\end{array}$ & $\begin{array}{l}\text { TCF-GFAAS } \\
\text { determined } \\
\text { [As] } \mathbf{( p p b )}\end{array}$ & $\begin{array}{l}\text { Percent } \\
\text { recovery }\end{array}$ & $\begin{array}{l}\text { TCF-GFAAS } \\
\text { determined } \\
\text { [Se] (ppb) }\end{array}$ & $\begin{array}{l}\text { Percent } \\
\text { recovery }\end{array}$ \\
\hline 100 & $93 \pm 2$ & $93 \pm 2$ & $96 \pm 3$ & $96 \pm 2$ \\
\hline 50 & $47 \pm 3$ & $94 \pm 6$ & $48 \pm 2$ & $96 \pm 4$ \\
\hline 20 & $18 \pm 3$ & $90 \pm 15$ & $18.7 \pm 1.7$ & $94 \pm 9$ \\
\hline 10 & $8.5 \pm 2$ & $85 \pm 20$ & $9.2 \pm 1.0$ & $92 \pm 10$ \\
\hline 5 & $3.5 \pm 1$ & $70 \pm 20$ & $4.4 \pm 1.0$ & $88 \pm 20$ \\
\hline 0 & $<1$ & - & $<2$ & - \\
\hline
\end{tabular}

\subsection{Conclusions}

The combination of microwave digestion followed by TCF analyte isolation coupled with lower flow rates and centrifugation prior to analysis by GFAAS has been applied to the arsenic and selenium analysis of several Marcellus shales. The TCF extraction procedure followed by GFAAS has also been used for hydrofracture flowback wastewater (WRF6) and highly saline water (HSW). Excellent recoveries for arsenic and selenium from shale samples as well as WRF6 and HSW were obtained. 


\subsection{References}

[1] Soeder D. J., Water resource and natural gas production from the marcellus shale (http://pubs.usgs.gov/fs/2009/3032/, website browsed on Feb. 20 2011).

[2] Vidic, R. D., Brantley, S. L., Vandenbossche, J. M., Yoxtheimer D. and Abad, J. D., Science, 2013, 340, 826-835.

[3] Warner, N. R., Jackson, R. B., Darrah, T. H., Osborn, S. G., Down, A., Zhao, K., White, A. and Vengosh, A., Geochemical eveidence for possible natural migration of Marcellus formation brines to shallow aquifers in Pennyslavania, 2012, 109(30), 11961-11966.

[4] Kargbo, D. M., Wilhelm, R. G. and Campbell, D. J., Environmental Science and Technology, 2010, 44(15), 5679-5684.

[5] Howarth, R. W. and Ingraffea, A., Nature, 2011, 477, 271-275.

[6] Schmidt, C.W., Environmental Healthy Perspectives, 2011, 119(8), A348-A353.

[7] Gregory, K. B., Radisav, D. V., and Dzombak, D. A., Elements, 2011, 7, 181-186.

[8] Bomgardner, M. M., Chemical and Engineering News, October $15^{\text {th }}$, 2012, 13-16.

[9] Shramko A., Palmgren T., Gallo D. and Dixit R., $16^{\text {th }}$ Annual Petroleum \& Biofuels

Environmental Conference (IPEC), 2009, Houston, Nov. 3-5.

[10] Hazelton S.G. and Plerce D.T., Analytical Chemistry, 2007, 79, 4558-4563.

[11] Pretty, J. R., Blubaugh, E. A. and Caruso, J. A, Analytical Chemistry, 1993, 65, 3396-3403.

[12] Niedzielski P., Siepak M., Siepak J. and Przybylek J., Polish Journal of Environmental Studies, 2002, 11(3), 219-224.

[13] McShane, W. J., Pappas, R. S. and Paschal, D., Journal of Analytical Atomic Spectrometry, 2007, 22, 630-635.

[14] Kawabata, K., Kishi Y. and Thomas R., Analytical Chemistry, 2003, 75(9), 422A. 
[15] Xiao-Quan S. and Kai-Jing H., Talanta, 1985, 32, 23-26.

[16] Marin L., Lhomme J. and Carignan J., Journal of Geostandards and Geoanalysis, 2001, 25(2-3), 317-324.

[17] Yu M., Liu G. and Jin Q., Talanta, 1983, 30, 265-270.

[18] Yu, M., Liu, G. and Jin, Q., Talanta, 1983, 30, 265-270.

[19] Yu, M., Sun, D. , Tian, W., Wang, G., Shen, W. and Xu, N., Analytica Chimica Acta, 2002, 456, 147.

[20] Kubota T., Suzuki K. and Okutani T., Talanta, 1995, 42, 949-955.

[21] Xiong, C., He, M. and Hu, B., Talanta, 2008, 76, 772-779.

[22] Chen, M., Yang, T. and Wang, J., Analytica Chimica Acta, 2009, 631, 74-79.

[23] Town R. M., van Leeuwen H. P., Journal of Electroanalytical Chemistry, 2001, 509,58-65.

[24] Basa A., Magnuszewska J., Krogulec T., and Baranski A. S., Analytical Chemistry, 2006, 78,6747-6755.

[25] Dugo G., La Pera L, Lo Turco V., Di Bella G., Chemosphere, 2005, 61, 1093-1101.

[26] Jagner, D., Analytical Chemistry, 1979, 51, 342-345.

[27] Bi, S. and Yu J. J., Journal of Electroanalytical Chemistry, 1996, 405, 51-58.

[28] Creed, J., Martin, T., Lobring, L., and O'Del, J., Environmental Science and Technology 1992, 26, 102-106. 


\section{Chapter Three}

\section{Determination of Arsenic in Marcellus Shale by Microwave Digestion-Graphite}

\section{Furnace Atomic Absorption Spectroscopy: Dual Role of Hydrofluoric Acid}

\subsection{Introduction}

Aluminum and arsenic coexist in a variety of samples in the environment, but accurate and precise arsenic determination by GFAAS in samples with high aluminum content is difficult due to molecular absorption of gas phase aluminum (I) oxide interference [1-5]. This broadband absorption enhances the arsenic signal which leads to erroneous results. The three resonance lines mainly used for arsenic quantitation are $189.0 \mathrm{~nm}, 193.7 \mathrm{~nm}$ and $197.2 \mathrm{~nm}$, and all are prone to aluminum interference due to the extensive broadband resonance line of aluminum(I) oxide. The $189.0 \mathrm{~nm}$ line is the most sensitive of the three. Non-specific absorption due to light scattering and autoionization lines of aluminum at 193.7 and $192.7 \mathrm{~nm}$ may also affect arsenic signals. Erroneous deuterium background correction for arsenic in the presence of aluminum has also been reported [5-10].

Accurate and interference-free determination of arsenic in the presence of up to $40 \mu \mathrm{g}$ of aluminum (as aluminum chloride) for $10 \mu \mathrm{L}$ aliquots of sample $\left(0.15 \mathrm{M} \mathrm{Al}^{3+}\right)$ has been reported [1]. This was accomplished by the addition of rhodium, citric acid, and $200 \mu \mathrm{g}$ of ammonium fluoride $(0.54 \mathrm{M})$ to the sample prior to GFAAS at $189 \mathrm{~nm}$. The addition of sufficient fluoride to the aluminum-rich sample enabled formation of aluminum fluoride which melts at $1291^{\circ} \mathrm{C}$, significantly reducing the spectral interference [1-2]. 
A mixture of hydrofluoric and nitric acid, and sometimes in combination with hydrochloric acid has been used in the digestion of finely ground siliceous materials such as rocks, slags and coal fly- ash [11-12] and plant materials [13]. After sample digestion a variety of different interferences were obtained for different analytes, with aluminum being a major common interference for arsenic at $189.0 \mathrm{~nm}$ in such digested samples. Elimination of the aluminum matrix interference through hydride generation atomic absorption is also inaccurate because hydride generation efficiency is impaired if more than $1 \%$ hydrofluoric acid is present in the mixture [1-2].

Our previous work on the GFAAS measurement of arsenic and selenium in Marcellus shale relied upon microwave digestion of the shale in the presence of HF [15]. Thiol cotton fiber (TCF) was then used to remove arsenic from the sample digest in order to eliminate any matrix interferences during the GFAAS measurement. Attempts to secure accurate measurements without the use of TCF led to inconsistent results.

Nine core samples from the WV Marcellus shale (Monongalia county, depths 7483-7720 ft) have been analyzed by the US Geological Survey in 1980 and the average concentration of aluminum as $\mathrm{Al}_{2} \mathrm{O}_{3}$ was $17 \%$ with a range of $11-19 \%$ [15]. In light of these concentrations, the effect of HF on the GFAAS measurement of arsenic in aqueous aluminum solutions was examined. The robustness of the procedure was tested using a US Geological Survey SGR-1b reference shale (6.25\% as $\mathrm{Al}_{2} \mathrm{O}_{3}$ ) [14-18], WV Marcellus shale (Gilmer 1978) and $0.01 \mathrm{M}$ sodium nitrate. 


\subsection{Experimental}

\section{2.1 Reagents}

All standard solutions were prepared from commercial reagents using nanopure deionized water $(18.0 \mathrm{~m} \Omega)$. Trace metal grade nitric acid (Fisher Scientific), trace metal grade hydrofluoric acid (49-50\%) (Fisher Scientific) and ultrapure hydrochloric acid (Optima, Fisher Scientific) were used in preparation of dilute acid solutions used. All glassware and polypropylene bottles were washed and left overnight in $5 \%$ nitric acid, and rinsed finally with ultrapure water before use. The aluminum standards were prepared by diluting a high aluminum standard of $40000 \mathrm{mg}$ $\mathrm{kg}^{-1} \mathrm{Al}(\mathrm{w} / \mathrm{v})$ which was prepared by dissolving aluminum nitrate nonahydrate (Fisher Scientific) in $2 \%$ nitric acid.

\subsubsection{Microwave digestion}

Microwave digestion was done using a Mars 5 microwave digester (Matthews, NC) at a power of $400 \mathrm{~W}$ and 730 psi pressure by ramping to a maximum temperature of $220^{\circ} \mathrm{C}$ over a period 40 minutes, holding for 10 minutes followed by cooling to room temperature. Each digested sample was then transferred into a $100 \mathrm{~mL}$ volumetric flask and diluted with $3 \%$ nitric acid. These solutions were then transferred into polyethylene sample bottles.

US Geological Survey (USGS) certified reference shale samples (SGR-1b, 67 $\pm 3 \mu \mathrm{g}$ arsenic/g sample) were weighed $(0.25 \mathrm{~g}, \mathrm{n}=3)$ and transferred into thoroughly clean digestion vessels. Concentrated nitric acid $(4.0 \mathrm{~mL})$ and varying amounts of concentrated hydrofluoric acid (0.3, 0.5 and $0.8 \mathrm{~mL}$ ) were added to the sample prior to digestion. Samples of the Marcellus shales $(0.25 \mathrm{~g}, \mathrm{n}=3)$ were digested in a similar manner. 
To assess the recovery of the digestion method, samples of SGR-1b and Marcellus shale were spiked with arsenic and the digestion procedure was done simultaneously with unspiked samples. The resultant solutions were diluted to $100 \mathrm{~mL}$ using a $3 \%$ solution of nitric acid and the samples were analyzed by GFAAS as outlined in section 2.3.

\subsubsection{GFAAS}

The arsenic concentrations were measured using GFAAS (Varian SpectraA Model 55B, GTA 101 with autosampler) with deuterium lamp background correction at $189 \mathrm{~nm}$. A $3 \mu \mathrm{L}$ aliquot of $50 \mathrm{mg} \mathrm{kg}^{-1}(\mathrm{w} / \mathrm{v})$ nickel modifier solution prepared from nickel nitrate hexahydrate (Fisher Scientific) and $10 \mu \mathrm{L}$ sample injections were used for arsenic quantitation. The GFAAS temperature profile used was drying from $85-120{ }^{\circ} \mathrm{C} 22$ seconds, ashing at $1450{ }^{\circ} \mathrm{C}$ for 8 seconds, signal graphics reading and storage at $2600{ }^{\circ} \mathrm{C}$ for 2.6 seconds and graphite tube

cleaning at $2800{ }^{\circ} \mathrm{C}$ for 2 seconds. The argon gas flow rate was $3.0 \mathrm{~mL} \mathrm{~min}{ }^{-1}$ for the entire temperature profile but zero signal graphics reading and recording. At the ashing temperature of $1450{ }^{\circ} \mathrm{C}$ (for 8 seconds), atomization temperature of $2600{ }^{\circ} \mathrm{C}$, and graphite tube cleaning temperature of $2800{ }^{\circ} \mathrm{C}$, the graphite furnace tube (partition tubes (coated)-GTA by Agilent technologies, Germany) could be used for 350 firings.

\section{Results and Discussion}

\subsubsection{Recovery of arsenic versus aluminum concentration}

To study the effect of hydrofluoric acid on the measurement of arsenic in aluminum-rich samples by GFAAS, aqueous solutions with various aluminum concentrations were spiked with $100 \mu \mathrm{g} \mathrm{L}^{-1}$ arsenic. Recoveries were determined after addition of $0.30 \mathrm{~mL}(0.093 \mathrm{M} \mathrm{F}), 0.50 \mathrm{~mL}$ 
$\left(0.14 \mathrm{M} \mathrm{F}^{-}\right)$or $0.75 \mathrm{~mL}\left(0.21 \mathrm{M} \mathrm{F}^{-}\right)$of concentrated HF. An aluminum concentration range of 0.0042-0.053 M was chosen based on the expected concentrations found in Marcellus and SGR1b shale. A $0.25 \mathrm{~g}$ sample of Marcellus shale with $17 \% \mathrm{Al}_{2} \mathrm{O}_{3}$ in $100 \mathrm{~mL}$ of solution is equivalent to $8.3 \times 10^{-3} \mathrm{M} \mathrm{Al}^{3+}$ or $225 \mathrm{mg} \mathrm{kg}^{-1} \mathrm{Al}(\mathrm{w} / \mathrm{v})$ and $0.15 \mathrm{~g}$ of the $6.52 \% \mathrm{Al}_{2} \mathrm{O}_{3}$ in 100 mL of solution contains $1.9 \times 10^{-3} \mathrm{M} \mathrm{Al}^{3+}$ or $52 \mathrm{mg} \mathrm{kg}^{-1} \mathrm{Al}(\mathrm{w} / \mathrm{v})$.

As shown in Figure 3.1, less than 70\% recovery of arsenic was observed for samples which contained no HF. The addition of HF gave arsenic recoveries greater than $90 \%$ for aluminum concentrations up to $0.053 \mathrm{M} \mathrm{Al}^{3+}$. The highest recovery was obtained with $0.21 \mathrm{M} \mathrm{HF}$ and all recoveries decreased slightly as the concentration of aluminum increased. The recoveries also decreased in the more dilute HF solutions. This is likely the result of an insufficient fluoride concentration to totally convert the aluminum oxides into volatile aluminum fluorides in the furnace during the ash step. These results are consistent with those reported by other s [1]. 


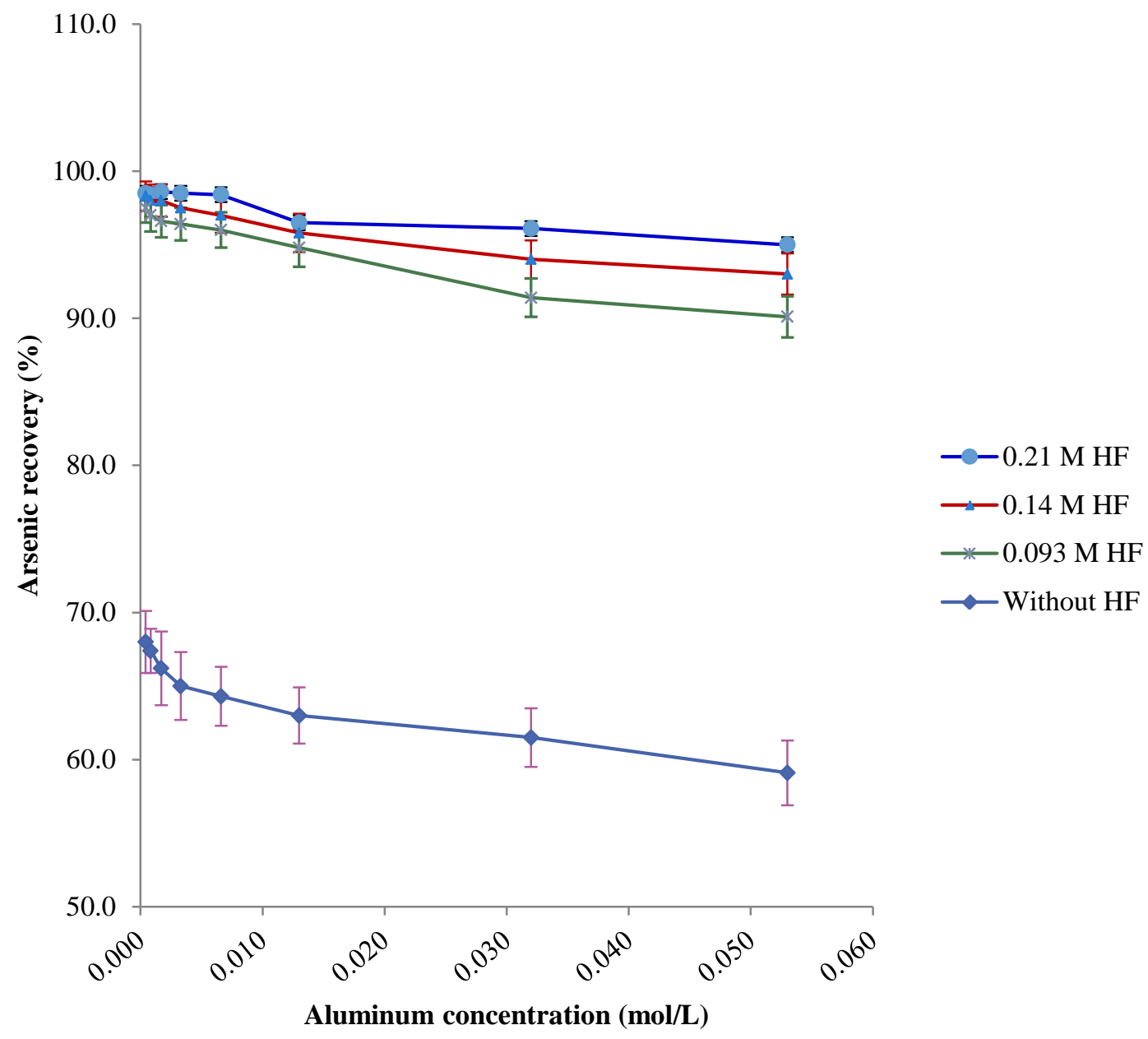

Figure 3.1. Effect of aluminum on arsenic quantitation by GFAAS (Error bars are 95\% C.I). Ash temperature $1450^{\circ} \mathrm{C}$ and ash time $8 \mathrm{~s}$.

\subsubsection{Effect of ash temperature and HF concentration}

The optimum temperature for sample ashing during GFAAS of SGR-1b microwave digests was determined using different ash temperatures in the heating profile in the graphite furnace tube. These measurements $(n=3)$ were obtained using three different HF concentrations during digestion as shown in Figure 3.2.

A $0.5 \mathrm{~mL}$ aliquot of $\mathrm{HF}(0.14 \mathrm{M} \mathrm{HF})$ and an ash temperature of $1450{ }^{\circ} \mathrm{C}$ gave good agreement $(68 \pm 4 \mu \mathrm{g} / \mathrm{g})$ with the certified arsenic value for the USGS SGR-1b (67 $\pm 5 \mu \mathrm{g} / \mathrm{g})$. At 
volumes less than $0.5 \mathrm{~mL} \mathrm{HF}$, incomplete sample dissolution occured. Apparently the concentration of HF was insufficient to dissolve all of silicon oxides in the shale. The aluminum is removed from the furnace as volatile $\mathrm{AlF}_{3}$ at $1450{ }^{\circ} \mathrm{C}$, which is above the melting temperature of $\mathrm{AlF}_{3}\left(1291^{\circ} \mathrm{C}\right)$ and close to its boiling point $\left(1537^{\circ} \mathrm{C}\right)$.

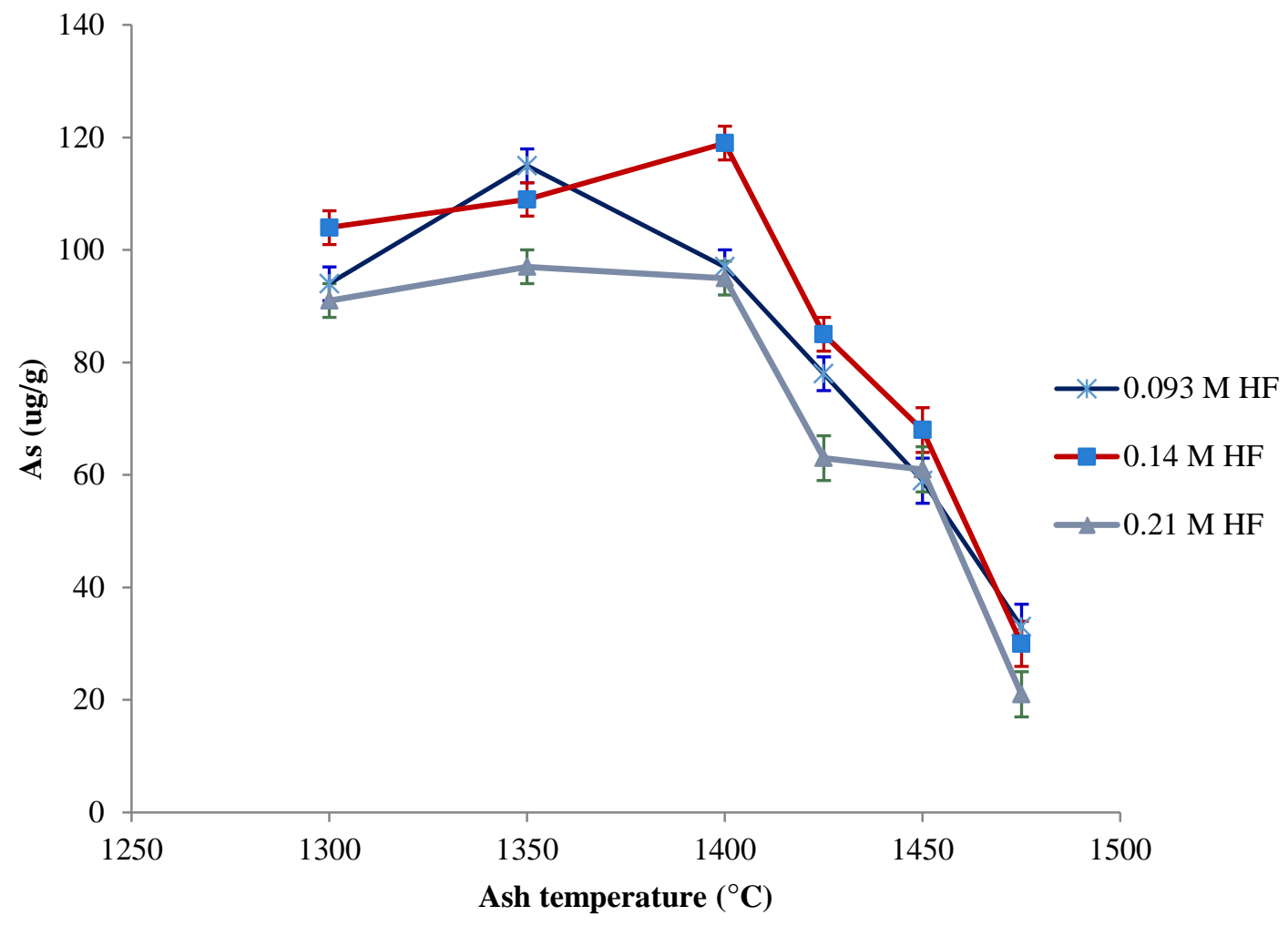

Figure 3.2. Arsenic concentration determined at various ash temperatures and HF concentrations for SGR-1b (Error bars are 95\% C.I). Ash time 8 s (Target value $=67$ $\pm 3 \mu \mathrm{g} / \mathrm{g})$.

The effects of ash temperature and HF concentration on the determination of arsenic in Marcellus shale are shown in Figure 3.3. The arsenic concentration measured at $1450{ }^{\circ} \mathrm{C}$ for Gilmer $1978(147 \pm 3 \mu \mathrm{g} / \mathrm{g})$ is in good agreement with that previously determined by the TCF method (153 $\pm 4 \mu \mathrm{g} / \mathrm{g})$ [15]. 


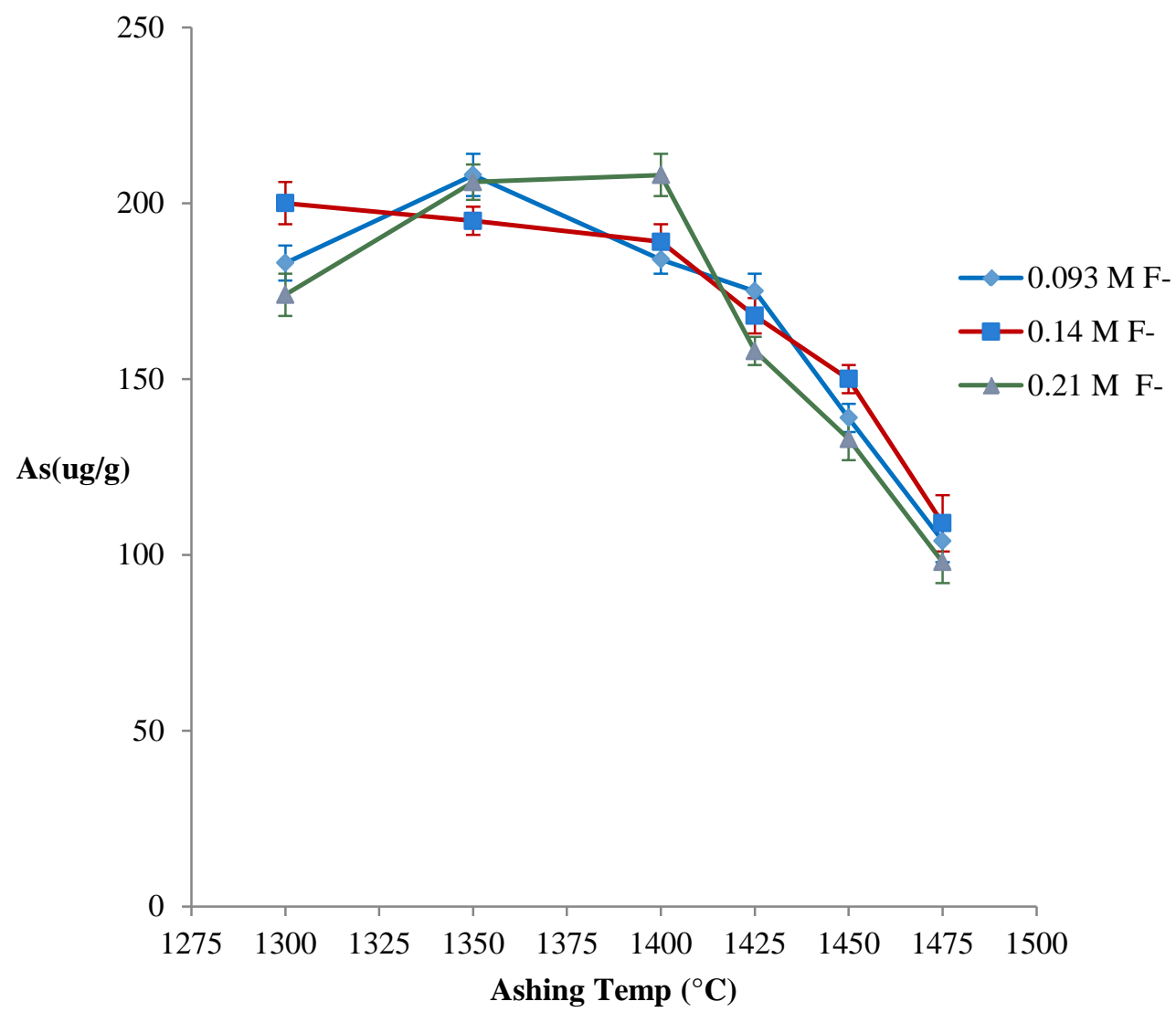

Figure 3.3. Concentration at various ash temperatures for the Marcellus shale (Gilmer 1978) at different HF concentrations. Ash time of $8 \mathrm{~s}$ (Error bars are 95\% C.I). (Target value = $153 \pm 4 \mu \mathrm{g} / \mathrm{g})$.

\subsubsection{Effect of ash time at various temperatures}

Ash times were varied at constant ash temperature in order to evaluate whether any arsenic is lost during this step. Similarly digested samples of SGR-1b (0.14 M HF) were analyzed using three different ash temperatures at different ash times and the results are shown in Figure 3.4. When silicon oxide reacts with HF, hexafluorosilicic acids are formed [19]. These will likely decompose at high temperature producing the fluoride concentration needed to eliminate the aluminium interference. An ash temperature of $1425{ }^{\circ} \mathrm{C}$ yielded high arsenic 
concentrations at all ash times due to aluminum oxide spectral interference that enhanced the arsenic signal. At an ash temperature of $1475{ }^{\circ} \mathrm{C}$, low arsenic concentrations were obtained for all ash times. This is most likely a result of arsenic loss from the graphite furnace tube prior to the atomization step at $2600{ }^{\circ} \mathrm{C}$. An ash time of 8 seconds at an ash temperature of $1450{ }^{\circ} \mathrm{C}$ provided an accurate determination (68 $\pm 5 \mu \mathrm{g} / \mathrm{g}$ ) for arsenic; however, the results at 6,5 , and 4 seconds were very similar at $61 \pm 4,69 \pm 4$, and $70 \pm 4 \mu \mathrm{g} / \mathrm{g}$, respectively. An ash time of 3 seconds at $1450{ }^{\circ} \mathrm{C}$ gave low arsenic $(51 \pm 6 \mu \mathrm{g} / \mathrm{g})$ concentration.

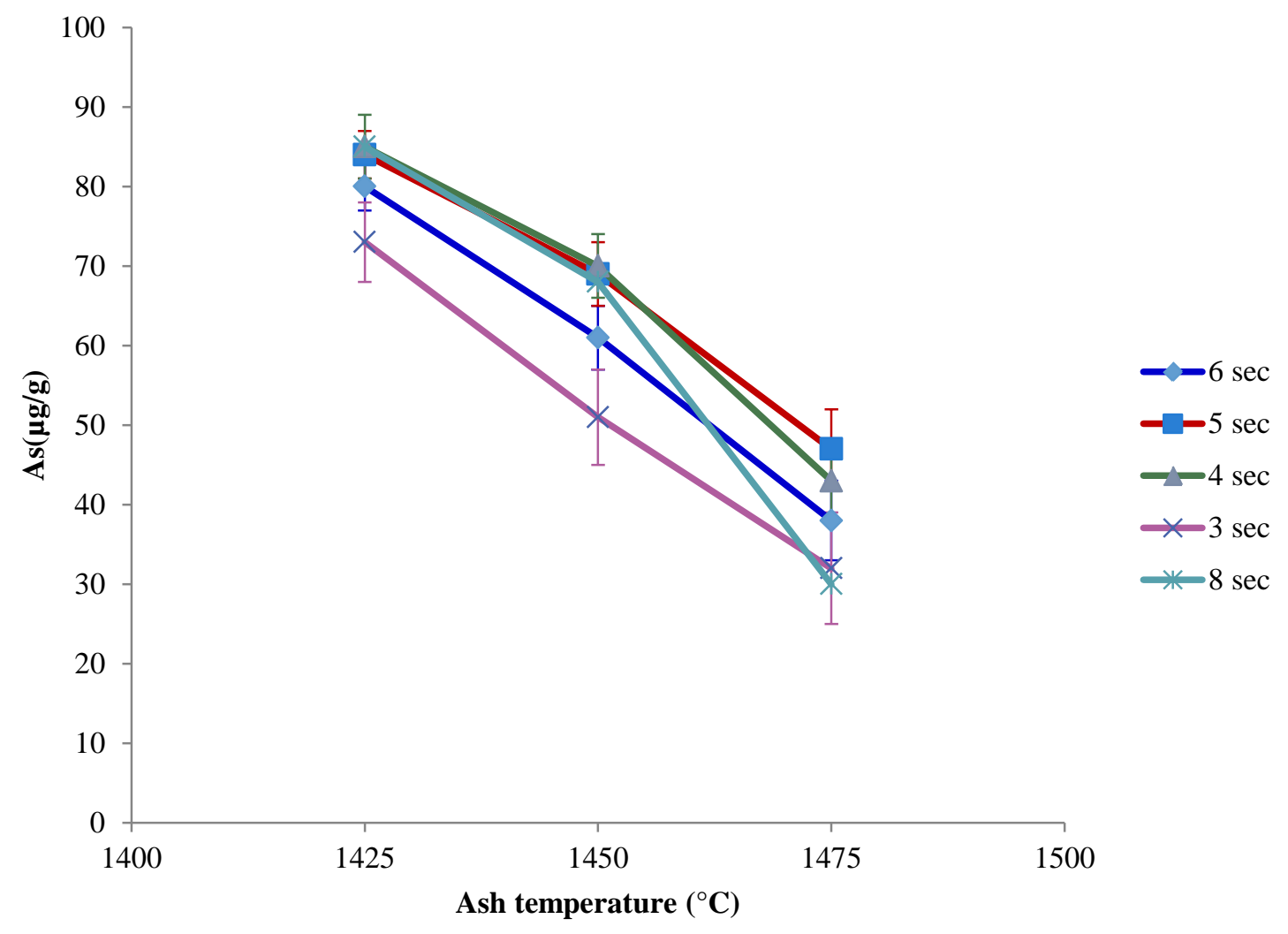

Figure 3.4. Arsenic concentrations determined at various ash temperatures and times for SGR-1b using 0.14 M HF (Error bars are 95\% C.I). 


\subsection{Arsenic concentration in WV Marcellus shale}

The results for the determination of arsenic in WV Marcellus shale samples using the optimum conditions from Figure 3.4 are summarized in Table 3.1. All spiked sample recoveries were greater than $90 \%$. The analysis of Boone 598 and Wet 465 shale also agree well with the

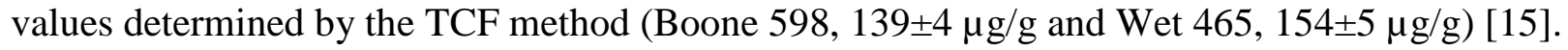

Table 3.1. Arsenic concentration and spiked sample recoveries for three WV Marcellus shales (88ug Arsenic spike).

\begin{tabular}{|l|c|c|}
\hline \multirow{2}{*}{ Sample } & \multicolumn{2}{|l}{ Arsenic } \\
& $\mu \mathrm{r} / \mathrm{g}$ & $\begin{array}{c}\text { Percent } \\
\text { recovery }\end{array}$ \\
\cline { 2 - 2 } & $147 \pm 3$ & \multirow{2}{*}{$92 \pm 3$} \\
\hline Gilmer 1978 & 1470 \\
\hline Gilmer 1978 spike & $216 \pm 3$ & \\
\hline Boone 598 & $136 \pm 4$ & \multirow{2}{*}{$94 \pm 5$} \\
\hline Boone 598 Spike & $210 \pm 3$ & \\
\hline Wet 465 & $151 \pm 3$ & \multirow{2}{*}{$91 \pm 4$} \\
\hline Wet 645 spike & $217 \pm 2$ & $91 \pm 4$ \\
\hline
\end{tabular}

\subsection{Conclusions}

The optimum microwave digestion conditions and temperature profile for GFAAS of arsenic in the microwave digest have been determined for WV Marcellus shale. Accurate quantitation of arsenic in three Marcellus shales by GFAAS at $189 \mathrm{~nm}$ using a nickel modifier following microwave digestion in $\mathrm{HF}$ has been achieved. When a sufficient amount of concentrated HF is added to the sample, complete sample dissolution is attained. The HF also serves an additional role by removing the aluminum from the furnace tube during the ash step 
through formation of volatile aluminum fluoride. This effectively eliminated the spectral interferences in GFAAS of arsenic at $189 \mathrm{~nm}$ due to the aluminum in the sample matrix.

Residual fluoride ion in the digest serves to inhibit the formation of the aluminum oxide in the furnace through the formation of volatile aluminum fluoride during the sample ashing step. The use of HF together with nitric acid enables accurate and precise determination of $\mathrm{mg} \mathrm{kg}^{-1}$ (w/w) concentrations of arsenic in the complex shale matrix using an ashing temperature of 1450

${ }^{0} \mathrm{C}$ followed by atomization at $2600{ }^{0} \mathrm{C}$. The method LOD was $0.11 \mu \mathrm{g} \mathrm{L}^{-1}$ determined as $3 \mathrm{x}$ the standard deviation of the blanks and the linear dynamic range was $0-65 \mu \mathrm{g} \mathrm{L}^{-1}$.

\subsection{References}

[1] Husakova, L., Cernohorsky, T., Sramkova, J., and Urbanova-Dolezalova, Analytica Chimica Acta, 2009, 634, 22-26.

[2] Xu, Y., Iwashita, A., Nakajima, T., Yamashita, H., Takanashi, H. and Ohki, A, Talanta, 2005, 66 58-64.

[3] Castro, M. A., Faulds, A., Smith, W. E., Aller, A. J. and Littlejohn, D., Spectrochimica Acta $B, 2004$, 59, 1935-1942.

[4] Castro, M. A. and Aller, A. J., Spectrochimica Acta B, 2003, 58, 901-918.

[5] Volynsky, A. B., Spectrochimica Acta B, 2004, 59, 1799-1821.

[6] Carrion, N., Itriago, A. M., Alvalez, M. A. and Eljuri, E., Talanta, 2003, 61, 621-622.

[7] Scaccia, S. and Zappa, G., Spectrochimica Acta B, 2000, 55, 1271-1278.

[8] Karwowska, R. and Jackson, K. W., Journal of Analytical Atomic Spectrometry, 1987, 2, $125-126$.

[9] Hall. J., Determination of low levels arsenic using flame AAS and Agilent ultrAA lamps, Application Note, 2010. 
[10] Pohl, B., Horstkotte, B. and Steeg, L., Determination of arsenic and selenium using high intensity hollow cathode lamp, Application Note, 2010.

[11] Feldman, C., Analytical Chemistry, 1977, 46(6), 825-827.

[12] Bettinelli, M., Baroni, U. and Pastorelli, M., Journal of Analytical Atomic Spectrometry, 1988, 3, 1005-1011.

[13] Feng, X., Wu, S., Wharmby, A. and Wittmeier, A., Journal of Analytical Atomic Spectrometry, 1999, 14, 939-946.

[14] Petrick, K. and Krivan, V., Analytical Chemistry, 1987, 59, 2476-2479.

[15] Balaba, R.S. and Smart, R. B., Chemosphere, 2012, 89(11), 1437-1442.

[16] Leventhal, J. S., Comparative geochemistry of Devonian shale cores from the Appalachian basin, Mason, Monongalia and Upshur counties, West Virginia; Illinois Basin, Tazwell county, Illinois Clark county, Indiana; and Michigan Basin, Sanilac county, Michigan. US. Geological Survey, Open File Report, 1980, 80-938.

[17] Green River Shale, http://crustal.usgs.gov/geochemical_reference_standards/shale.html, , website browsed December 30 ${ }^{\text {th }}, 2011$.

[18] MSDS shale, http://www.martinmarietta.com/products/MSDS-Shale.pdf, website browsed January $28^{\text {th }}, 2012$.

[19] Monk, D.J. and Soane, D. S., Thin Solid Films, 1993, 232(1), 1-12. 


\section{Chapter Four}

\section{Investigation of Diffusive Gradients in Thin Film Techniques in the Quantitation of Arsenic and Selenium Bioavailable Fractions in Hydrofracture Wastewater}

\subsection{Introduction}

Arsenic and selenium mobility, bioavailability and toxicity are strongly dependent on the sample/environmental matrix and chemical speciation [1]. Complex matrices such as those from high salinity solutions might be significant depending on their composition. Thus, accurate determination of trace quantities of arsenic and selenium in highly concentrated brines is difficult due to a myriad of interferences. Recently, there has been a surge in natural gas exploration from the Marcellus shales employing hydraulic fracturing technologies that use high volumes of water with different chemicals added and generate millions of gallons of highly saline flowback waste water. $^{2}$ Many flowback wastewaters contain high concentrations of sodium ion (50-40000 ppm) and chloride ion (5000-80000 ppm). In addition, other components such as barium (50-9000 ppm), strontium (50-6000 ppm), magnesium (50-2000 ppm), calcium (500-12000 ppm), iron (50-160 ppm), manganese (5-7 ppm), sulphate (10-400 ppm), silica (50-300 ppm), total dissolved solids (1000-150000 ppm) as well as toxic inorganic constituents such as arsenic and selenium, radionuclides, and organics[2]. Field-collected flowback wastewater (WRF6) was composed of chloride (150,000 mg/L), TDS (187,000 mg/L), calcium (21,000 mg/L), barium (2,290 mg/L), magnesium (2,120 mg/L), iron (64 mg/L), potassium (1,180 mg/L), sodium (4,270 $\mathrm{mg} / \mathrm{L})$, and strontium $(5,060 \mathrm{mg} / \mathrm{L})$. Another flowback wastewater (FS) was composed of chloride (27500 ppm), TDS (45400 ppm), calcium (2310 ppm), barium (230 ppm), magnesium (436 ppm), iron (14.7 ppm), potassium (211 ppm), sodium (15900 ppm), and strontium (657 
ppm). The Criterion Continuous Concentration (CCC) is an estimate of the highest concentration of a material in surface water to which an aquatic community can be exposed indefinitely without resulting in an unacceptable effect. The U.S. Environment Protection Agency proposed a CCC for arsenic as $150 \mu \mathrm{g} / \mathrm{L}$ and $5 \mu \mathrm{g} / \mathrm{L}$ for selenium [3-4]. These values are based on total arsenic and selenium concentrations, but the bioavailable arsenic and selenium concentration limits that are ecotoxicologically harmful could even be lower. The bioavailable ("free” plus labile) arsenic and selenium concentrations are most important when considering the toxicity to aquatic organisms. However, the quantitation of the bioavailable arsenic and selenium in high ionic strength water is difficult due to the matrix interferences, which can either suppress or enhance the analyte signal.

A Diffusive Gradients in Thin Film Technique (DGT) employing a polyacrylamide diffusive gel and different binding agents such as high-capacity nanocrystalline titanium (IV) oxide (Metsorb), ferrihydride and 3-propylmercaptosilica gel adsorbents can be used to isolate the bioavailable analytes and thereby minimize the matrix effects observed in quantitation by graphite furnace atomic absorption spectroscopy (GFAAS) and other analytica techniques. DGT is a versatile and robust in situ quantitation method for labile chemical species in a variety of samples in the environment such as sediments, soil and water [5-6]. It employs different DGT probe designs for different samples, but in all, the labile analyte is allowed to pass through the filter paper, diffusive gel and accumulates in the binding gel in the DGT probes [6-7]. The analyte in the binding gels is analyzed directly by techniques such as Laser Ablation- Inductively Coupled Plasma-Mass Spectrometry (LA-ICP-MS) or Proton Induced X-ray Emission (PIXE). Alternatively, the analyte can be quantitatively eluted from the binding gel and the eluate analyzed using analytical techniques such as GFAAS, (Atomic Fluorescence Spectroscopy 
(AFS), Inductively Coupled Plasma-Atomic Emission Spectroscopy (ICP-AES) and ICP-MS, and appropriate DGT equations used to determine the bioavailable analyte concentration [5, 8].

The phenomenon of dependence of analyte accumulation in the binding layer on both the size and lability of eventual complexes was explicitly illustrated by Zhang and Davison [5]. Consider the equilibrium reaction of analyte ions, Me, and ligands, L, and the complex, MeL:

$\mathrm{Me}+\mathrm{L} \longrightarrow \mathrm{MeL}$

As Me is continually removed by adsorption to the binding layer, the equilibrium in the diffusive layer is perturbed which may promote dissociation of MeL. A schematic representation of potential concentration gradients of MeL complexes and the analyte ions is presented in Figure 4.1. Case A demonstrates the concentration profiles of the analyte and a completely labile complex. The MeL complex dissociates and not only free metal ions but all metal ions originally associated with the complex are adsorbed to the binding layer.

A

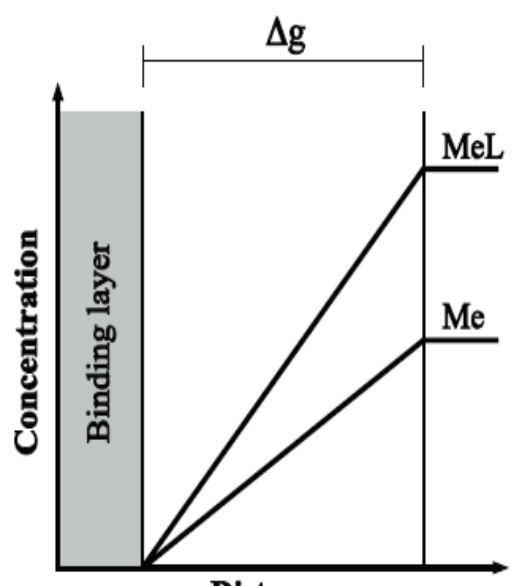

Distance
$\mathrm{B}$

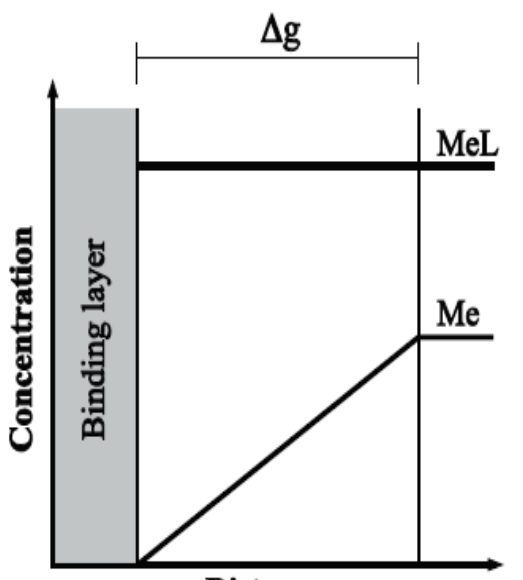

Distance

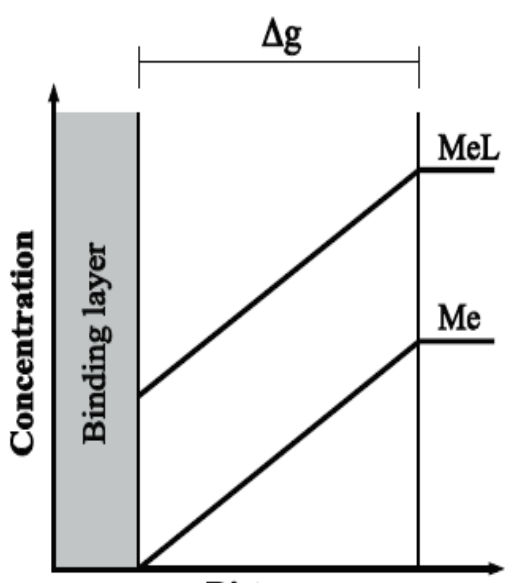

Distance

Figure 4.1. Schematic representation of the concentration gradients of Me and MeL in the diffusive layer showing, A: completely labile complex, B: completely inert complex, and C: partially labile complex [5]. 
In the second case, $\mathrm{B}$, the complex is totally inert and does not dissociate at all within the time taken to diffuse through the layer, and so analytes from this complex will not be measured. Case $\mathrm{C}$ shows the example of a partially labile complex resulting in a decrease in MeL concentration closer to the binding surface but not complete removal. This is due to slow dissociation of the complex in Eq. 4.1. Accumulation is controlled by kinetics and the estimated concentration becomes dependent on the thickness of the diffusion layer. Thicker diffusion layers result in longer times for dissociation. The time taken for a complex to traverse the gel $\left(t_{d}\right)$ can be estimated from Eq. 4.2 if the diffusion coefficient of MeL is known [9]:

$$
t_{d}=\frac{(\Delta g)^{2}}{2 D_{M e L}}
$$

Lability of complexes can be estimated by simultaneous deployment of DGT devices with different diffusive gel thicknesses [9-11]. Scally et. al [12] reported complexed metal ions have slower diffusion than the corresponding free metal ion. This was further substantiated by Warnken et. al [13] and Forsberg et. al [14] reported that Ni and especially Cu generally show lower DGT concentrations than measurements of dissolved (membrane filtered) and truly dissolved (ultrafiltered) fractions, which has been attributed to an effect of organic complexation. Therefore, adapting the diffusion coefficients determined for inorganic species to calculate DGTconcentrations will result in underestimation. Since the same procedure is also used for DBL thickness measurements it is recommended to quantify the DBL using ions that are fully labile and not kinetically limited, and it is for these reasons in conjunction with magnetic stirring that we assumed DBL was negligible.

DGT has been extensively used and characterized for a multitude of analytes such as phosphorus, arsenic, selenium, sulfides, mercury, zinc, aluminum, cadmium, copper, lead, uranium, tellurium, molybdenum, vanadium, tungsten and antimony [5-10, 15-18]. 
Different adsorbents such as ferrihydride, chelex, 3-mercaptopropyl-functionalized silica and commercially available nanocrystalline titanium dioxide, metsorb, have been used for different analytes in both fresh and marine or seawaters due to different affinities of the adsorbent for the analyte of interest or adsorbent capacities [19-20]. Metsorb has been reported to be a better adsorbent for arsenic and selenium quantitative accumulation due to its highly relative tolerance to a wide $\mathrm{pH}$ range (3.5-8.5) and wide ionic strength range $(0.0001-0.75 \mathrm{M}$ $\mathrm{NaNO}_{3}$ ) [17, 20]. Therefore, accurate and precise determination of bioavailable arsenic and selenium in high-salinity waters such as flowback waste water using DGT with metsorb adsorbent and a the new DGT-Fe-Zr binary oxide adsorbent could be important for regulatory environmental monitoring, in addition to quantifying the total arsenic and selenium.

\subsection{Experimental}

\subsubsection{General procedures (Reagents, materials, solutions and GFAAS)}

All reagent solutions were prepared from ACS reagent grade chemicals using ultrapure d.i. water $(18.0 \mathrm{~m} \Omega)$. Trace metal grade nitric acid, optima hydrochloric acid, and trace metal grade hydrofluoric acid (Fisher Scientific) were used for preparation of acid solutions. Arsenic (III \&V) and selenium (IV\&VI) solutions were prepared from certified high purity stock 1000 ppm Spex Certiprep Assurance grade standard solutions. All glassware and polyethylene bottles were washed and left overnight in $5 \%$ nitric acid, and rinsed with ultrapure water before use. Nanocrystalline titanium dioxide, Metsorb (Graver Technologies), 3-mercaptopropyl silica functionalized gel (Sigma Aldrich) and iron-zirconium binary oxide were used as the binding agents and polyacrylamide (Sigma Aldrich) gel used as the diffusive gel. The Marcellus shale 
samples were obtained from the WV Economic and Geological Survey and ground to $\leq 60$ micron size. The flowback wastewaters used were WRF6 and FS.

The arsenic and selenium concentrations were measured using GFAAS (Varian SpectraA Model 55B, GTA 101 with autosampler) with deuterium lamp correction at 193.7 and $196.0 \mathrm{~nm}$, respectively. A 6000 ppm palladium nitrate modifier (Sigma Aldrich) was used for selenium, while $3 \mu \mathrm{L}$ of $50 \mathrm{ppm}$ nickel solution prepared from nickel nitrate hexahydrate (Fisher Scientific) was used as modifier for arsenic quantitation.

\subsubsection{Diffusive and binding gels preparation}

The diffusive gels were prepared by mixing $0.25 \mathrm{~g}$ of DGT agarose cross-linker (2\%) (DGT Research Ltd, Lancaster UK), $7.92 \mathrm{~mL}$ of ultrapure d.i water and $6.25 \mathrm{~mL}$ of $40 \% \mathrm{w} / \mathrm{v}$ acrylamide (Sigma Aldrich) solution in a polypropylene bottle, and the gel solution was mixed thoroughly by stirring and stored at $4{ }^{\circ} \mathrm{C}$. To $10.0 \mathrm{~mL}$ of the gel stock solution, $70 \mu \mathrm{L}$ of freshly prepared $10 \% \mathrm{w} / \mathrm{v}$ ammonium persulfate initiator and $25 \mu \mathrm{L}$ of TEMED catalyst and the resultant solution thoroughly mixed for two minutes and immediately cast between two glass plates separated by teflon plastic spacers $(0.8 \mathrm{~mm})$ as shown in Figure 4.2 and held together by strong clamps. The mixture was allowed to set at $40 \pm 5^{\circ} \mathrm{C}$ for 50 minutes. The set gels were stored in 0.01 M sodium nitrate (Sigma Aldrich) solution and cut to specified circular DGT probe dimensions using a teflon circular disc before deployment in DGT probes $(\mathrm{n}=3)$. 


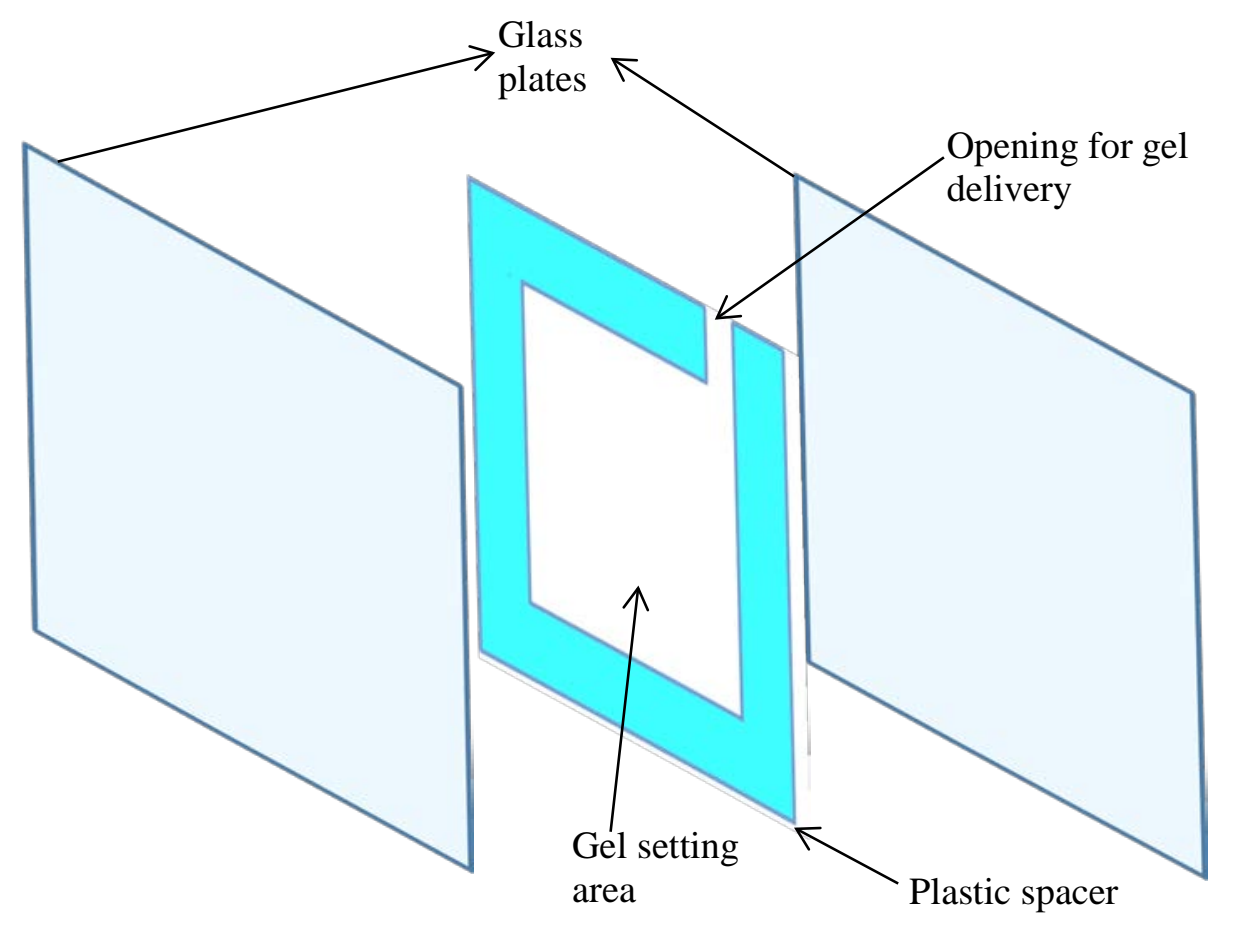

Figure 4.2. Assembly for making diffusive and binding gels.

Fe-Zr binary oxide adsorbent powder was prepared following the procedure by Ren et. al [21]. It involved mixing $13.515 \mathrm{~g}$ (0.05 moles) of iron(III) chloride hexahydrate (Sigma Aldrich), $4.028 \mathrm{~g}$ (0.0125 moles) of zirconyl chloride octahydrate (Sigma Aldrich) and $400 \mathrm{~mL}$ of ultrapure d.i water and the resultant solution was thoroughly magnetically stirred for 5 minutes at $350 \mathrm{rpm} .2$ molar sodium hydroxide was added dropwise up to a $\mathrm{pH}$ of 7.5 and the resultant suspension was continuously magnetically stirred for 1 hour and aged at room temperature, 24 ${ }^{\circ} \mathrm{C}$ for 4 hours. The clear supernatant solution was decanted and the resulting semisolid washed thrice with ultrapure d.i, filtered and dried at $65{ }^{\circ} \mathrm{C}$ for 4 hours. The dry solid was ground into a fine powder and stored in a desiccator. 
Metsorb, 3-mercaptopropyl silica functionalized gel or Fe-Zr binary oxide binding gels ( $0.4 \mathrm{~mm})$ were prepared by adding $1 \mathrm{~g}$ of the fine powder $(50 \mu \mathrm{m})$ of the binding agent to 10 $\mathrm{mL}$ of the gel stock solution and sonicated for 5 minutes using an ultrasonic cleaner (Model 75HT, VWR International, West Chester, PA, USA). $70 \mu \mathrm{L}$ of freshly prepared $10 \% \mathrm{w} / \mathrm{v}$ ammonium persulfate initiator and $25 \mu \mathrm{L}$ of TEMED catalyst and the resultant solution was magnetically stirred for 2 minutes to ensure uniform mixing throughout the gel solution, and immediately cast between two glass plates separated by an inert teflon plastic spacer of $0.4 \mathrm{~mm}$, and held firmly by strong clamps. The mixture was allowed to set at the same conditions and duration as the diffusive gels. The set gels were removed from the plates, hydrated with d.i water four times over 24 hours. The side of the gel where the binding agent settled was placed face up in DGT probe assemblies. The binding gels were stored in d.i water and were cut to specified circular DGT probe dimensions using a teflon circular disc before deployment in DGT probes $(n=3)$.

\subsubsection{Assembly of DGT samplers}

DGT probes were obtained from DGT Research Limited (Lancaster, UK). DGT bases and caps were washed by leaving them over night in $5 \%(\mathrm{v} / \mathrm{v})$ trace metal grade nitric acid (Fisher Scientific) and then washed three times in ultrapure d.i water. Assembled DGT probes with diffusive gel, filter paper and binding gel were deployed in water samples in triplicate in one-liter polyethylene bottles and magnetically stirred at 125 rpm using a Fisher Scientific magnetic stirrer plate. 


\subsubsection{Effect of $\mathrm{pH}$ and ionic strength}

Metsorb (1.0 g) was weighed into a polyethylene vessel $(\mathrm{n}=3)$ and dissolved in $50.0 \mathrm{~mL}$ of 100 ppb As standard (Spex Certiprep) prepared by using $3 \%$ trace metal grade nitric acid and $18.1 \mathrm{~m} \Omega$ ultrapure d.i water. The mixture was left to stand for 24 hours, but with intermittent one-minute vigorous swirlings per hour for the first 14 hours. The resultant solution was centrifuged for 5 minutes and the clear solution decanted and solid kept for arsenic quantitation. The solid was then dissolved in $5.0 \mathrm{~mL}$ of $1 \mathrm{M}$ sodium hydroxide (Fisher Scientific) for 24 hours to desorb the arsenic with intermittent one-minute vigorous swirlings per hour for the first 14 hours. The resultant solution was centrifuged, the solid washed twice and the clear solution diluted ten times using $3 \%$ trace metal grade nitric acid and analyzed for arsenic using GFAAS. This was repeated, but at various $\mathrm{pH}$ and ionic strengths (based on sodium nitrate) to ascertain the optimal $\mathrm{pH}$ and ionic strength for arsenic adsorption by Metsorb.

In addition, arsenic determination in flow back waste water was carried out following the above procedure, and the diffusive gradient in thin film technique was applied to flow back waste water, but without arsenic spikes.

\subsubsection{Preliminary analysis of DGT samplers, uptake and elution for arsenic(V) in WRF6}

Diluted (5x) flowback water aliquots $(20.0 \mathrm{~mL})$ were spiked with $8 \mu \mathrm{L}$ of $100 \mathrm{ppm}$ Arsenic standard (Spex Certiprep) to yield flowback water $40 \mathrm{ppb}$ in arsenic in triplicate. DGT probes with Metsorb binding gel were immersed in the diluted spiked flowback water solutions for 1, 2, 4, 8 and 12 hours with constant magnetic stirring (125 rpm). The probes were disassembled, immersed in $10 \mathrm{~mL}$ of DI water for 2 hours to remove any potential excess unbound interfering or competing ions, and the binding gels placed in $5.0 \mathrm{~mL}$ of $1 \mathrm{M}$ sodium 
hydroxide for 48 hours with constant stirring to effect maximum arsenic elution/desorption. The resultant solution was diluted to $20 \mathrm{~mL}$ using $3 \%$ trace metal nitric acid and analyzed for arsenic using GFAAS as in section 4.2.1. The same procedure was applied for selenium quantitation.

The following DGT equations (explained in detail in chapter 1 section 1.6) and information were applied:

$\mathbf{C}_{\text {SoLN }}=$ GFAAS determined from the solution eluted from the gel (eluate)

$\mathbf{C}_{\mathbf{D G T}}=$ DGT- calculated concentrations using formulas below:

$\mathrm{M}=\frac{\mathrm{C}_{\mathrm{e}}\left(\mathrm{V}_{\mathrm{g}}+\mathrm{V}_{\mathrm{e}}\right)}{\mathrm{f}_{\mathrm{e}}}$, where $\mathrm{M}=$ Mass of analyte in binding gel (ng)

$\mathrm{C}_{\mathrm{e}}=$ Analyte concentration in eluate $=\mathrm{C}_{\text {SOLN }}$

$\mathrm{V}_{\mathrm{g}}$ and $\mathrm{V}_{\mathrm{e}}=$ Volume of gel $\sim 0.16 \mathrm{~mL}$ and elution volume $(20 \mathrm{~mL})$

$f_{e}=$ ratio of eluted to bound analyte

$\mathrm{C}_{\mathrm{DGT}}=\frac{\mathrm{M} \Delta \mathrm{g}}{\mathrm{DtA}}$, or $\mathrm{D}=\frac{\alpha \Delta \mathrm{g}}{\mathrm{C}_{\mathrm{CDGT}} \mathrm{A}^{\prime}}$, where $\Delta \mathrm{g}, \mathrm{D}$ and $\mathrm{A}$ are the thickness of the diffusive gel

$(0.08 \mathrm{~cm})$, diffusion coefficient in gel in $\mathrm{cm}^{2} \mathrm{~s}^{-1}$ and area in $\mathrm{cm}^{2}\left(3.14 \mathrm{~cm}^{2}\right)$, respectively, and $\alpha$ is the slope of the linear regression of the mass of analyte, $\mathrm{M}$ (ng), accumulated in the binding gel over time, $\mathrm{t}(\mathrm{s})$.

\subsubsection{Long-term mass accumulation versus deployment time evaluation}

The same procedure was applied as in section 4.3.5, but DGT probes were deployment for longer times up to 3 days (72 hours), and arsenic was quantified at specific time intervals.

Undiluted or 5x diluted WRF6 (50.0 mL) was spiked with $20 \mu \mathrm{L}$ of $100 \mathrm{ppm}$ arsenic (III), arsenic (V) or selenium (IV) working standard for initial Metsorb-DGT experiments. For Fe-Zr-DGT experiments and some Metsorb-DGT experiments, 1 liter of 5x diluted WRF6 was spiked with $200 \mu \mathrm{L}$ of $100 \mathrm{ppm}$ Arsenic (III) prepared standard (GFS chemicals) to yield a 
solution $20 \mathrm{ppb}$ in arsenic (III) and pH 6.77. DGT probes were immersed in the spiked $50 \mathrm{~mL}$ or 1 liter water solutions in triplicate for 2, 4, 8, 12, 16, 20 and 24 hours with constant magnetic stirring (125 rpm). The probes were disassembled and subsequently treated and analyzed similarly for arsenic and selenium as described in section 4.2.5 and 4.2.1.

4.2.7. Fe-Zr -Bioavailable arsenic and selenium quantitation in undiluted unspiked and $5 x$ diluted WRF6

Bioavailabe arsenic and selenium fractions in undiluted unspiked and 5x diluted unspiked WRF6 were determined using the same procedure as in section 4.2.6, but with no spikes whatsoever. Fe-Zr-DGT probes were deployed in $50.0 \mathrm{~mL}$ of undiluted WRF6 and 5x diluted WRF6.

4.2.8 Arsenic (III), arsenic(V) and selenium (IV) mass accumulation over deployment time using Metsorb and Fe-Zr binary oxide adsorbents in FS

The same section 4.2.6 procedure was applied, but using 1 liter of FS.

\subsubsection{Fe-Zr - Bioavailable arsenic and selenium quantitation in undiluted unspiked and 5x diluted FS}

The same section 4.2.7 procedure was applied, but using 1 liter of FS.

\subsubsection{Evaluation of arsenic (III) mass accumulation over time using DGT-Fe-Zr binary oxide adsorbent in $0.01 \mathrm{M} \mathrm{NaNO}$}


The same section 4.3.6 procedure was applied, but using 1 liter of $0.01 \mathrm{M} \mathrm{NaNO}$ spiked with $200 \mu \mathrm{L}$ of 100 ppm Arsenic (III) working standard (GFS chemicals) to yield a sample of 20 ppb in arsenic (III) and pH 6.95.

\subsubsection{Speciation analysis}

Speciation analysis for bioavailable arsenic (III) and arsenic (V) fractions in $0.01 \mathrm{M}$ $\mathrm{NaNO}_{3}$ and FS was carried out by using 3-mecarptopropyl-functionalized silica gel (Sigma Aldrich), which selectively binds arsenic (III), and allowed quantitation of As(V) by difference from the total bioavailable or free arsenic [arsenic (III) + arsenic (V)] determined by Fe-ZrDGT-GFAAS.

Two liters of $0.01 \mathrm{M}$ sodium nitrate was spiked with $200 \mu \mathrm{L}$ of $100 \mathrm{ppm}$ arsenic(III) (GFS chemicals) and $200 \mu \mathrm{L}$ of 100 ppm arsenic (V) (Fisher Scientific) working standards to yield a solution $10 \mathrm{ppb}$ in both arsenic(III) and arsenic(V). DGT probes with Fe-Zr binary oxide adsorbent were deployed for varying time lengths and analyzed for total bioavailable arsenic, arsenic (III) and arsenic (V).

\subsubsection{Determination of total arsenic and selenium in WRF6 and FS solids}

\subsubsection{Method}

WRF6 and FS were left to stand serenely for five days to enable maximum settlement of the solid. The clear solution was decanted off, the solid filtered and dried at room temperature in the hood for one week. 


\subsubsection{Microwave digestion}

Samples of the WRF6 or FS solid (0.30 g, $\mathrm{n}=2)$ and FS solid $(0.17 \mathrm{~g}, \mathrm{n}=2)$ were weighed and transferred into acid-washed microwave digestion vessels. Trace metal grade concentrated nitric acid $(4.0 \mathrm{~mL})$ and $0.5 \mathrm{~mL}$ of concentrated hydrofluoric acid (Fisher Scientific) were added and the vessels were placed into a CEM Corporation Mars 5 (Matthews, NC) microwave digester. The digestion was done at $400 \mathrm{~W}$ and 700 psi pressure, with ramping to a maximum temperature of $190^{\circ} \mathrm{C}$ over a period 40 minutes followed by holding at that temperature for 15 minutes. Samples were cooled to room temperature and each transferred into a polyethylene vial and diluted to $40 \mathrm{~mL}$ with $3 \%$ solution of trace metal grade $\mathrm{HNO}_{3}$. No solid remained after digestion. The samples were analyzed for total arsenic and selenium by TCFGFAAS at a wavelength of 193.7 and $196.0 \mathrm{~nm}$, respectively.

\subsection{Extraction of total arsenic and selenium from Marcellus shales}

In this section, Marcellus shale samples were exposed to flowback water WRF6, high salinity water (HSW), DI water and $3 \%$ trace metal grade nitric acid for varying lengths of time. TCF was used to determine the total arsenic and selenium and DGT used to determine the bioavailable arsenic and selenium in the extracts.

\subsubsection{Leaching of arsenic and selenium from Marcellus shale}

The potential for the WRF6 and HSW (100000 ppm Cl) to leach arsenic and selenium from Marcellus shale was investigated and compared by adding shale $(0.50 \mathrm{~g}$, Gilmer $1978, \mathrm{n}=$ 2) to $25 \mathrm{~mL}$ of unspiked WRF6 and HSW water. The mixtures were placed in polyethylene 
containers, sealed and placed in a rotating mixer for different times at room temperature. The total arsenic and selenium concentrations were measured after the various times. Another set of samples was treated similarly either using deionized water or $3 \%$ trace metal grade nitric acid and the selenium concentration was measured after the same time intervals. The actual rock to water ratios that occur during hydrofracturing and associated temperature and pressure are unknown.

The determination of bioavailable arsenic and selenium $\left(\mathrm{C}_{\mathrm{DGT}}\right)$ extracted from the Marcellus shale into WRF6 versus exposure time was determined in a similar manner.

\subsection{Results and Discussion}

\subsubsection{Effect of solution composition on arsenic accumulation}

\subsubsection{Metsorb-Arsenic-WRF6}

Initially, Metsorb was directly mixed into $100 \mathrm{ppb}$ aqueous solutions of arsenic(V) for 24 hours. The recoveries determined at $\mathrm{pH} 3.5$ - 10.0 for moderate ionic strength solutions did not vary significantly as shown in Table 4.1. When Metsorb was directly mixed into the high ionic strength flowback wastewater (WRF6) spiked with $100 \mathrm{ppb}$ arsenic(V), no recovery was observed after 24 hours. Any arsenic initially present in WRF6 as well as that added by the spike was either not adsorbed by Metsorb or the high concentration of other ions in WRF6 inhibited arsenic adsorption. 
Table 4.1. Arsenic spike concentrations obtained at various pHs and ionic strengths using DGTMetsorb and $100 \mathrm{ppb}$ arsenic solutions and various ionic strengths $\left(\mathrm{NaNO}_{3}\right)$.

\begin{tabular}{|c|c|c|c|}
\hline \multirow{2}{*}{ pH } & \multicolumn{3}{|c|}{ As (ppb) at various ionic strengths } \\
\cline { 2 - 4 } & $\mathbf{0 . 7 5}$ & $\mathbf{0 . 8 5}$ & $\mathbf{1 . 0}$ \\
\hline 3.5 & $85.4 \pm 4.5$ & $88.5 \pm 3.5$ & $89.1 \pm 3.1$ \\
\hline $\mathbf{7 . 0}$ & $85.3 \pm 4.3$ & $84.3 \pm 4.4$ & $87.2 \pm 3.4$ \\
\hline $\mathbf{8 . 5}$ & $88.2 \pm 2.9$ & $90.2 \pm 3.3$ & $86.9 \pm 3.5$ \\
\hline $\mathbf{1 0 . 0}$ & $89.2 \pm 4.4$ & $92.5 \pm 2.5$ & $88.6 \pm 3.0$ \\
\hline
\end{tabular}

The initial DGT-Metsorb experiment was carried out in undiluted WRF6 spiked with 40 ppb arsenic(V) to determine the mass accumulated over time; however, the recovery of arsenic was less than 1\%. This suggests that arsenic is could be present as a non-labile complex or species that cannot diffuse through the diffusive gel. The high concentration of other ions present in WRF6 might also compete for arsenic binding sites on Metsorb and block them. The rate of analyte uptake in the binding gel is dependent on the proportion of free or kinetically labile analyte species, which is strongly influenced by both kinetic and thermodynamic factors as well as the formation of constant and dissociation constant for the analyte complex species. ${ }^{9-10}$

Since the ionic strength of WRF6 was very high, it was diluted 5x and $20 \mathrm{~mL}$ was spiked with $40 \mathrm{ppb}$ arsenic(V). The DGT-Metsorb accumulation of arsenic was then examined over a total time of 72 hours, and the results are shown in Figure 4.3. The elution efficiencies for both arsenic and selenium were above $80 \%$ and were used in the generation of arsenic and selenium mass accumulation versus deployment time plots. 


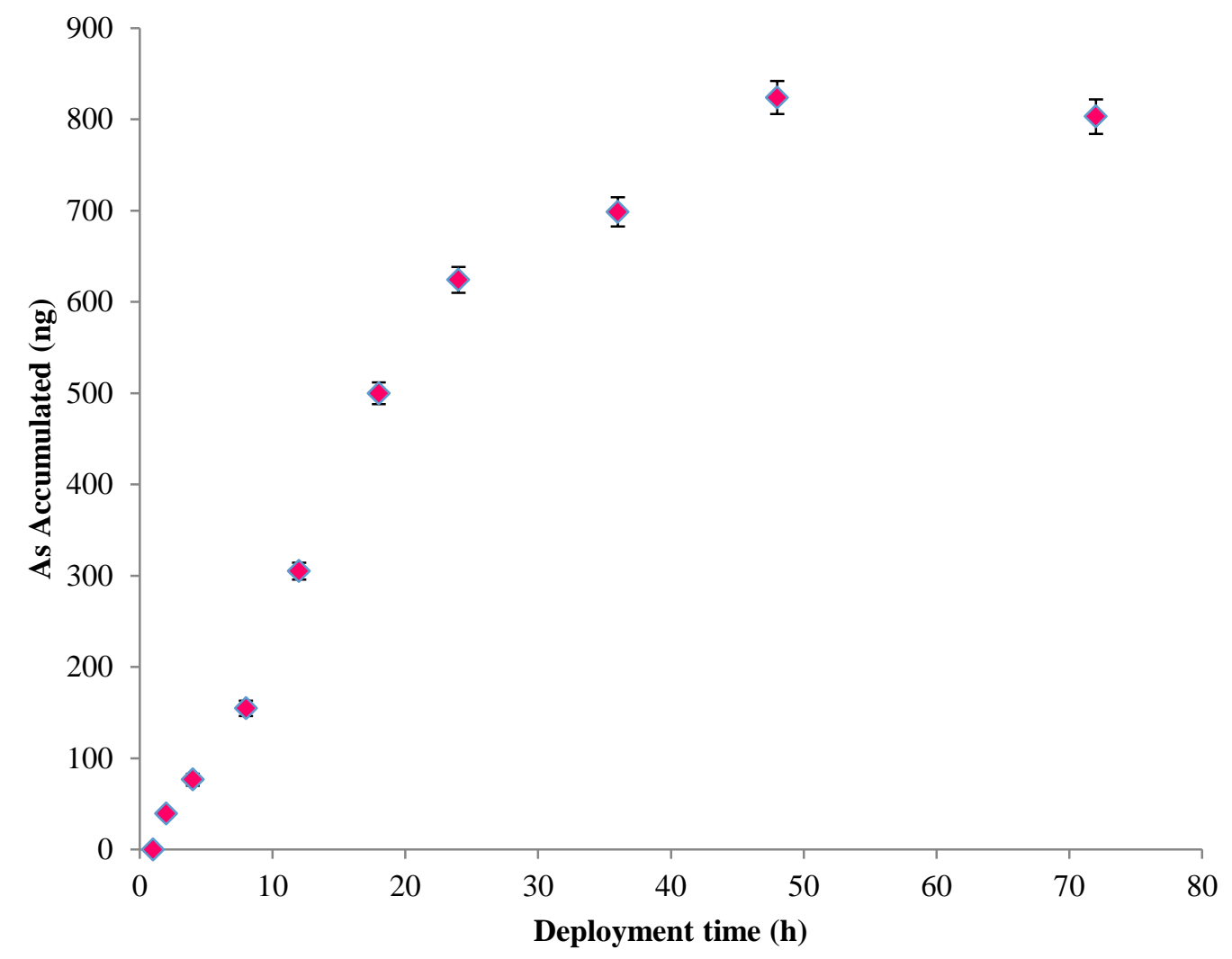

Figure 4.3. Long-term arsenic mass (ng) accumulation versus deployment time (h) in 5x diluted WRF6 (Error bars are 95\% C.I). 40 ppb As(V) in 20 mL.

The mass accumulated versus deployment time was linear up to 12 hours, after which deviations occurred at longer times, finally plateauing around $800 \mathrm{ng}$ after 40 hours. Since the total mass of arsenic added to the solution was $800 \mathrm{ng}$, a volume of solution larger than $20.0 \mathrm{~mL}$ was needed to ensure linearity and collect data at longer times. The volume used for all subsequent experiments with WRF6 was therefore increased to $50 \mathrm{~mL}$. Other authors have reported adsorbent capacity and deployment time as critical factors in the accuracy of DGT measurements [22-23]. In addition, total analyte mass in confined volumes is also important in the accuracy of DGT measurements. 
The diluted WRF6 was also spiked with 40 ppb arsenic(V) and after 12 hours of DGTMetsorb probe deployment the mass increased by $99 \%$ compared to the undiluted WRF6 and the recovery was $101 \pm 7 \%$ shown in Figure 4.4. Dilution influences the dissociation of the inert complexes of arsenic into labile or partially labile species, thereby releasing more 'free'" or kinetically labile (bioavailable) arsenic ions in solution.

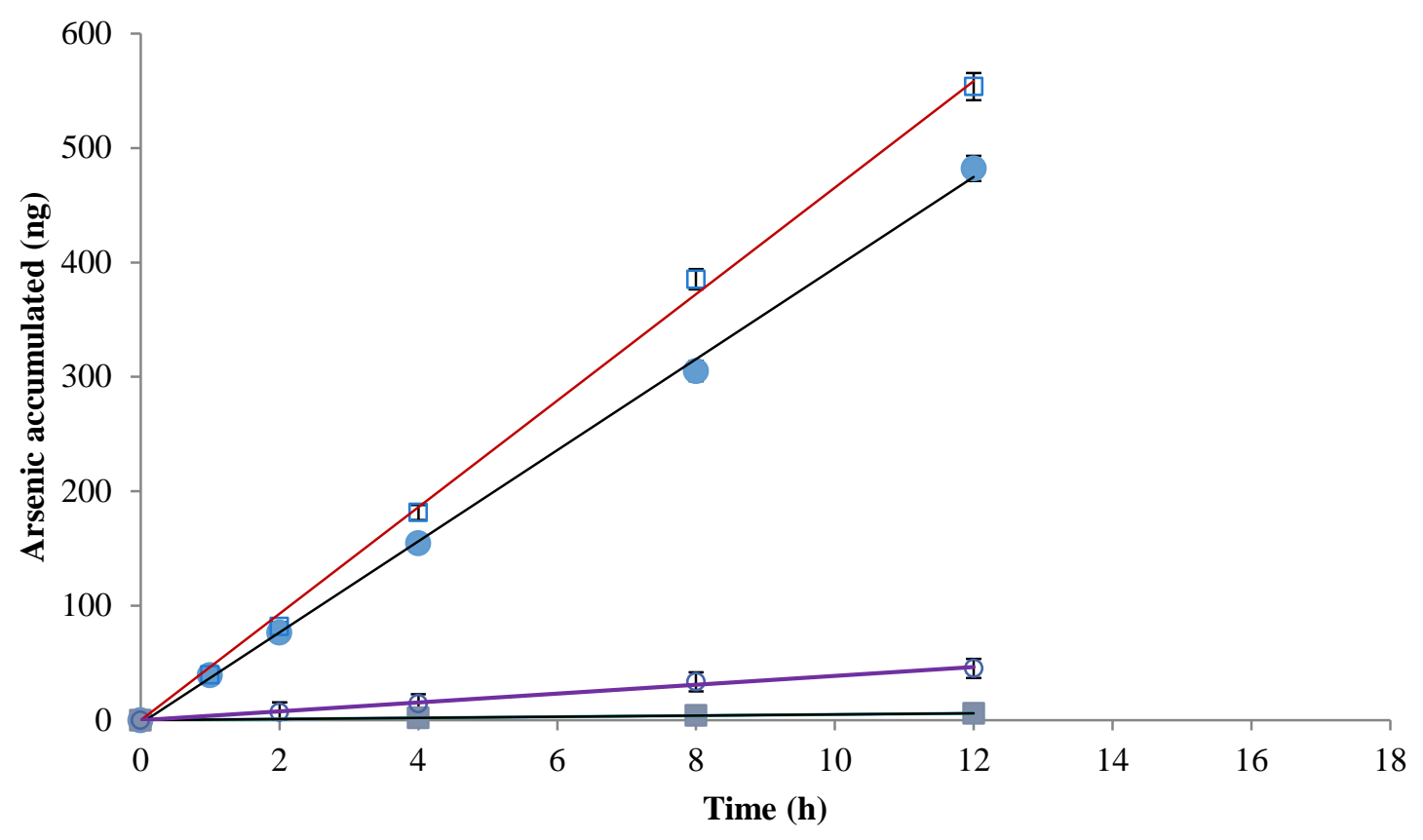

Figure 4.4. Arsenic(III) and arsenic(V) mass (ng) accumulation in diluted (5x) and undiluted WRF6 spiked with 40 ppb versus deployment time (h) for $n=3$. $\square=$ As(III) in diluted WTF6; = As(V) in diluted WTF6; O = As(III) in undiluted WRF6; $\mathbf{\square}=$ As(V) in undiluted WRF6 (Error

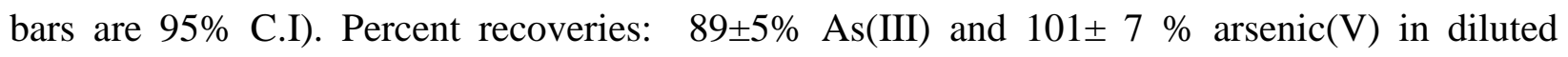

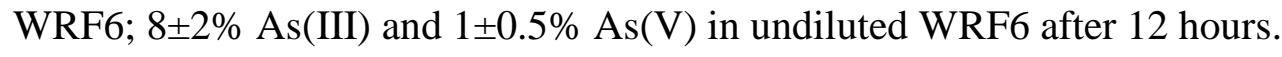

This resulted in higher analyte mass accumulation by DGT with dilution of WRF6. This type of behavior could lead to serious consequences if Marcellus shale flowback wastewater is simply added directly into a receiving water or diluted prior to disposal. 
Similar DGT-Metsorb experiments were performed with arsenic(III) in diluted and undiluted WRF6 and results for both arsenic(III) and (V) are shown in Figure 4.4. Less than $1 \%$ of arsenic (V) was recovered in the undiluted WRF6 compared to $7.5 \%$ arsenic(III). This is likely due to differences in both the adsorption and complexation behavior of the two oxidation states. In the diluted sample $89 \pm 5 \%$ of arsenic(III) was recovered compared to $101 \pm 7 \%$ of arsenic(V) reflecting the changes in complexation due to dilution. This mass of arsenic(III) accumulated from the diluted sample was greater than that of arsenic(V), yet the recovery of arsenic(III) was less than that of arsenic(V). This is because the calculated "diffusion coefficient" of arsenic(III) is greater than that of arsenic(V).

\subsubsection{Metsorb-Selenium-WRF6}

When undiluted WRF6 was spiked with 40 ppb of selenium(IV), less than 1\% recovery was observed after 48 hours. However, 5x dilution and spiking with 40 ppb selenium (IV), the recovery after 12 hours was $101 \%$ as shown in Figure 4.5. This behavior is similar to that shown previously by both arsenic (III) and arsenic (V).

The corresponding diffusion coefficients were calculated using Eq. 1.9 and found to be in the same range to previously reported values (Table 4.2) [17, 19-20, 22-23]. 


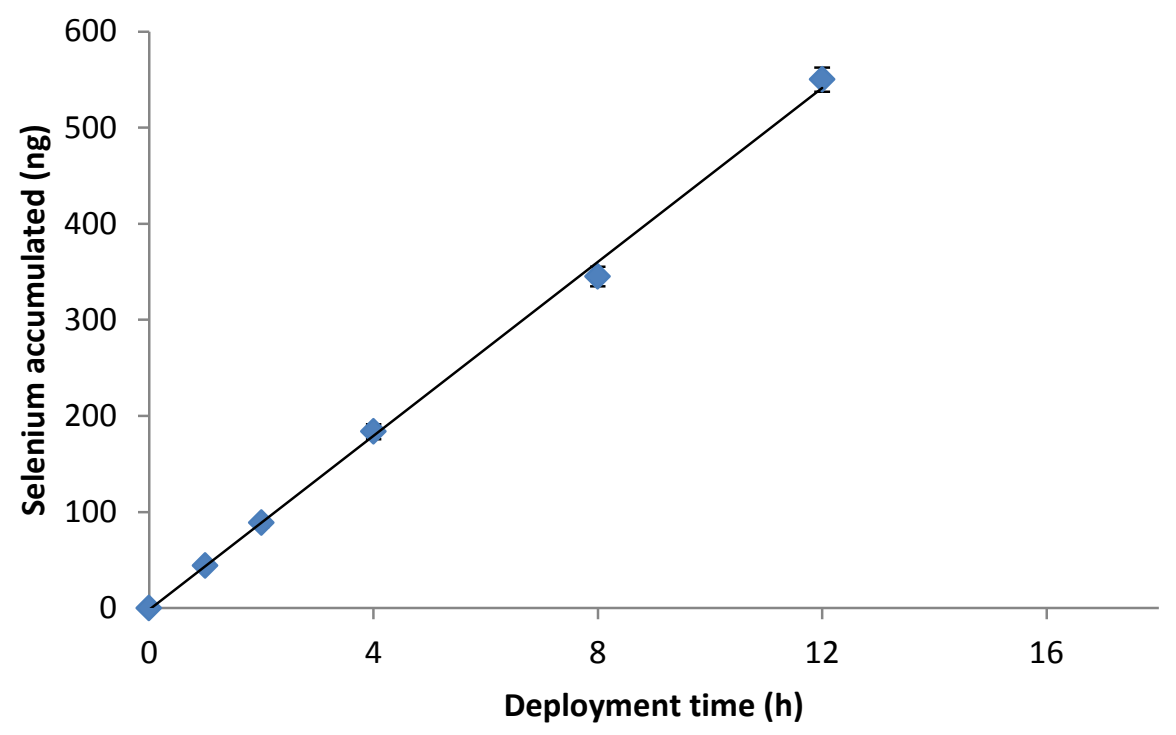

Figure 4.5. Selenium (IV) mass (ng) accumulation in diluted (5x) WRF6 spiked with $40 \mathrm{ppb}$ versus deployment time (h) (Error bars are 95\% C.I). Percent recovery: $101 \%$ after 12 hours.

\subsubsection{Fe-Zr-Arsenic(III)-WRF6}

Similar experiments were done with arsenic(III) in undiluted WRF6 with Fe-Zr binary oxide adsorbent and compared to Metsorb data (Figure 4.6) and the corresponding diffusion coefficients are also given in Table 4.2. 


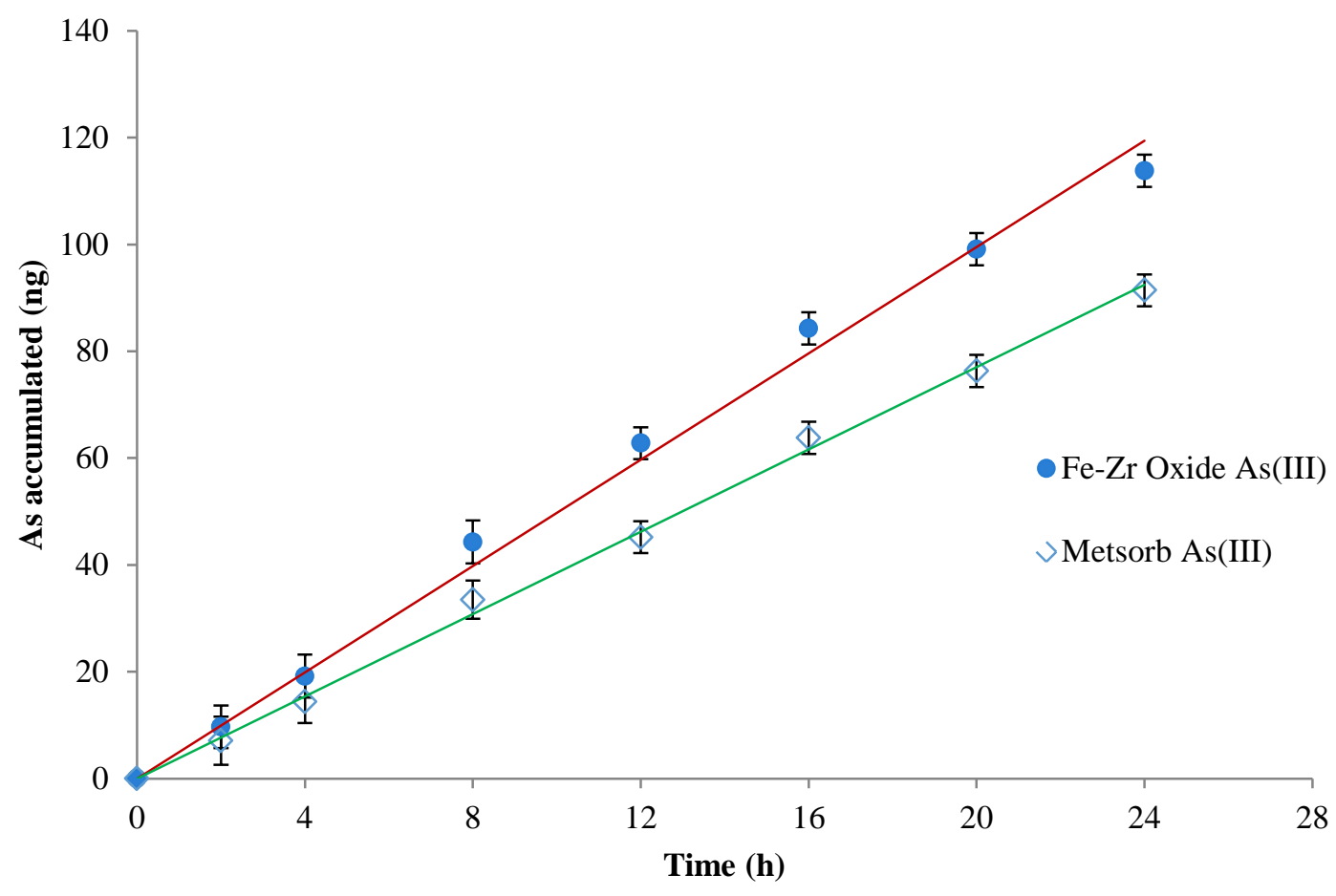

Figure 4.6. Arsenic (III) mass (ng) accumulation versus deployment time (h) in undiluted WRF6 using 40ppb spike (Error bars are 95\% C.I). Percent recoveries: $7.5 \%$ with metsorb and $10.5 \%$ using Fe-Zr after 12 hours.

Table 4.2 Diffusion coefficients $\left(\mathrm{cm}^{2} / \mathrm{s}\right)$ for various arsenic species and selenium in spiked undiluted WRF6.

\begin{tabular}{|c|c|c|c|}
\hline \multirow{2}{*}{ Analyte } & \multicolumn{3}{|c|}{ Diffusion Coefficient $\left.\mathbf{~ ( m ~}^{2} / \mathbf{s}\right)$ in } \\
\cline { 2 - 4 } & Undiluted WRF6 & $5 \times$ Diluted WRF6 \\
\cline { 2 - 4 } & Metsorb & Fe-Zr oxide & Metsorb \\
\hline \multirow{2}{*}{$\mathrm{As}(\mathrm{III})$} & $6.81 \times 10^{-7}$ & $8.81 \times 10^{-7}$ & $8.86 \times 10^{-6}$ \\
\hline $\mathrm{As}(\mathrm{V})$ & $9.00 \times 10^{-8}$ & $\mathrm{ND}^{*}$ & $7.04 \times 10^{-6}$ \\
\hline $\mathrm{Se}(\mathrm{IV})$ & $\mathrm{ND}^{*}$ & $\mathrm{ND}^{*}$ & $8.01 \times 10^{-6}$ \\
\hline
\end{tabular}

$\mathrm{ND}^{*}=$ the accumulated analyte mass was too low even at longer deployment times (48 hours); $<0.11 \mu \mathrm{g} / \mathrm{L}$ of arsenic and $0.18 \mu \mathrm{g} / \mathrm{L}$ of selenium, the method detection limit (based on $3 \mathrm{x}$ absorbance of the blanks). 


\subsubsection{Fe-Zr -Arsenic and Selenium-Undiluted unspiked and 5x diluted unspiked WRF6}

Fe-Zr binary oxide adsorbent was used to measure the concentration of the total bioavailable arsenic and selenium in unspiked WRF6. No bioavailable arsenic was detected (< $0.11 \mu \mathrm{g} / \mathrm{L}$, the method detection limit) and the bioavailable selenium was less than the total selenium concentration in WRF6 determined by TCF-GFAAS. This implies that some arsenic and selenium is not bioavailable in WRF6. However, when the samples were diluted five times, the concentrations of bioavailable arsenic and selenium quantified (multiplied by 5, the dilution factor) were almost twice the bioavailable fractions in the undiluted WRF6 as shown in Figure 4.7 and Table $4.3[7.3 \pm 1.5 \mu \mathrm{g} / \mathrm{L}$ selenium (undiluted WRF6) vs $2.6 \pm 0.5$ x $5=13 \pm 2.5 \mu \mathrm{g} / \mathrm{L}$ selenium (diluted WRF6)]. This could mean that dilution releases more bioavailable arsenic and selenium fractions and may exacerbate ecotoxicological hazards if it continues unabated in the environment.

Table 4.3. Arsenic and selenium concentrations in unspiked WRF6.

\begin{tabular}{|l|c|c|c|c|c|c|}
\hline \multirow{3}{*}{ Sample } & \multicolumn{3}{|c|}{ Arsenic concentration $(\mu \mathrm{g} / \mathrm{L})$} & \multicolumn{2}{c|}{ Selenium concentration $(\mu \mathrm{g} / \mathrm{L})$} \\
\cline { 2 - 4 } & TCF-GFAAS & \multicolumn{2}{|c|}{ DGT-GFAAS } & \multirow{2}{*}{ TCF-GFAAS } & \multicolumn{2}{c|}{ DGT-GFAAS } \\
\cline { 2 - 6 } & & Metsorb & Fe-Zr & & Metsorb & Fe-Zr \\
\hline $\begin{array}{l}\text { Undiluted } \\
\text { WRF6 }\end{array}$ & ND & ND & ND & $10.1 \pm 2.2$ & $6.7 \pm 1.7$ & $7.3 \pm 1.5$ \\
\hline $\begin{array}{l}\text { 5x diluted } \\
\text { WRF6 }\end{array}$ & ND & ND & ND & $1.7 \pm 0.6$ & ND & $2.6 \pm 0.5$ \\
\hline
\end{tabular}

$\mathrm{ND}=$ Not detected $(<0.11 \mu \mathrm{g} / \mathrm{L}$ of arsenic, the method detection limit (based on 3x absorbance of the blanks). 


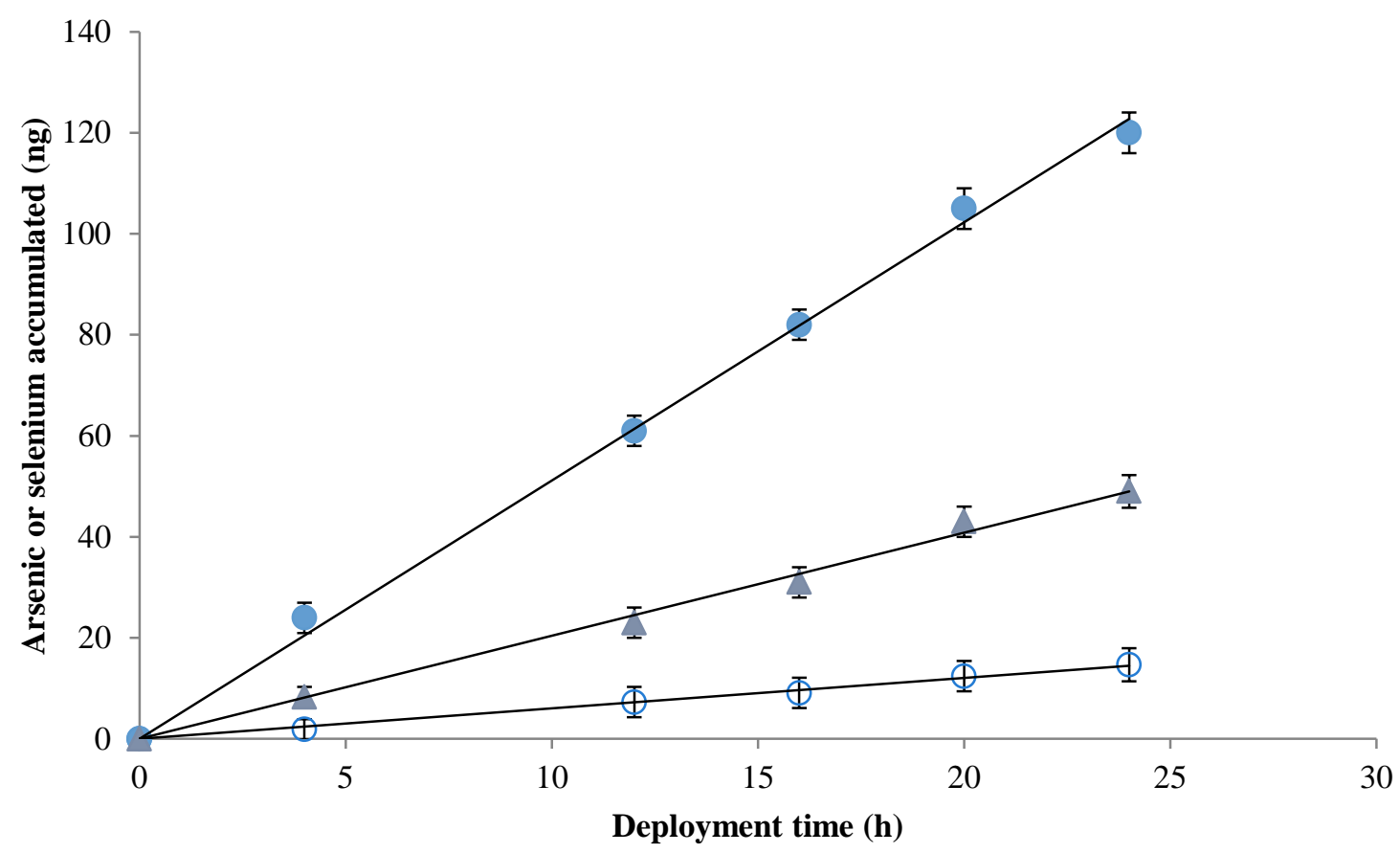

Figure 4.7. Total bioavailable arsenic and selenium mass (ng) accumulation versus deployment time in unspiked diluted (5x) and undiluted WRF6 $(\mathrm{n}=3) \cdot \boldsymbol{\bullet}=$ Se in undiluted WTF6; $\mathbf{\Delta}=$ Se in diluted WTF6; $\mathbf{O}=$ As in diluted WRF6 (Error bars are 95\% C.I). Arsenic in undiluted WRF6 was below $0.11 \mu \mathrm{g} / \mathrm{L}$, the method detection limit.

\subsubsection{Comparison of Fe-Zr and Metsorb for determination of bioavailable arsenic and selenium in FS}

When similar experiments were carried out in spiked undiluted FS using Fe-Zr binary adsorbent and Metsorb, similar trends of recoveries of arsenic and selenium were observed. However, the percentage recoveries were much higher, over $95 \%$ in undiluted FS, and the mass of analyte and the diffusion coefficient were larger in comparison to Metsorb experiments (Figures 4.8, 4.9, 4.110 and Table 4.4). This suggests that the majority of the spikes in FS was bioavailable arsenic and selenium compared to WRF6 . 


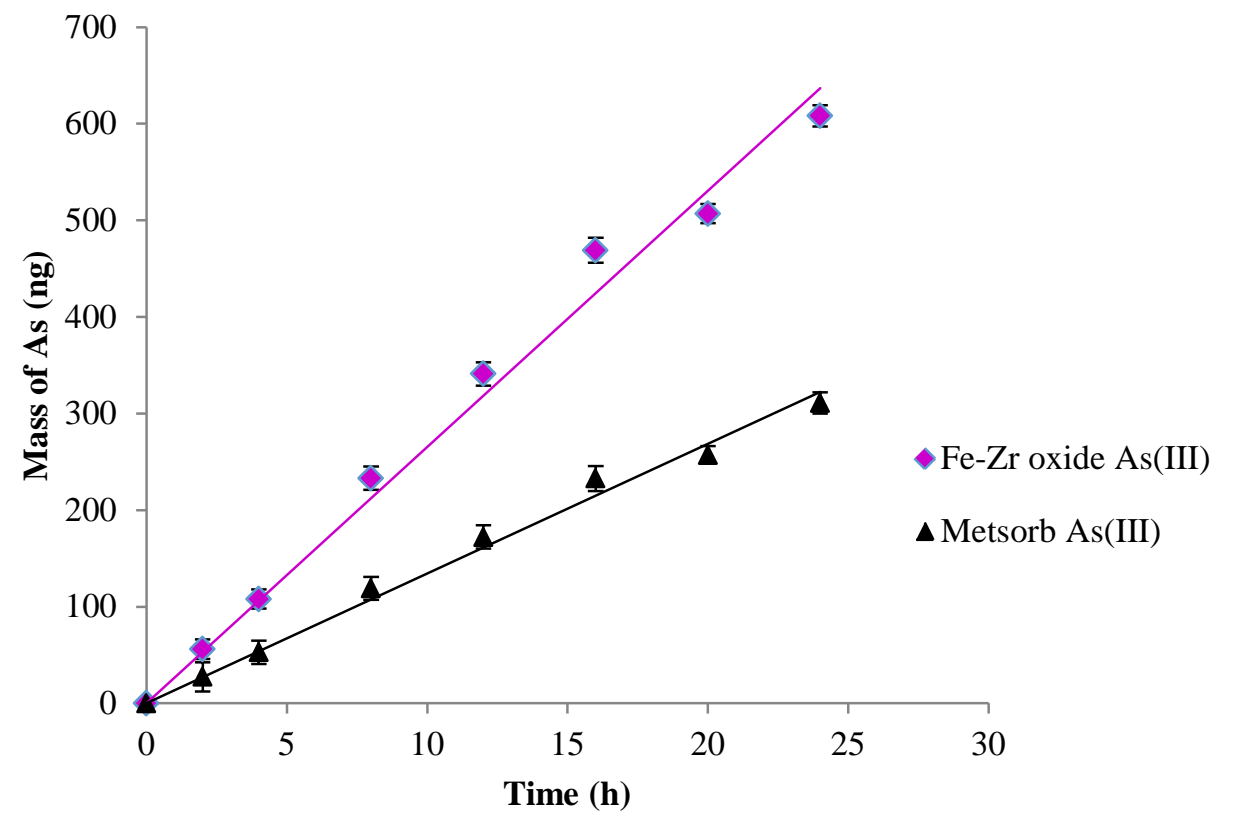

Figure 4.8. Arsenic (III) mass (ng) accumulation versus deployment time (h) in undiluted FS (Error bars are 95\% C.I). Percent recoveries: 96.3 \% with metsorb and $95.5 \%$ using Fe-Zr after 24 hours.

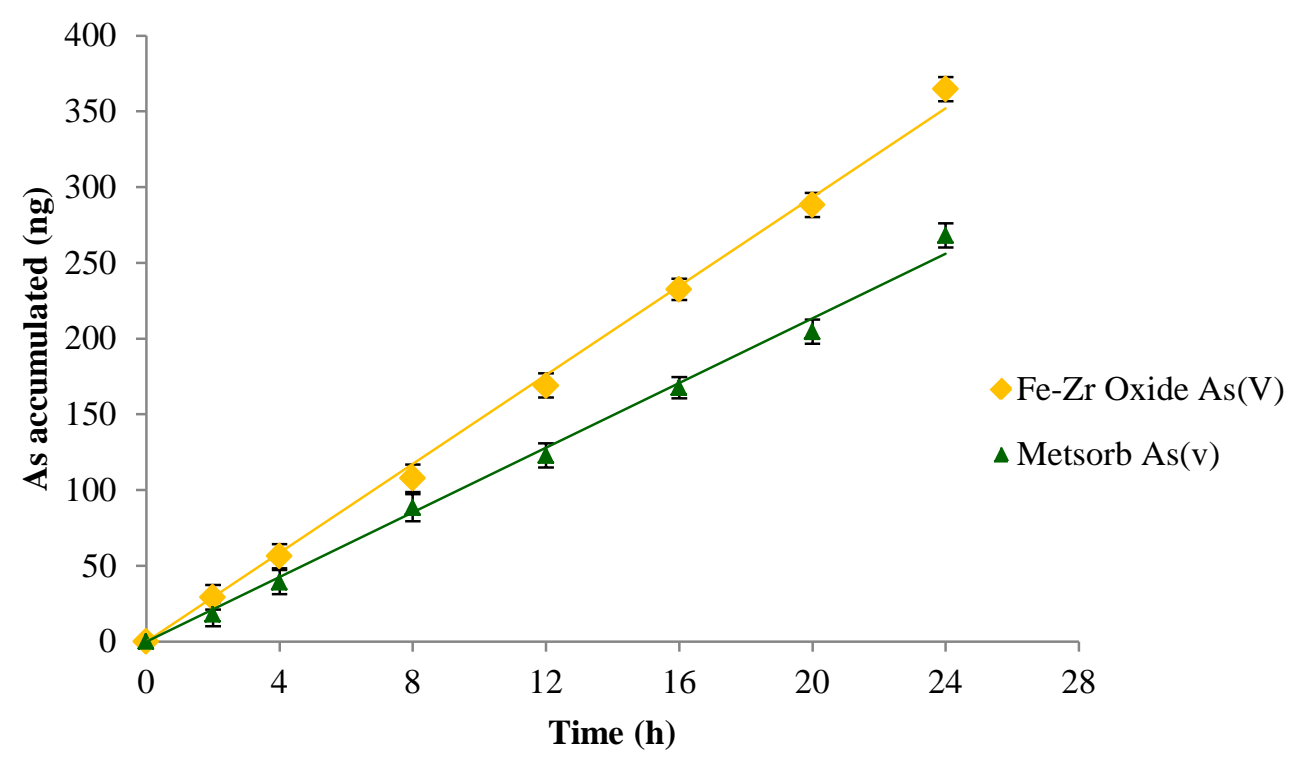

Figure 4.9. Arsenic (V) mass (ng) accumulation versus deployment time (h) in 20 ppb spiked undiluted FS (Error bars are 95\% C.I). Percent recoveries: 104.5\% with metsorb and 103.6\% using Fe-Zr after 24 hours. 


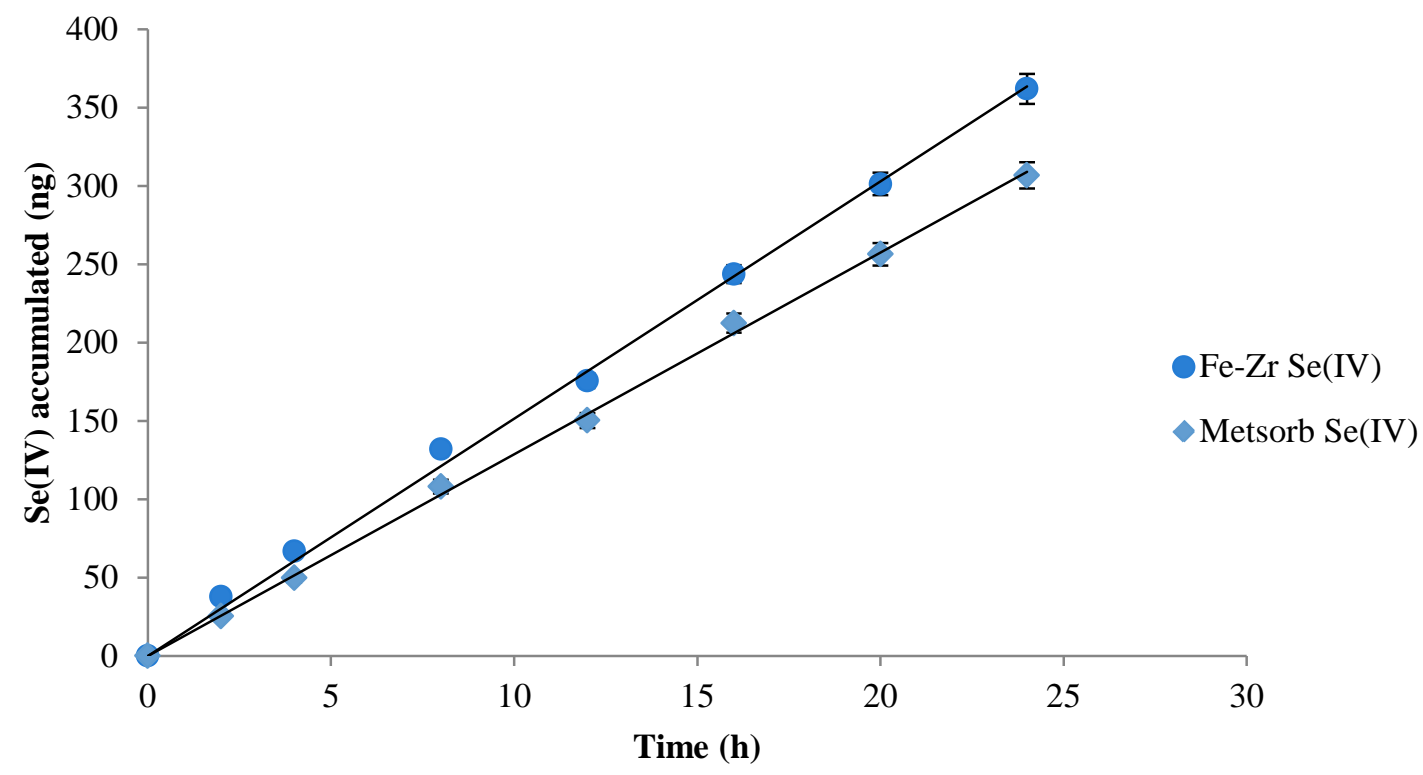

Figure 4.10. Selenium (IV) mass (ng) accumulation versus deployment time (h) in 20ppb spiked undiluted FS (Error bars are 95\% C.I). 102.9 \% with Metsorb and 103.7 \% using Fe-Zr after 24 hours.

Table 4.4 Diffusion coefficients $\left(\mathrm{cm}^{2} / \mathrm{s}\right)$ for various arsenic species and selenium in spiked undiluted FS.

\begin{tabular}{|c|c|c|}
\hline \multirow{2}{*}{ Analyte } & \multicolumn{2}{|c|}{ Diffusion Coefficient $\left(\mathrm{cm}^{2} / \mathrm{s}\right)$} \\
\cline { 2 - 3 } & Metsorb & Fe-Zr oxide \\
\hline $\mathrm{As}(\mathrm{III})$ & $4.76 \times 10^{-6}$ & $9.39 \times 10^{-6}$ \\
\hline $\mathrm{As}(\mathrm{V})$ & $3.78 \times 10^{-6}$ & $5.19 \times 10^{-6}$ \\
\hline $\mathrm{Se}(\mathrm{IV})$ & $4.38 \times 10^{-6}$ & $4.78 \times 10^{-6}$ \\
\hline
\end{tabular}

\subsubsection{Why different diffusion coefficients and analyte mass accumulation with Fe-Zr binary oxide and Metsorb?}

Since the diffusive layer was the same in both experiments using different binding layers, the diffusive coefficients were expected to be the same provided other factors were constant, but 
they were not. The diffusion coefficient and mass accumulated after per unit time was higher for the Fe-Zr binary oxide adsorbent (Figures 4.8, 4.9 and 4.10). This could be attributed to the high affinity of the Fe-Zr binary oxide adsorbent for analyte which minimizes the build-up of the analyte in the diffusive gel or along the diffusion path to the binding layer by depleting it quickly and enabling more faster diffusion from the solution and irreversible binding with the analyte. In addition, at around neutral $\mathrm{pH}(\mathrm{pH}$ 7), Fe-Zr binary oxide adsorbent has a high surface area (339 $\mathrm{m}^{2} / \mathrm{g}$ ) and adsorbent capacities of 120 and $46.1 \mathrm{mg} / \mathrm{g}$ for arsenic(III) and arsenic(V), respectively compared to metsorb with a surface area of $200-240 \mathrm{~m}^{2} / \mathrm{g}$ and adsorbent capacities of 59.9 and $37.5 \mathrm{mg} / \mathrm{g}$ for arsenic(III) and arsenic(V), respectively.

The mechanisms for arsenic adsorption on the Fe-Zr binary oxide was reported by Ren et al, 2011. As(III) is adsorbed by formation of both inner- and outer-sphere surface complexes whereas $\mathrm{As}(\mathrm{V})$ is adsorbed by formation of inner-sphere surface complexes. Figure 4.11 illustrates the proposed mechanism. 

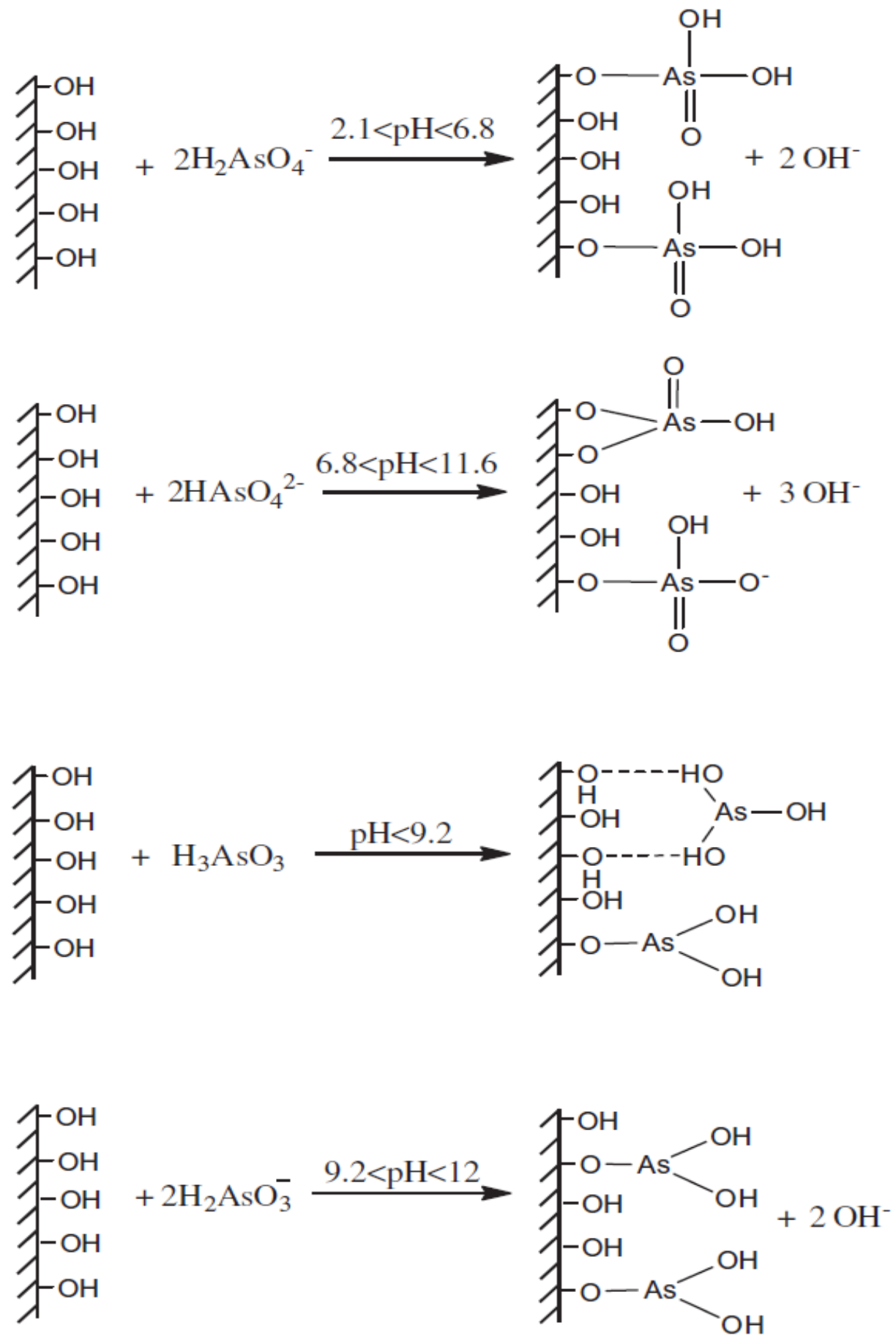

Figure 4.11.Mechanism of arsenic (V) and arsenic (III) adsorption on Fe-Zr binary oxide adosrbent [21]. 
Pena et. al [24] investigated the arsenate $[\mathrm{As}(\mathrm{V})]$ and arsenite [As(III)] interactions at the solid-water interface of nanocrystalline $\mathrm{TiO}_{2}$ (Metsorb) and ascertained that the adsorption of As(V) and As(III) involved the formation of negatively charged inner-sphere surface complexes for both arsenic species. Their studies showed that both As(V) and As(III) form bidentate binuclear surface complexes and the surface complexes on $\mathrm{TiO}_{2}$ maintained the same nonprotonated speciation at $\mathrm{pH}$ values from 5 to 10 . The dominant adsorbed surface species were $(\mathrm{TiO})_{2} \mathrm{AsO}_{2}{ }^{-}$and $(\mathrm{TiO})_{2} \mathrm{AsO}^{-}$for $\mathrm{As}(\mathrm{V})$ and $\mathrm{As}(\mathrm{III})$, respectively. They suggested that $\mathrm{TiO}_{2}$ is an effective adsorbent for arsenic removal due to its high surface area and the presence of high affinity surface hydroxyl groups [24].

The arsenic As(V) and As(III) adsorption mechanisms on Metsorb have been suggested as illustrated below [24]:

$$
\begin{aligned}
& 2 \mathrm{TiOH}+3 \mathrm{H}^{+}+\mathrm{AsO}_{4}{ }^{-}+=\mathrm{Ti}_{2} \mathrm{AsO}_{4}{ }^{-}+2 \mathrm{H}_{2} \mathrm{O}+\mathrm{H}^{+} \quad \text { (Arsenic V) } \\
& 2 \mathrm{TiOH}+\mathrm{H}_{2} \mathrm{AsO}_{3}{ }^{-}=\mathrm{Ti}_{2} \mathrm{AsO}_{3}{ }^{-}+2 \mathrm{H}_{2} \mathrm{O} \quad \text { (As III) }
\end{aligned}
$$

\subsubsection{Fe-Zr -Arsenic and selenium-undiluted unspiked and 5x diluted unspiked FS}

When Fe-Zr binary oxide adsorbent was used to determine the concentration of the total bioavailable arsenic and selenium in unspiked FS, no bioavailable arsenic was detected (< $0.11 \mu \mathrm{g} / \mathrm{L}$, the method detection limit) and the bioavailable selenium was less than the total selenium concentration in FS determined by TCF-GFAAS. This implies that some arsenic and selenium is not bioavailable in FS. However, when the samples were diluted five times, the concentrations of bioavailable arsenic and selenium quantified (multiplied by 5, the dilution factor) were almost twice the bioavailable fractions in the undiluted WRF6 as shown in Figure 4.12 and Table $4.5[2.4 \mu \mathrm{g} / \mathrm{L}$ arsenic (undiluted FS) vs $0.9 \pm 0.4$ x5 $=4.5 \pm 2.0 \mu \mathrm{g} / \mathrm{L}$ arsenic 
(undiluted FS)]. This could similarly mean, as in WRF6, that dilution releases more bioavailable arsenic and selenium fractions in FS and could have detrimental ecotoxicological ramifications in the environment.

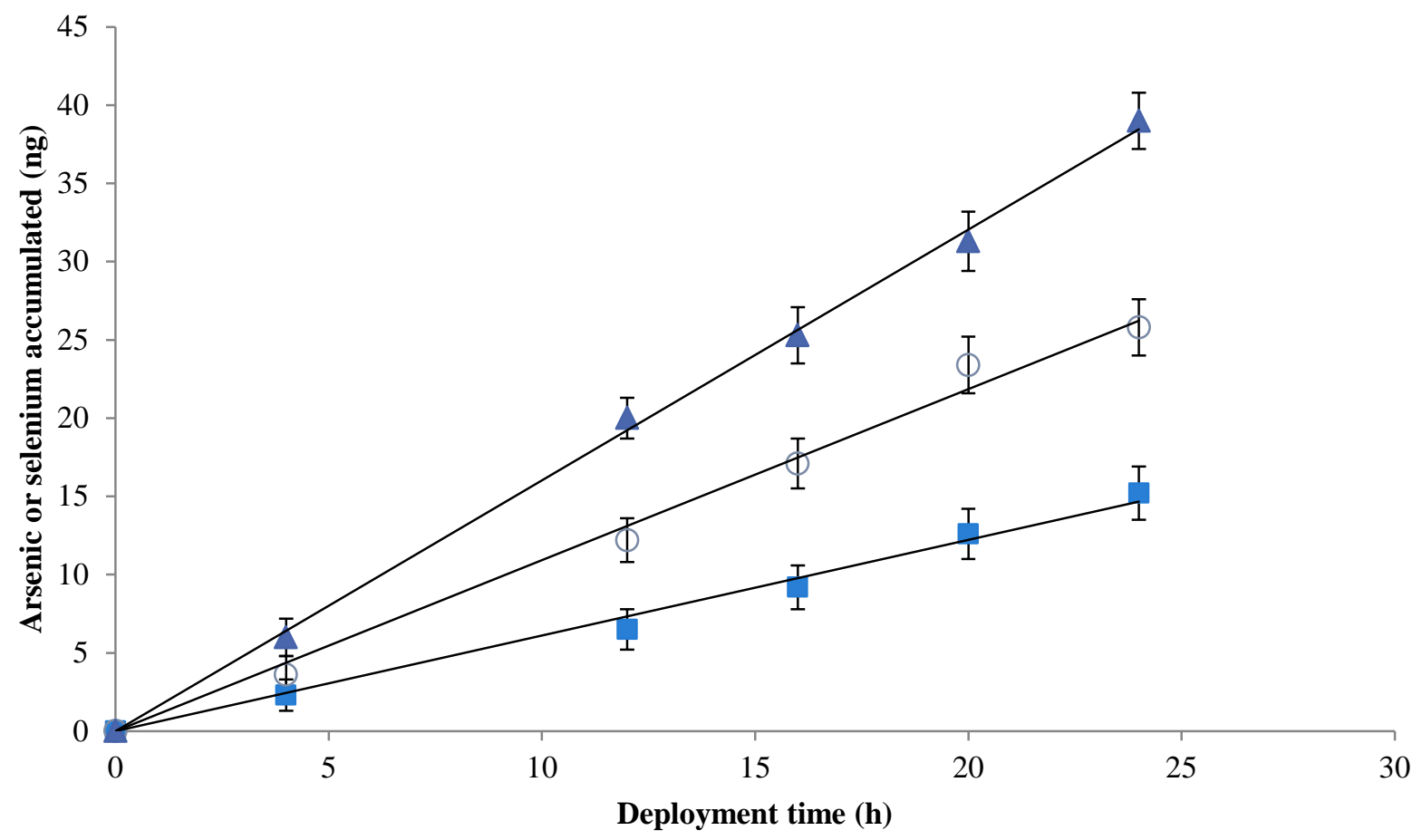

Figure 4.12. Total bioavailable arsenic and selenium mass (ng) accumulation versus deployment time (h) in diluted (5x) and undiluted FS $(\mathrm{n}=3) . \mathbf{\Delta}=$ Se in undiluted FS; $\mathbf{0}=$ As in diluted FS; - = Se in diluted FS (Error bars are 95\% C.I). Arsenic in undiluted was not determined ( $<0.011$ $\mu \mathrm{g} / \mathrm{L})$

Table 4.5. Arsenic and selenium concentrations in unspiked FS.

\begin{tabular}{|c|c|c|c|c|c|c|}
\hline \multirow{2}{*}{ Sample } & \multicolumn{3}{|c|}{ Arsenic concentration $(\mu \mathrm{g} / \mathrm{L})$} & \multicolumn{2}{c|}{ Selenium concentration $(\mu \mathrm{g} / \mathrm{L})$} \\
\cline { 3 - 5 } & \multirow{2}{*}{ TCF-GFAAS } & \multicolumn{2}{|c|}{ DGT-GFAAS } & \multirow{2}{*}{ TCF-GFAAS } & \multicolumn{2}{c|}{ DGT-GFAAS } \\
\cline { 3 - 5 } \cline { 5 - 7 } & & Metsorb & Fe-Zr & & Metsorb & Fe-Zr \\
\hline Undiluted FS & ND & ND & ND & $3.3 \pm 0.4$ & $2.1 \pm 0.6$ & $2.4 \pm 0.5$ \\
\hline 5x diluted FS & ND & ND & ND & ND & ND & $0.9 \pm 0.4$ \\
& & & & & & \\
\hline
\end{tabular}


$\mathrm{ND}=$ Not detected $(<0.11 \mu \mathrm{g} / \mathrm{L}$ of arsenic and $0.14 \mu \mathrm{g} / \mathrm{L}$ of selenium, the method detection limit, based on 3x absorbance of the blanks).

\subsubsection{Speciation Analysis}

The initial study involved comparing Fe-Zr binary oxide adsorbent with Metsorb bioavailable arsenic and selenium determinations in $0.01 \mathrm{M} \mathrm{NaNO}$. Similar trends of recoveries of arsenic and selenium were observed as in FS. However, the percentage recoveries were over $99 \%$ and the mass of analyte and the diffusion coefficient were higher in comparison to Metsorb (Figures 4.13, 4.14 and Table 4.6).

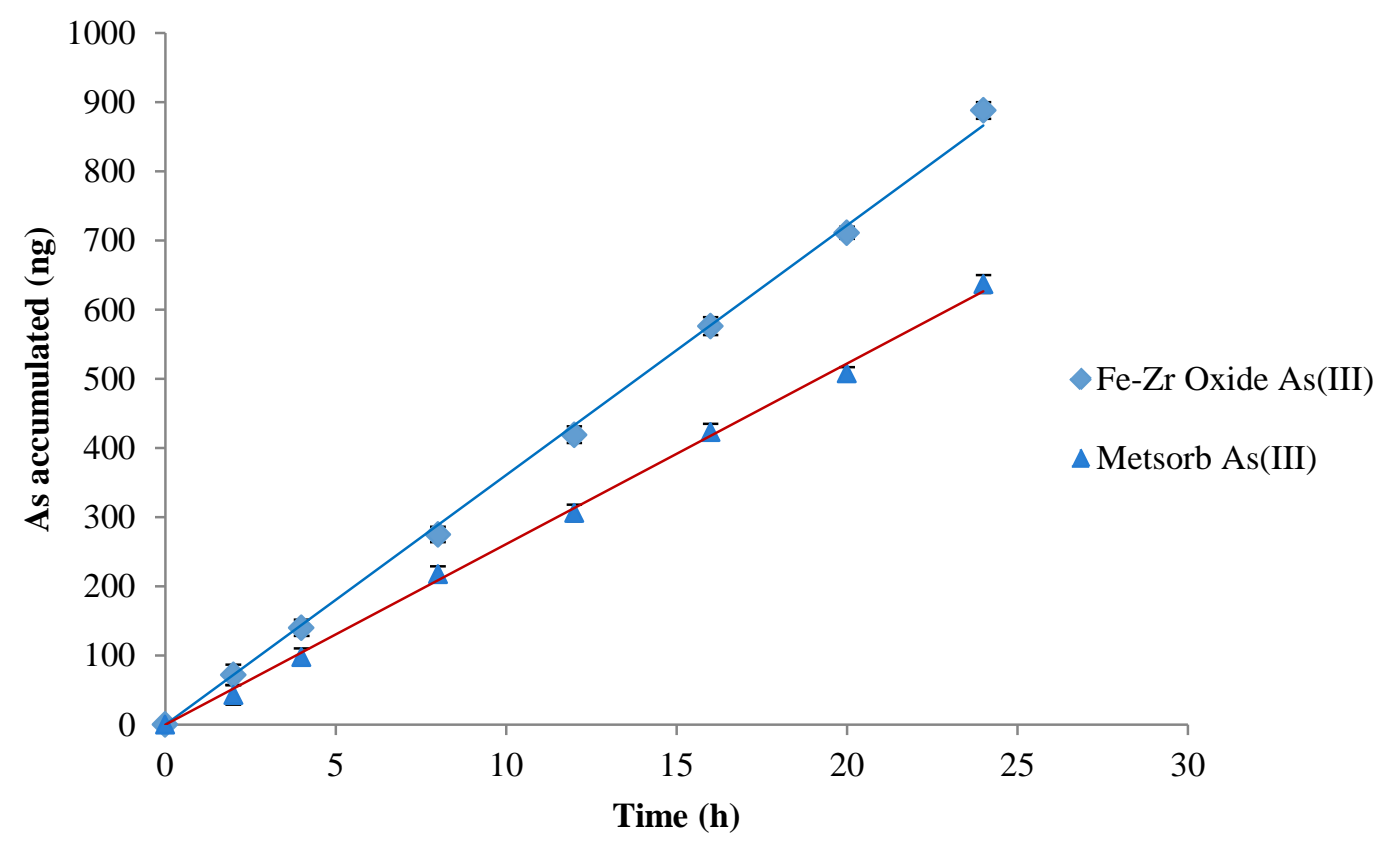

Figure 4.13. Arsenic(III) mass (ng) accumulation versus deployment time (h) 20 ppb spiked 0.01M NaNO 3 (Error bars are 95\% C.I). Percent recoveries: $99.2 \pm 4.2 \%$ with Metsorb and 99.5 $\pm 4.3 \%$ using Fe-Zr after 24 hours. 


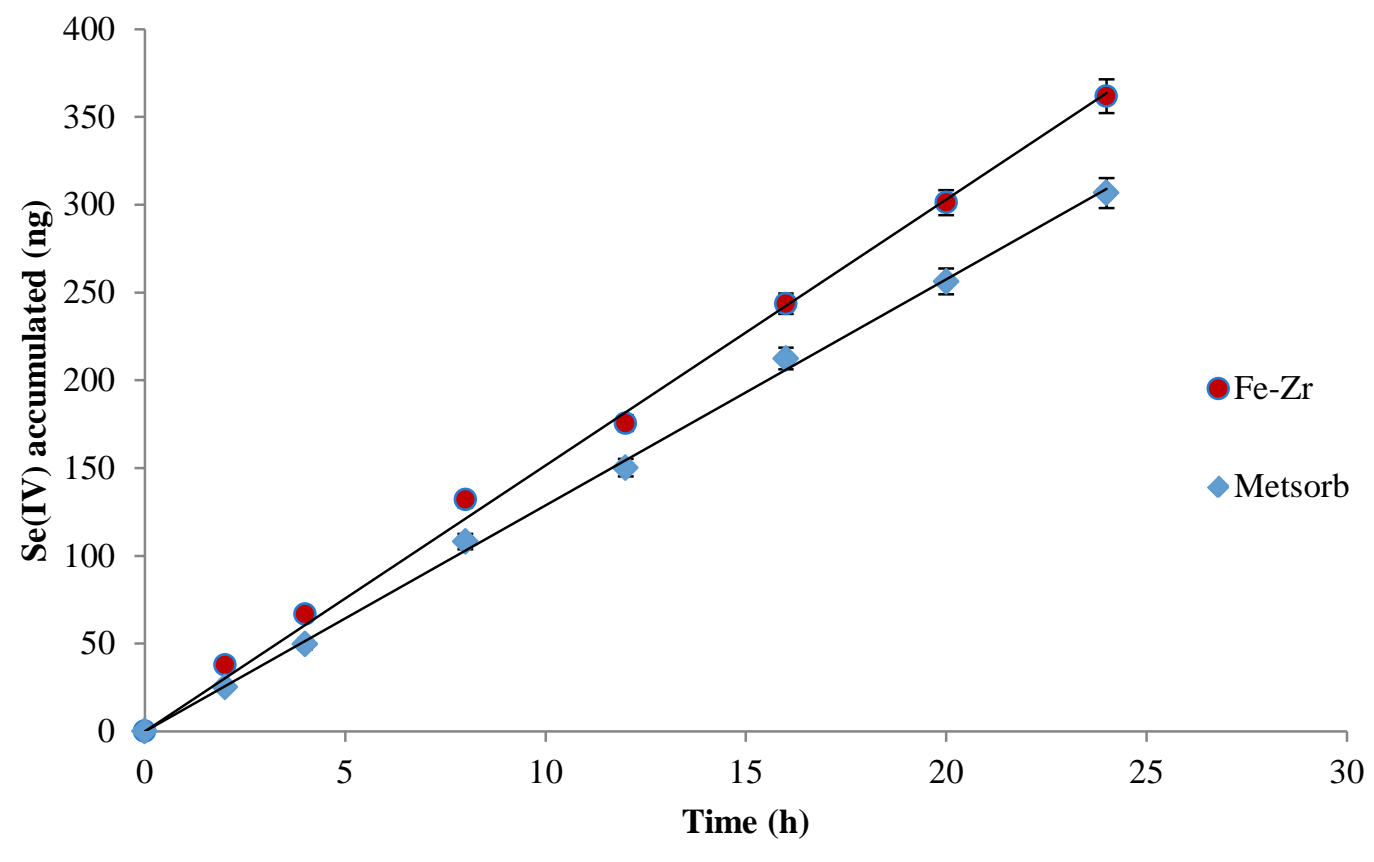

Figure 4.14. Selenium(IV) mass (ng) accumulation versus deployment time (h) in $0.01 \mathrm{M}$ $\mathrm{NaNO}_{3}$ (Error bars are 95\% C.I). Percent recoveries: $99.1 \pm 5.6 \%$ with Metsorb and $99.6 \pm 5.6 \%$ using Fe-Zr after 24 hours.

Table 4.6. Diffusion coefficients $\left(\mathrm{cm}^{2} / \mathrm{s}\right)$ for various arsenic species and selenium in $0.01 \mathrm{M} \mathrm{NaNO}$ and FS.

\begin{tabular}{|l|c|c|c|c|}
\hline \multirow{3}{*}{ Analyte } & \multicolumn{4}{|c|}{ Diffusion Coefficient $\left.\mathbf{( c m}^{2} / \mathbf{s}\right)$ in } \\
\cline { 2 - 5 } & \multicolumn{3}{|c|}{$0.01 \mathrm{M} \mathrm{NaNO}_{3}$} & Undiluted FS \\
\cline { 2 - 5 } & Metsorb & Fe-Zr oxide & Mercaptosilica & Mercaptosilica \\
\hline As(III) & $9.24 \times 10^{-6}$ & $1.28 \times 10^{-5}$ & $1.45 \times 10^{-5}$ & $1.05 \times 10^{-5}$ \\
\hline As(V) & $\mathrm{ND}^{\mathrm{a}}$ & $1.03 \times 10^{-5 *}$ & $\mathrm{ND \#}$ & $\mathrm{ND \#}$ \\
\hline $\mathrm{Se}(\mathrm{IV})$ & $4.56 \times 10^{-6}$ & $5.36 \times 10^{-6}$ & $\mathrm{ND \#}$ & $\mathrm{ND \#}$ \\
\hline
\end{tabular}

$\mathrm{ND \#}=$ Not done because mercaptosilica adsorbent only binds As(III); $\mathrm{ND}^{\mathrm{a}}=$ Not done since appreciable results were obtained for Fe-Zr and $\mathrm{As}(\mathrm{V})$ is adsorbed slower; * = determined by difference 
Speciation analysis for bioavailable arsenic(III) and arsenic(V) fractions in $0.01 \mathrm{M}$ $\mathrm{NaNO}_{3}$ and then in FS. The total bioavailable arsenic [arsenic(III) $\left.+\operatorname{arsenic}(\mathrm{V})\right]$ in the mixture was determined using Fe-Zr binary oxide adsorbent. 3-mecarptopropyl-functionalized silica binding agent was then used to selectively bind the arsenic (III). The concentration of As(V) was finally determined by difference. The initial arsenic speciation analysis study was in $0.01 \mathrm{M}$ $\mathrm{NaNO}_{3}$ (Figure 4.15).

Another initial study involved use of a $40 \mathrm{ppb}$ arsenic (III) spiked solution of undiluted FS and analyze it for bioavailable arsenic using 3-mecarptopropyl-functionalized silica binding agent and determine the diffusion coefficient. This yielded a recovery of $94.6 \%$ (Figure 4.16). Then speciation analysis was carried out in undiluted FS and data is shown in Figure 4.17.

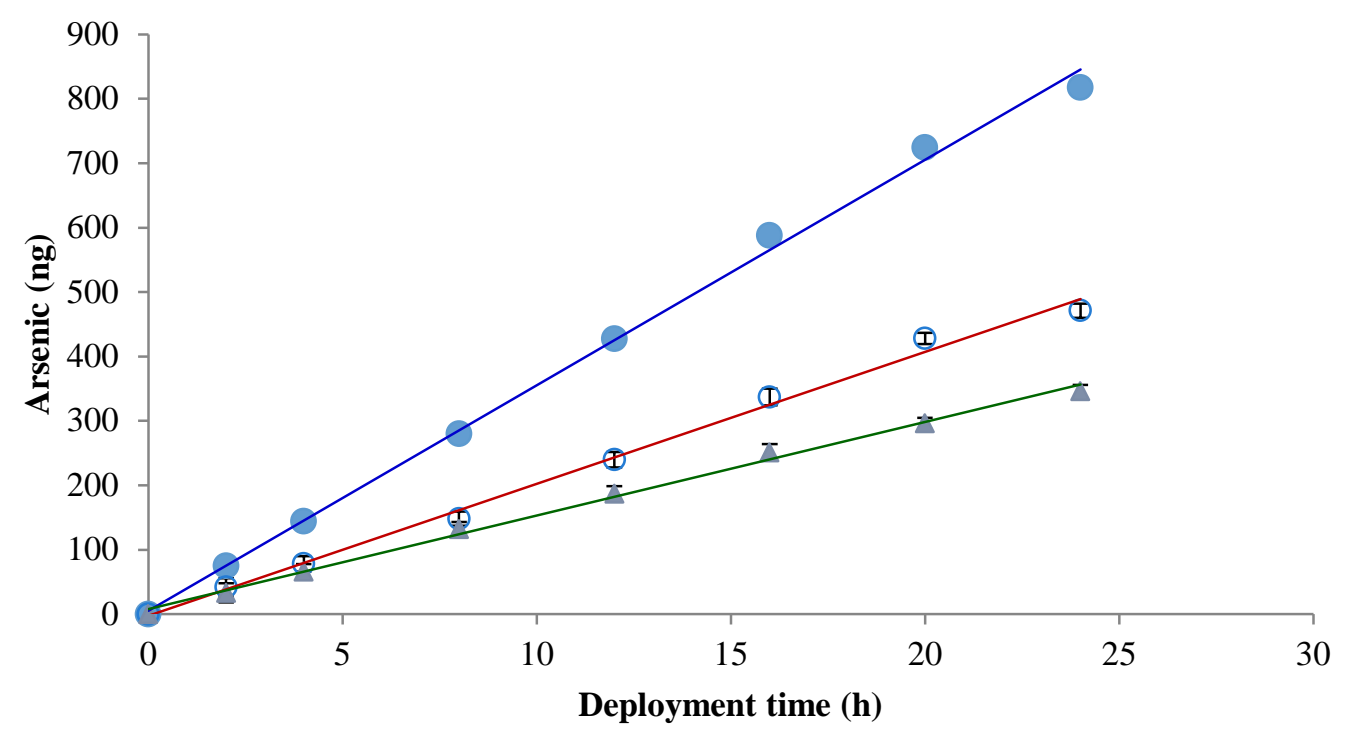

Figure 4.15 Total arsenic versus arsenic(III) and Arsenic(V) mixture in the same sample of 10 ppb of each in 0.01M NaNO $3, \mathrm{n}=3$ (Error bars are 95\% C.I). $\bullet=$ Total arsenic; $\mathbf{O}=\mathrm{As}(\mathrm{III}) ; \mathbf{\Delta}=$ As(V) determined by difference. Percent recoveries: $99.4 \pm 4.6 \%$ As(III) and $99.1 \pm 4.2 \%$ arsenic(V) after 24 hours. 


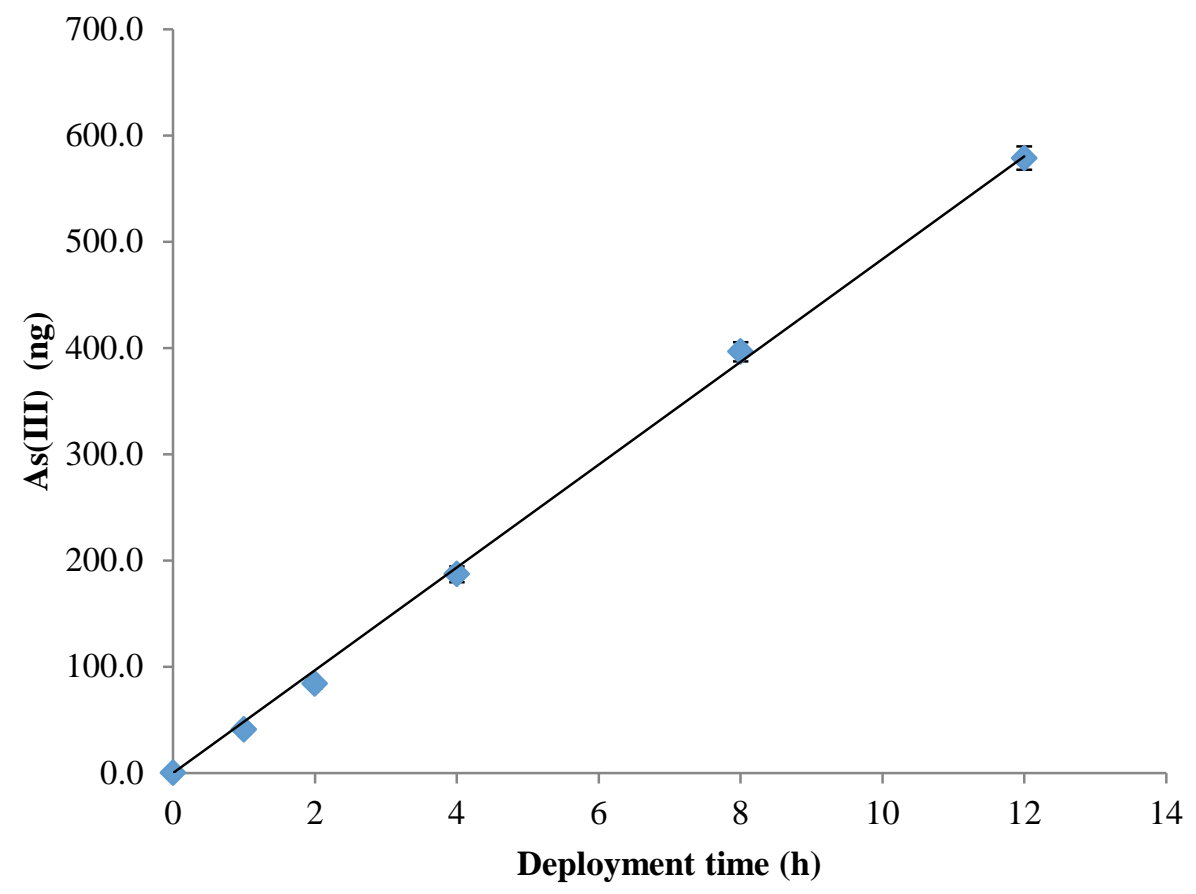

Figure 4.16. Arsenic(III) mass (ng) accumulation versus deployment time (h) in $40 \mathrm{ppb}$ spiked undiluted FS using mercaptosilica (Error bars are 95\% C.I). Percent recovery: $94.6 \%$ after 12 hours.

The arsenic(III) diffusion coefficient was higher in FS than $0.01 \mathrm{M} \mathrm{NaNO}_{3}$ in a mixture of arsenic(V) and arsenic(III) (Figures 4.14 and 4.16, and Table 4.6). This could be due to conversion of arsenic(V) to arsenic(III) which leads to increased arsenic(III) concentration gradient in solution. This conversion could be triggered and accelerated by a myriad of factors stemming from the complex matrix of FS, such as $\mathrm{pH}$ fluctuations and ionic strength.

After 24 hours of deployment both arsenic(III) and arsenic (V) determined were $5 \%$ higher in $0.01 \mathrm{M} \mathrm{NaNO}_{3}$ than FS (Figure 4.14 and 4.15). This is due to the complexity of FS matrix with a multitude of competing or complexing ions that hamper the diffusion rate of both arsenic(III) and arsenic(V) in FS or complex lability. 


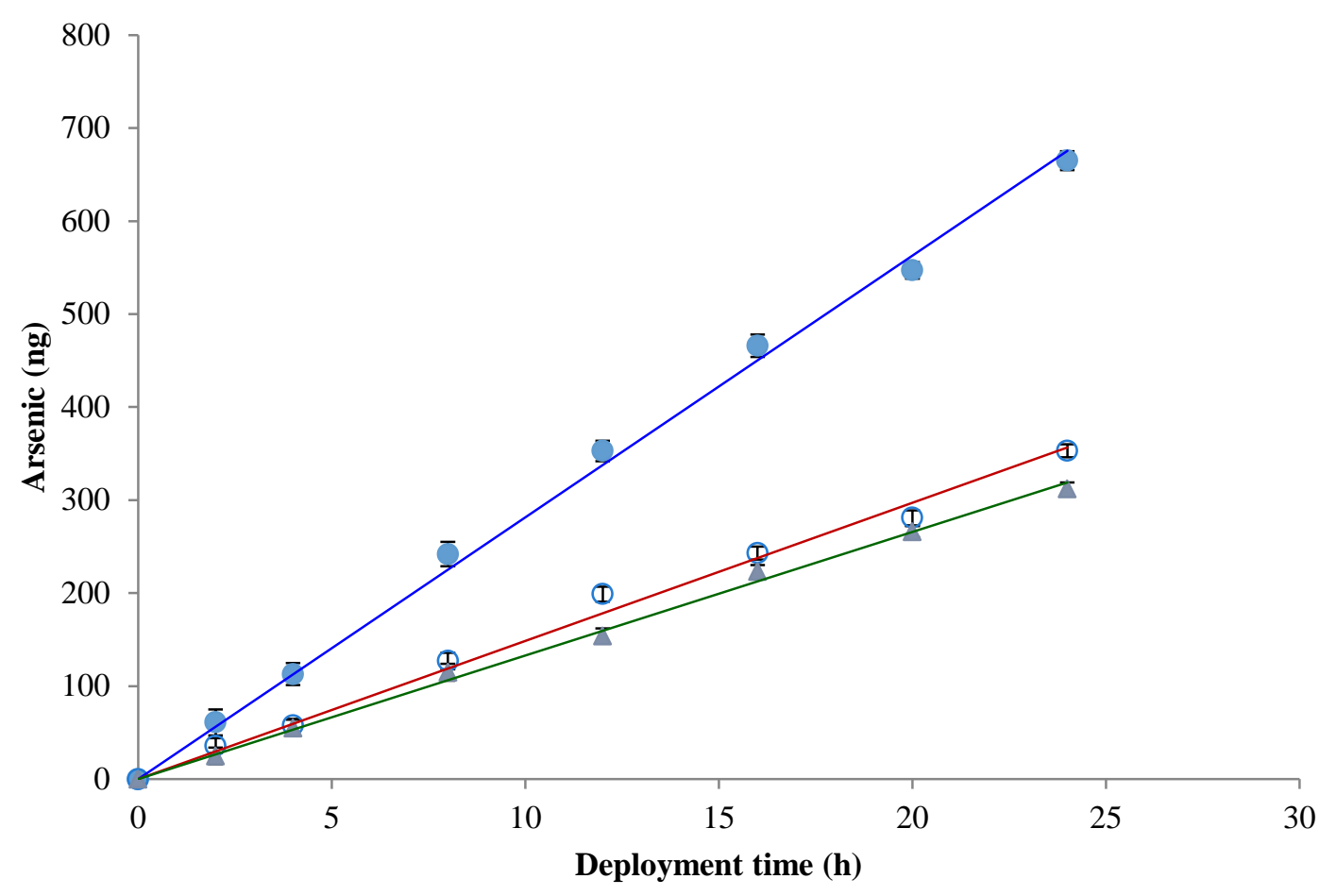

Figure 4.17 Total arsenic versus arsenic(III) and Arsenic(V) mixture in the same sample of 10 ppb of each in undiluted FS, $\mathrm{n}=3$ (Error bars are 95\% C.I). $\bullet=$ Total arsenic; $\mathbf{O}=\mathrm{As}(\mathrm{III}) ; \mathbf{\Delta}=$ As(V) determined by difference. Percent recoveries: $111 \pm 9 \%$ As(III) and $108 \pm 8 \%$ arsenic(V) after 24 hours.

\subsubsection{Why different diffusion coefficients in $0.01 \mathrm{M}$ sodium nitrate in DI water, diluted FBW and FBW?}

In DI water with $0.01 \mathrm{NaNO}_{3}$ there is no complexation whatsoever. All the analyte is entirely free or labile. However, in FBW where there is high ionic strength a multitude of ions can complex with the analyte ions to form a bulky or inert complex. If the complex formed is too bulky to navigate through the pore network of the diffusive gel easily, its diffusion rate to the binding layer is diminished. On the other hand, if the complexation results in an inert bulky 
complex with molecular size greater than the pore size in the diffusive gel very little or no analyte is accumulated in the binding gel as its diffusion is impeded. This could be attributed to the lowering of the diffusion coefficient by $52 \%$ and the $51 \%$ accumulated arsenic (III) mass (ng) decrease in metsorb after 24 hours of DGT probe deployment in FS flowback wastewater, and the lower $\mathrm{C}_{\mathrm{DGT}} / \mathrm{C}_{\text {soln }}$ of 0.96 compared to the corresponding values in $0.01 \mathrm{M} \mathrm{NaNO}$ in $\mathrm{DI}$ water (Figures 4.15 and 4.16 and Table 4.6). The same trend was also observed using Fe-Zr binary oxide adsorbent where the diffusion coefficient decreased by $27 \%$, accumulated arsenic(III) mass(ng) by $32 \%$ and a $\mathrm{C}_{\mathrm{DGT}} / \mathrm{C}_{\text {Soln }}$ of 0.92 after 24 hours of DGT probe deployment in FS flowback wastewater.

There is no reported work so far about application of DGT in the quantitation of arsenic and selenium in highly saline waters such as WRF6 or FS. Longer deployment times can improve the detection limit since greater analyte amounts can be accumulated. However, in complex media such as undiluted flowback wastewater, the DGT concentrations may not be directly related to the total or dissolved analyte concentrations since species accumulated by DGT are dependent on size and lability. Zhang and Davison [7] reported that the size is determined by the diffusive gel and the normal DGT has a pore size of approximately $5 \mathrm{~nm}$. Although, $5 \mathrm{~nm}$ is not a definitive cut-off, it means that hydrated metal ions and complexes $<5$ nm diffuse relatively freely in the gel and larger complexes are impeded. Large complexes will therefore only contribute marginally to the total accumulated analyte mass. Analytes bound to ligands that are small enough to diffuse through the diffusive gel will be included if the time of diffusion is long enough for the complex to dissociate (Zhang and Davison 1995, Scally et al., 2003). 
The assumption that any trace analyte interactions with the diffusive gel in fairly high ionic strength complexation free media $\left(0.01 \mathrm{M} \mathrm{NaNO}_{3}\right)$ are minimal in DGT quantitation was tested and indicated good agreement between $\mathrm{C}_{\mathrm{DGT}} / \mathrm{C}_{\mathrm{Soln}}$ as earlier proven by early measurements of trace metals using DGT. However, at lower ionic strengths $(<0.001 \mathrm{M})$, it was reported that the observed values of $\mathrm{C}_{\mathrm{DGT}} / \mathrm{C}_{\text {Soln }}$ were systematically greater than 1 and this was attributed to the diffusion of metal ions being enhanced to maintain electroneutrality under dynamic conditions, and an apparently variable charge on the gel that led to erratic diffusion coefficients in the polyacrylamide diffusive gels [25-26]. Warnken et. al [5] addressed the apparent inconsistencies in $\mathrm{C}_{\mathrm{DGT}} / \mathrm{C}_{\text {Soln }}$ due to erratic diffusion coefficients by conducting systematic experiments that emphasized gel washing and showed that the extent of gel washing determines the value of $\mathrm{C}_{\mathrm{DGT}} / \mathrm{C}_{\text {Soln }}$. Poorly washed polyacrylamide gels have a residual negative charge due to the presence of excess reagent products. The extent of washing can be measured by measuring the $\mathrm{pH}$ of the rinse solution. Sufficient washing yields $\mathrm{pH}$ values less than 7 and $\mathrm{C}_{\mathrm{DGT}} / \mathrm{C}_{\text {Soln }}$ values $\sim 1$ at very low ionic strength $(0.0001 \mathrm{M})$, whereas $\mathrm{pH}$ values greater than 7 indicate incomplete removal of reagent products.

A mechanistic basis for observed erratic values of $\mathrm{C}_{\mathrm{DGT}} / \mathrm{C}_{\text {Soln }}$ greater than 1 in pure agarose gel, based on the effect of gel charge was provided by Fatin-Rouge et. al [27] by investigating quantitatively several solute-gel interactions, including steric hindrance and specific binding of metals to the gel. They reasoned that effect of gel charge becomes significant at very low ionic strength and creates a Donnan potential. This was supported by Yesek and van Leeuwen [28] who derived the Donnan potential from measurements of the conductivity of polyacrylamide gels copolymerized with sodium acrylate to ensure a high charge. They noted that when gels are negatively charged, cations become electrostatically associated with the gel and their 
concentrations on either side of the gel-solution interface are then unequal, which results in an enhanced cation concentration inside the gel. The charged-induced cation enhancement increases the diffusion gradient of ions through the gel in comparison uncharged gel and $\mathrm{C}_{\mathrm{DGT}}$ is consequently higher than expected if calculated using Eq. 4.3, where the Donnan potential (c) established between gel and solution, because of the charge density of the gel (r), can be used to calculate the elevation of the concentration in the gel $\left(\mathrm{C}_{\text {gel }}\right)$ over the solution (Eqs. 4.3 and 4.4).

$$
\begin{aligned}
& \frac{\mathrm{C}_{\text {gel }}}{\mathrm{C}_{\text {soln }}}=\mathrm{e}^{-\mathrm{Z}_{\mathrm{M}} \mathrm{F} \psi / \mathrm{RT}} \\
& \psi\left(\frac{\mathrm{RT}}{\mathrm{zF}}\right) \mathrm{asinh}=\left(\frac{\rho}{2 \mathrm{zFc}}\right)
\end{aligned}
$$

Where $\mathrm{zM}$ is the valence of the metal ion, and that of the supporting electrolyte, of concentration c, is z. F, R and T are the Faraday constant, molar gas constant and absolute temperature, respectively. For positively charged gels, cations are repelled and the concentration at the gel side of the interface is subsequently lowered. This culminates in lowering the concentration gradient in the gel and $\mathrm{C}_{\mathrm{DGT}} / \mathrm{C}_{\text {soln }}$ becomes less than 1 in very low ionic strength [9]. The effect of gel charge is reduced as ionic strength (related to zc) is increased (Eq. 4.4).

Even at fairly constant relatively high ionic strength, there are some discrepancies in the diffusion coefficients of arsenic(III) and arsenic(V) in different water matrices used in this work, compared to previous measurements [17, 20, 22]. However, it should also be noted that there is a spread in already reported values. For instance, while Bennett et al [17] estimated the diffusion coefficient of arsenic(III) to be $(1.05 \pm 0.25) \times 10^{-5} \mathrm{~cm}^{2} / \mathrm{s}$ at $\mathrm{pH} 6.70$, Panther et al. 2008 got a value of $(5.95 \pm 0.30) \times 10^{-6} \mathrm{~cm}^{2} / \mathrm{s}$ at $\mathrm{pH} 5.00$ (both values recalculated to be valid at $25^{\circ} \mathrm{C}$ ). The differences could be attributed to differences in matrix composition, $\mathrm{pH}$ and/or the precision and accuracy associated to the diffusion coefficient determination methods. There could for example be small discrepancies in diffusive boundary layer thickness caused by different stirring rates and 
measurements of the diffusive gel thickness or the area of the connecting interfaces between the DGT probe compartments [6].

\subsubsection{Total arsenic and selenium quantitation in the FS solid by TCF-GFAAS}

Although the total arsenic concentrations in WRF6 had less than $0.11 \mu \mathrm{g} / \mathrm{L}$, the method detection limit, the solid did contain some arsenic as shown in Table 4.7.

Table 4.7 Arsenic and selenium concentrations in flowback waste water solids by TCF GFAAS.

\begin{tabular}{|l|c|c|}
\hline Sample solid & $\begin{array}{c}\text { Arsenic concentration } \\
(\mu \mathrm{g} / \mathrm{kg})\end{array}$ & $\begin{array}{c}\text { Selenium concentration } \\
(\mu \mathrm{g} / \mathrm{kg})\end{array}$ \\
\hline WRF6 & $3.7 \pm 0.7$ & $1.8 \pm 0.5$ \\
\hline FS & $6.3 \pm 0.8$ & $2.5 \pm 0.6$ \\
\hline
\end{tabular}

The total selenium concentrations in WRF6 and FS were 10.1 $\pm 2.2 \mu \mathrm{g} / \mathrm{L}$ and $3.3 \pm 0.4$ $\mu \mathrm{g} / \mathrm{L}$, respectively. The concentration in WRF6 is approximately two times higher than the CCC. Similar to arsenic, some selenium was also found in the solid as shown in Table 4.7.

\subsubsection{Extraction of Arsenic and Selenium from Marcellus shale}

The concentrations of arsenic and selenium extracted from the shale are proportional to the duration of exposure of the Gilmer 1978 Marcellus shale and ionic strength of aqueous solution as shown in Figure 4.18 and 4.19. The mass extracted from the shale varied with the exposure time in both WRF6 and HSW, while the masses extracted were higher in WRF6 than HSW for both analytes. This implies that both the ionic strength and solution composition are likely to play a key role in the extraction of arsenic or selenium into these solutions. The mass of 
selenium extracted by either deionized water or 3\% nitric acid was significantly less than that extracted by the WRF6 or HSW.

The selenium and arsenic concentrations in unspiked WRF6 were 10 ppb selenium and $\leq$ 1 ppb, respectively. Only 1\% of the total arsenic could be extracted from Gilmer 1978 after 72 hours by WRF6; however, the selenium extracted after 72 hours by WRF6 represented 21\% of the total. This suggests that the selenium could be bound differently than arsenic within the shale matrix. Although it is not known how the arsenic and selenium species are bound or speciated in this shale, a higher percentage of selenium is extracted.

The concentration of selenium obtained after 72 hours of exposure (16 ppb) is already over $3 \mathrm{X}$ the selenium CCC. In a previous study it was reported that the leaching of trace metals from different shales by aqueous brine solutions was dependent on the ionic strength as well as the temperature of the solutions [29]. An increase in either the temperature or the ionic strength increased the amount of metal leached and a change in the salt solution composition also changed the amount leached.

Although the $\mathrm{pH}$ of fracturing water which resulted in flow back water, WRF6, was unknown, the pH of WRF6 and HSW were 6.71 and 6.83, respectively. There were significant differences in the amounts of arsenic and selenium extracted by these two solutions. This implies that although $\mathrm{pH}$ is a factor influencing chemisorption of arsenic and selenium species, it is possible that under conditions of high ionic strength its effect is diminished. 


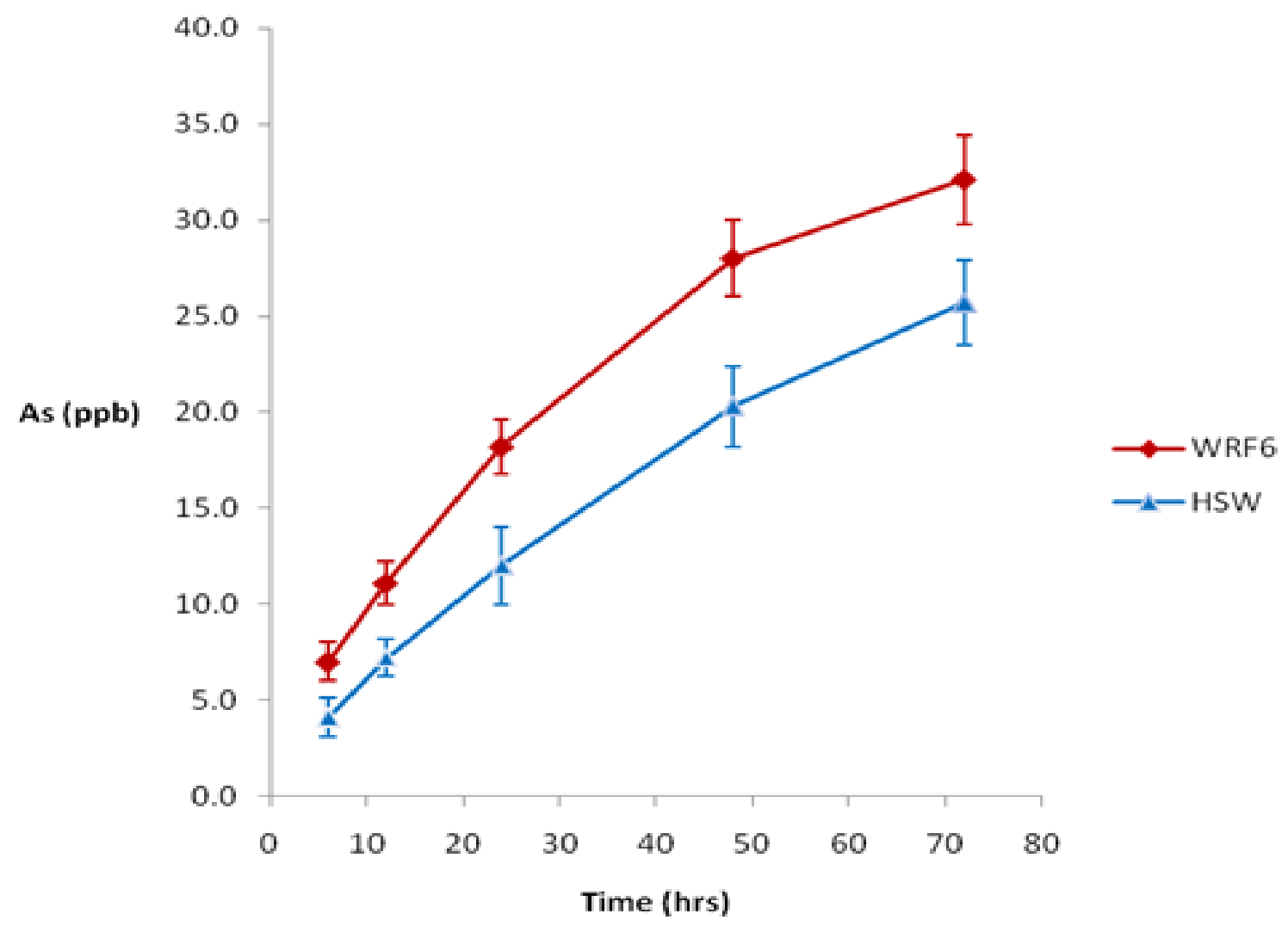

Figure 4.18. Arsenic extracted from Marcellus shale (Gilmer 1978) by WRF6 and HSW at various exposure times (Error bars are 95\% C.I). 


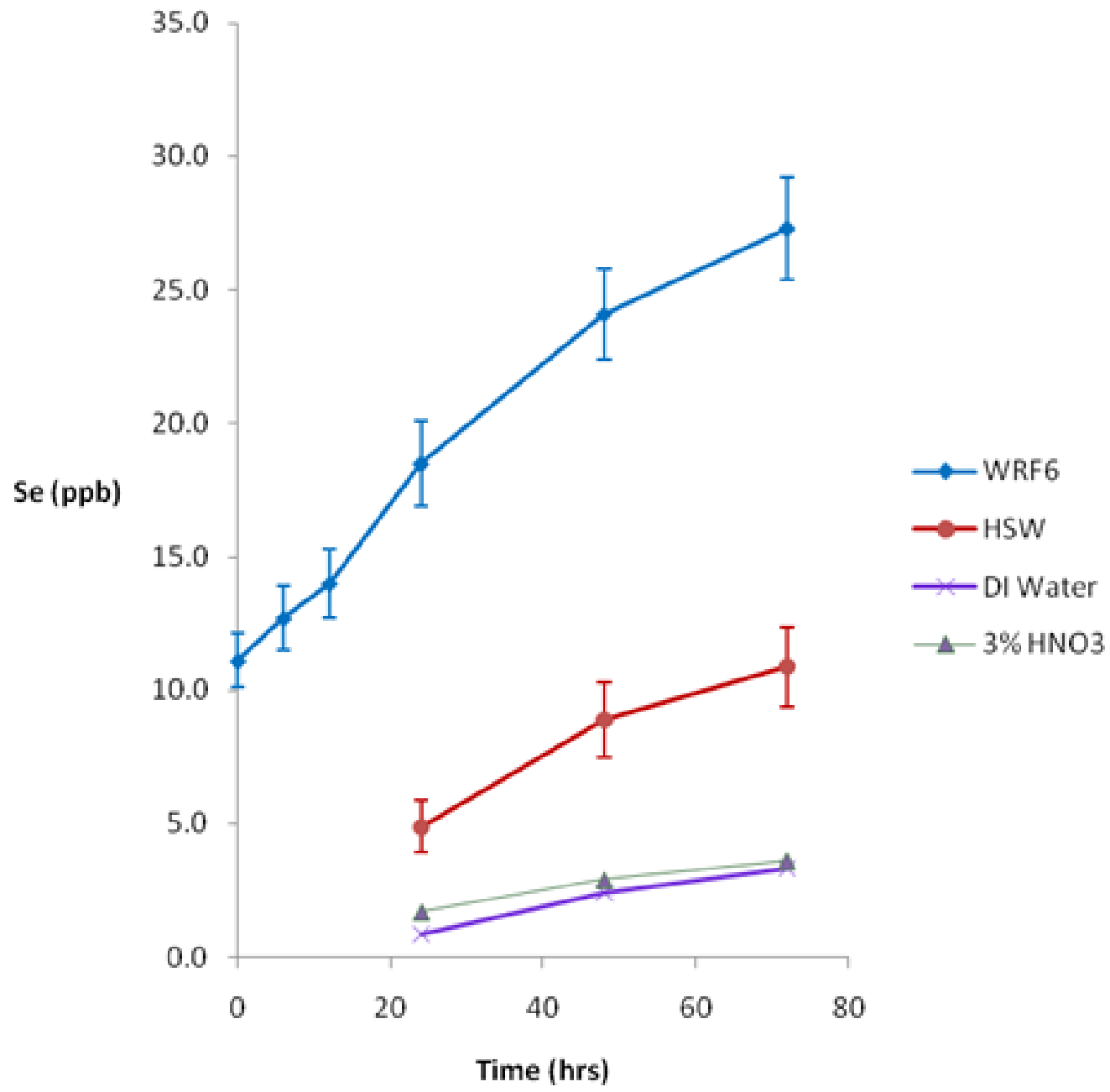

Figure 4.19. Selenium extracted from Marcellus shale (Gilmer 1978) by WRF6 and HSW at various exposure times (Error bars are 95\% C.I).

\subsubsection{Bioavailable arsenic and selenium $\left(C_{D G T}\right)$ and total arsenic and selenium $\left(C_{T C F}\right)$ extraction from the Marcellus shale into WRF6 vs exposure time}

The potential for the WRF6 to contain labile arsenic and selenium from Marcellus shale has been investigated and compared by adding the ground Marcellus shale (0.50 g, Gilmer 1978, $\mathrm{n}=2$ ) to $25 \mathrm{~mL}$ of water. 


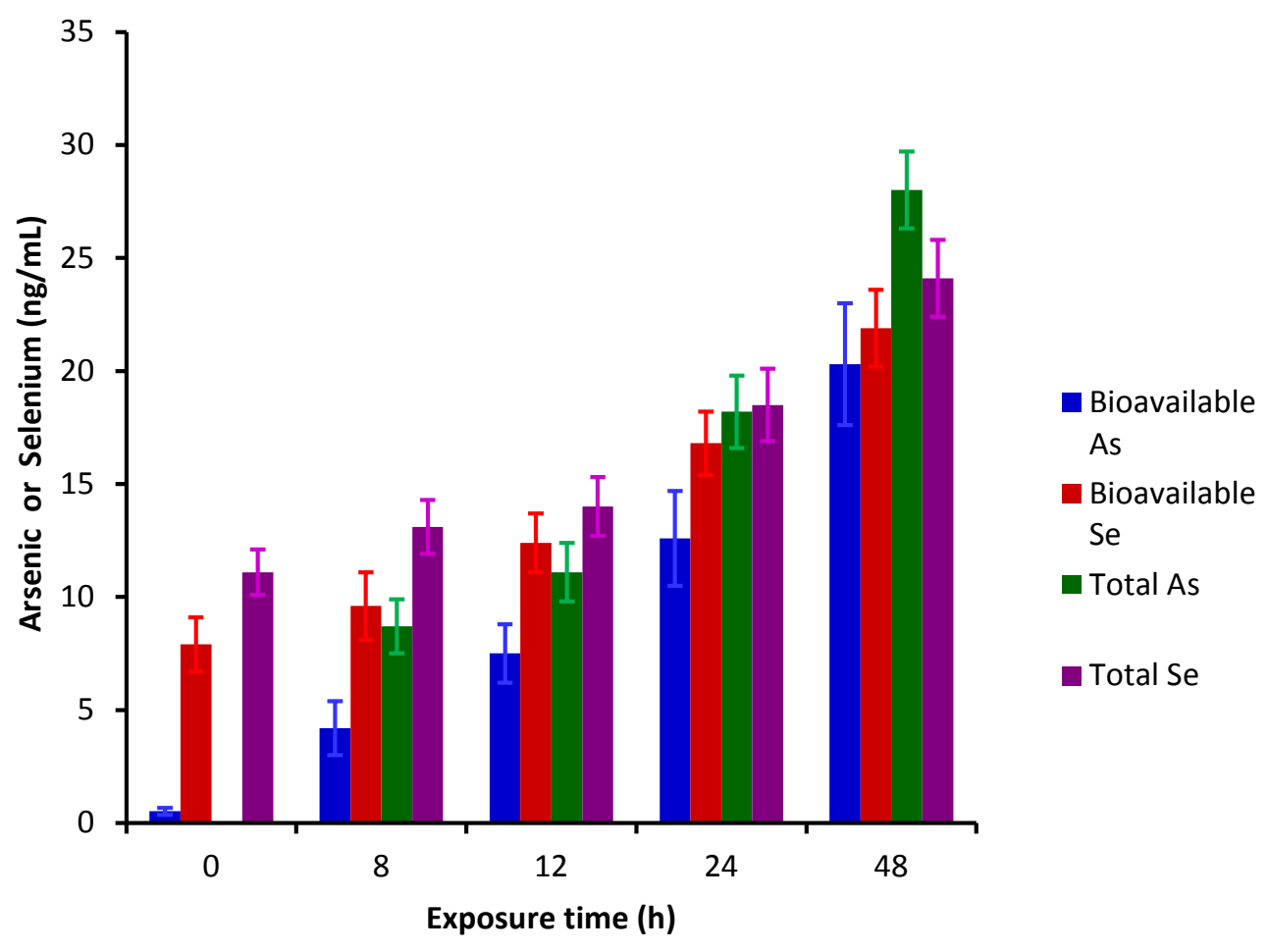

Figure 4.20. Labile arsenic and selenium $\left(\mathrm{C}_{\mathrm{DGT}}\right)$ and total arsenic and selenium $\left(\mathrm{C}_{\mathrm{TCF}}\right)$ extracted from the Marcellus shale* into WRF6 vs exposure time (Error bars are 95\% C.I). $(*=$ Total arsenic and selenium concentrations in the Gilmer 1978 Marcellus shale were $153 \pm 4$ and $3.9 \pm$ $0.4 \mu \mathrm{g} / \mathrm{g}$, respectively [30]).

As shown in Figure 4.20, the amount of bioavailable arsenic or selenium in WRF6 increased proportionally with exposure time. Although, the bioavailable arsenic proportion appears to have increased markedly compared to that of bioavailable selenium, bioavailable selenium increased much more markedly (14 \% higher) after 48 hours of exposure in comparison to the original analyte concentrations in the shale. The bioavailable selenium concentration after 48 hours was also above 3x the CCC. Although, it is difficult to simulate the exact conditions such as pressure, surface area and temperature, hydraulic fracturing occurs, this preliminary 
study gives insights into the probable hazardous environmental ramifications of extended exposure of the Marcellus shales to highly saline waters.

\subsection{Conclusions}

The major findings in application of DGT to flowback wastewaters are that diffusion coefficients and the ratio $\mathrm{C}_{\mathrm{DGT}} / \mathrm{C}_{\text {Soln }}$ of analyte ions depend on ionic strength, type of adsorbent and dilution. Dilution of high ionic strength waters enables release of more free or labile analyte ions that increase the bioavailable fractions of arsenic and selenium in solution. This could be of potential long-term ecotoxicological repercussions as most of the hydrofracture wastewater is not treated well but just disposed of in underground streams or open streams. Dilution of WRF6 enabled considerable bioavailable arsenic and selenium fractions quantitation from linear DGT plots but not in undiluted WRF6. This means that when flowback wastewater is disposed of in the environment and gets diluted by streams or rain, arsenic and selenium which are complexed are released into the water and become bioavailable. The bioavailable arsenic and selenium can permeate aquatic ecosystems. This could consequently lead to arsenic and selenium bioaccumulation and biomagnification in aquatic ecosystems with disastrous ramifications if the arsenic and selenium release continues unabated.

The exposure of the Marcellus shales to WRF6 and HSW has shown that significant amounts of both arsenic and selenium can be extracted, and the mass extracted increases with exposure time. The ionic strength and composition of the solution contacting the shale also have a very significant effect on the amount of analyte extracted.

Although the concentration of arsenic is much higher than selenium in the shale, the two analytes appear to be bound differently by the shale. The selenium concentration in unspiked 
WRF6 was $10 \mathrm{ppb}$, but the arsenic concentration was $\leq 1 \mathrm{ppb}$, the detection limit for arsenic for this method. The detection limit for selenium was 2 ppb. Because the Marcellus shales contain significant amounts of arsenic and selenium, the extraction of these analytes into high ionic strength water at depths of a mile or more where higher temperatures and pressures exist, is a potential environmental concern. The high volumes of water used in the hydrofracturing process (millions of gallons) makes it imperative to carefully control the disposal and/or re-use of this water.

Although no significant bioavailable and total arsenic concentration was found in flow back water (WRF6), prolonged exposure of the Marcellus shale to WRF6 increased markedly the bioavailable arsenic and selenium fractions in WRF6. Both total and bioavailable selenium concentrations were above the CCC $(5 \mu \mathrm{g} / \mathrm{L})$, which could pose ecotoxicologically hazardous ramifications. In addition to adsorbent capacity and deployment time, accuracy of DGT measurements is also dependent on total analyte mass in confined volumes.

\subsection{References}

[1] Kot A., Namiesnk, J, Trends in Analytical Chemistry, 2000, 19, 69-79.

[2] Soeder D. J., Water resource and natural gas production from the Marcellus shale (http://pubs.usgs.gov/fs/2009/3032/, website browsed at 1500 hours on Feb. 16 ${ }^{\text {th }}$ 2011).

[3] USEPA, 2009a. United States Environmental Protection Agency. National Recommended Water Quality Criteria for Priority Pollutants.. Available from:

<http://water.epa.gov/scitech/swguidance/standards/current/upload/nrwqc-2009.pdf>

[4] USEPA, 2009b. United States Environmental Protection Agency. National Primary Drinking Water Regulations. Available from: < http://www.epa.gov/safewater/consumer/pdf/mcl.pdf $>$ 
[5] http://www.dgtresearch.com/dgtresearch/dgtresearch.pdf, Website browsed on January $17^{\text {th }}$, 2011.

[6] Zhang, H. and Davison, W., Analytical Chemistry, 1995, 67, 3391-3400.

[7] Zhang, H., Davison,W., Analytica Chimica Acta,, 1999, 398, 329.

[8] Zhang, H. and Davison, W., Gadi R. and Kobayashi T., Analytica Chimica Acta, 1998, 370, 29-39.

[9] Warnken, K., Zhang, H. and Davison, W., Analytical Chemistry, 2005, 77, 5440

[10] Warnken, K. W., Davison, W., Zhang, H., Galceran, J. and Puy, J., Environmental Science and Technology, 2007, 41, 3179.

[11] Yapici, T., Fasfous, I. I., Murimboh, J., and Chakrabarti, C. L., Analytica Chimica Acta, 2008, 622, 70-76.

[12] Warnken, K. W., Davison, W., Zhang, H., Environmental Science and Technology, 2008, 42, 6903.

[12] Scally, S., Davison, W. , and Zhang, H., Environmental Science and Technology. 2003, 37, 1379.

[13] Warnken, K. W., Lawlor, A. J., Lofts, S., Tipping, E., Davison, W., and Zhang, H., Environmental Science and Technology, 2009, 43, 7230.

[14] Forsberg, J., Dahlqvist, R., Gelting-Nystrom, J., Ingri, J., Environmental Science and Technology, 2006, 40, 3901.

[15] Luo J., Zhang H., Santner J. and Davison W., Analytical Chemistry, 2010, 82 (21), 89038909.

[16] Österlund, S. Chlot, M. Faarinen, A. Widerlund, I. Rodushkin, J. Ingri, D. C. Baxter,. Analytica Chimica Acta, 2010, 682, 59. 
[17] Bennett, W.W., Teasdale, P. R., Panther, J. G., Welsh, D. T., and Jolley, D. F., Analytical Chemistry, 2010, 82,7401-7407.

[18] Buzier, R., Tusseau-Vuillemin, M. and Mouchel J., Science of the Total Environment, 2006, 358, 277-285.

[19] Santner, J., Prohaska T., Luo, J., and Zhang, H., Analytical Chemistry, 2010, 82,7668-7674

[20] Bennett, W.W., Teasdale P. R., Panther, J. G., Welsh, D. T. and Jolley, D. F., Analytical Chemistry, 2011, 83, 8293-8299.

[21] Ren, Z., Zhang, G., and Chen, J. P., Journal of Colloid and Interfacial Science, 2011, 358, 230-237.

[22] Panther, J. G., Stillwell, K. P., Powell, K. J. and Downard, A. J., Analytica Chimica Acta, 2008, 622, 133

[23] Panther, J. G., Teasdale, P. R., Bennett, W. W., Welsh, D. T. and Zhao, H., Analytica Chimica Acta, 2011, 698, 20.

[24] Pena, M., Meng, X., Korfiatis, G. P. and Jing, C., Environmental Science and Technology, 2006, 40, 1257-1262.

[25] Alfaro-De la Torre, M. C. , Beaulieu, P. Y., and Tessier, A., Analytica Chimica Acta, 2000, 418, 53.

[26] Peters, A., Zhang, H., Davison, W., Analytica Chimica Acta, 2003, 478, 237.

[27] Fatin-Rouge, N., Milon, A., Bu ffle, J., Goulet, R. R. and Tessier, A., Journal Physical Chemistry B, 2003, 107, 12126.

[28] Yezek, L. P. and van Leeuwen, H. P., Journal of Colloid Interface Science, 2004, 278, 243.

[29] Long, D.T. and Angino, E.E., Economic Geology, 1982, 77, 646-65.

[30] Balaba, S.R. and Smart, B. R., Chemosphere, 2012, 89(11), 1437-1442. 


\section{Chapter Five}

\section{Future Work /Directions}

These studies were carried out at room temperature and 1 atmosphere which are different conditions from the high pressures at which the hydraulic fracturing fluids are injected into the Marcellus shale at depths of $7000 \mathrm{ft}$. The corresponding temperatures are also higher at such depths. Therefore, studies at higher temperature and pressures could be done to examine the effects of flowback wastewater on the extraction of total inorganic and/or bioavailable arsenic and selenium fractions from the Marcellus shale.

Speciation analysis methods for bioavailable arsenic (III), arsenic(V), selenium(IV) and selenium(VI) should be developed using binding gels with more selectivity and capacity in highsalinity waters such as flowback wastewaters, since chemical species of the same element in different oxidation states have different toxicological effects.

There is a need to study and address potential transport pathways and fate of the hydraulic fluids and hydrofracture wastewaters, and arsenic and selenium concentrations in high salinity flowback waters at different times of sampling and storage.

The forms and binding mechanisms of arsenic and selenium compounds to the binding gels and thiol cotton fiber should be a focus for further research such that once ascertained and the factors affecting their formation optimized, method improvement and application to chemically identical analytes would ensue. 
Evaluation of Arsenic and Selenium Quantitation in Marcellus Shales and Flowback Saline Waters using Thiol Cotton Fibre-Graphite Furnace Atomic Absorption Spectroscopy and Diffusive Gradient in Thin Film Techniques

\title{
Ronald S. Balaba
}

Dissertation Submitted to the Eberly College of Arts and Sciences at West Virginia University in Partial Fulfillment of the Requirements for the Degree of

Doctor of Philosophy in Chemistry

\author{
C. Eugene Bennett Department of Chemistry
}

APPROVAL OF THE EXAMINING COMMITTEE

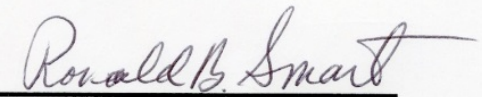

Ronald B. Smart, Ph.D., Chair

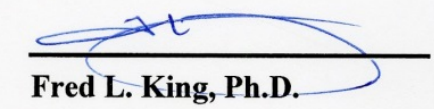

Fred L. King, Ph.D.

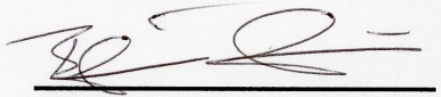

Bjørn Söderberg, Ph.D.,
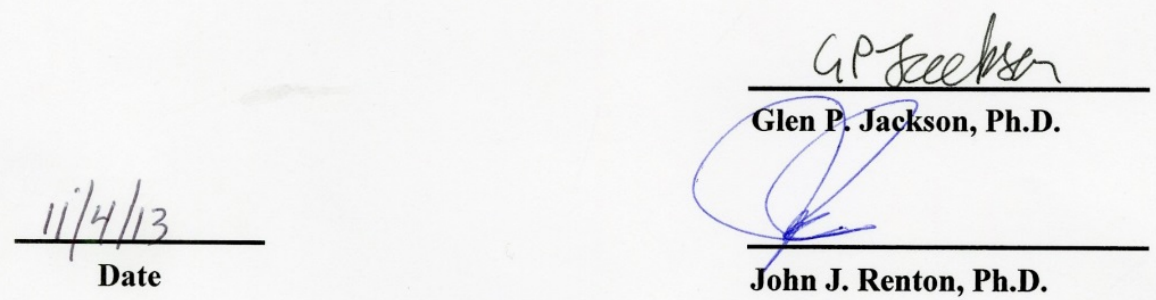
